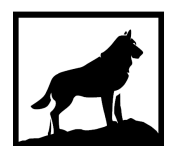

Michigan Technological

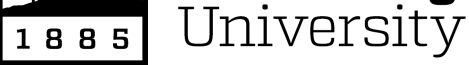

Michigan Technological University Digital Commons @ Michigan Tech

PREDICTING THE IMPACTS OF CLIMATE CHANGE ON THE GREAT LAKES WATER LEVELS USING A FULLY COUPLED 3D REGIONAL MODELING SYSTEM

Miraj Kayastha

Michigan Technological University, mkayasth@mtu.edu

Copyright 2021 Miraj Kayastha

Recommended Citation

Kayastha, Miraj, "PREDICTING THE IMPACTS OF CLIMATE CHANGE ON THE GREAT LAKES WATER LEVELS USING A FULLY COUPLED 3D REGIONAL MODELING SYSTEM", Open Access Master's Thesis, Michigan Technological University, 2021.

https://doi.org/10.37099/mtu.dc.etdr/1166

Follow this and additional works at: https://digitalcommons.mtu.edu/etdr

Part of the Climate Commons, Environmental Engineering Commons, and the Hydrology Commons 


\title{
PREDICTING THE IMPACTS OF CLIMATE CHANGE ON THE GREAT LAKES WATER LEVELS USING A FULLY COUPLED 3D REGIONAL MODELING SYSTEM
}

\author{
By \\ Miraj Bhakta Kayastha
}

\begin{abstract}
A THESIS
Submitted in partial fulfillment of the requirements for the degree of

MASTER OF SCIENCE

In Civil Engineering
\end{abstract}

MICHIGAN TECHNOLOGICAL UNIVERSITY

2021

(C) 2021 Miraj B. Kayastha 
This thesis has been approved in partial fulfillment of the requirements for the Degree of MASTER OF SCIENCE in Civil Engineering.

Department of Civil and Environmental Engineering

Thesis Advisor: $\quad$ Pengfei Xue

Committee Member: $\quad$ David Watkins

Committee Member: $\quad$ Brian Barkdoll

Department Chair: Audra Morse 


\section{Table of Contents}

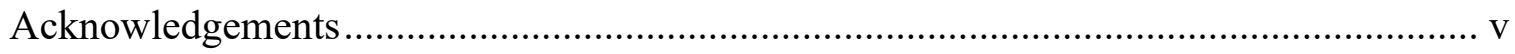

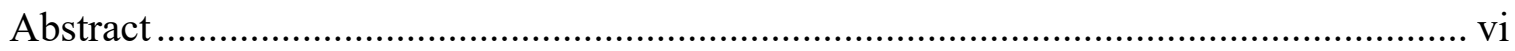

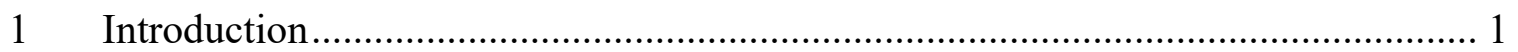

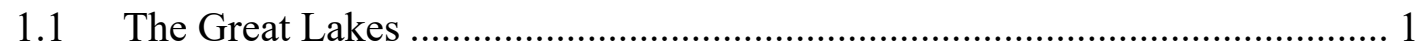

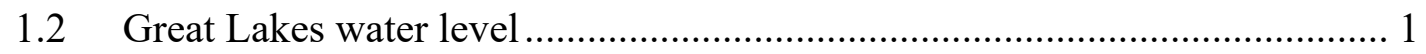

2 Research Motivation ................................................................................... 3

2.1 Observed changes in Great Lakes climate and water level due to climate

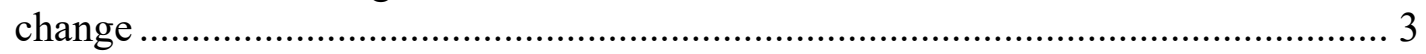

2.2 Future climate and water level predictions from previous studies .................. 3

2.3 Shortcomings of previous studies............................................................ 5

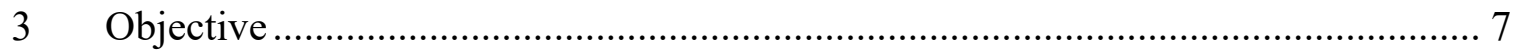

4 General models and concepts used in climate prediction studies .............................. 8

4.1 General Circulation Models (GCMs) and Regional Climate Models (RCMs) 8

4.2 Emissions scenarios........................................................................... 8

4.3 Ensemble approach in climate change studies ............................................... 9

$5 \quad$ Models and methods used in this study …………............................................... 10

5.1 Great Lakes-Atmosphere Regional Model (GLARM) .................................. 11

5.2 Large Basin Runoff Model (LBRM) ......................................................... 14

5.3 Coordinated Regulation and Routing Model (CGLRRM) ………................ 17

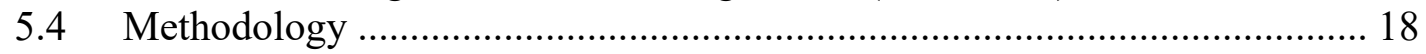

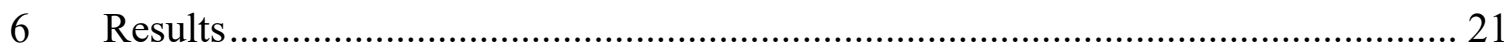

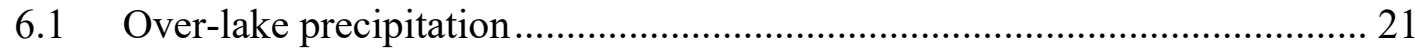

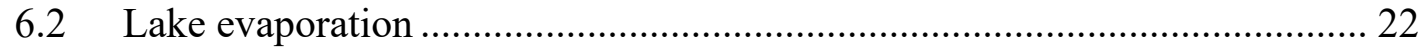

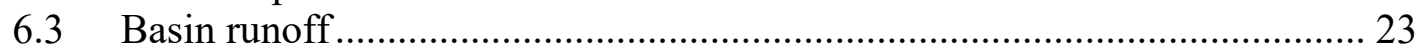

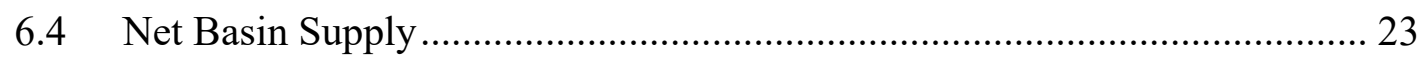

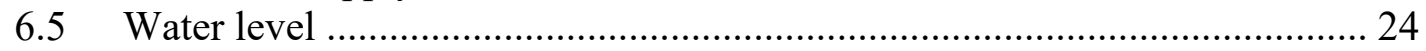

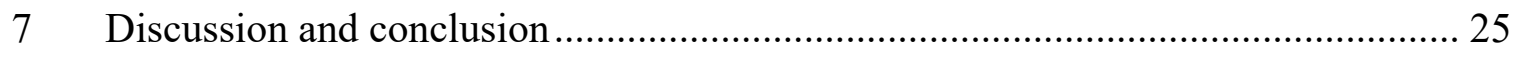

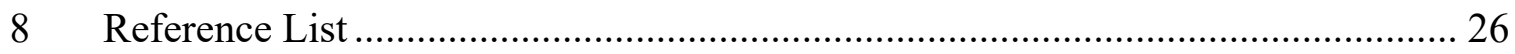

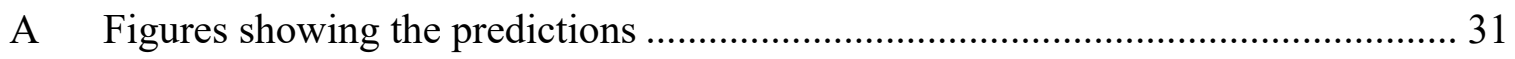

A.1 Over-lake precipitation predictions …………………............................. 31

A.2 Lake evaporation predictions ……………………................................. 35

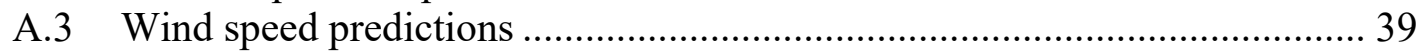

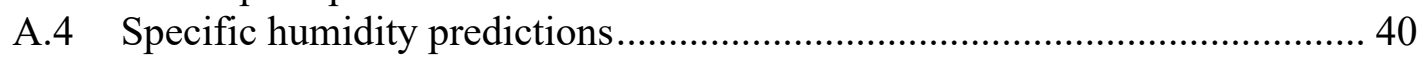

A.5 Basin runoff predictions ....................................................................... 41

iii 


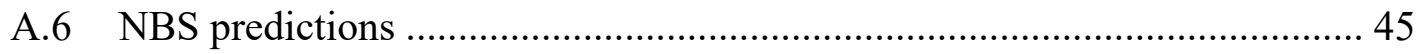

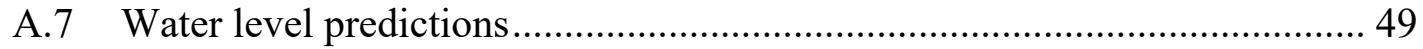

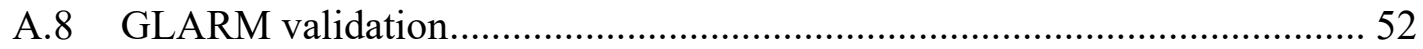

A.9 Air temperature and LST predictions ................................................... 55 


\section{Acknowledgements}

I would like to sincerely thank my advisor Dr. Pengfei Xue for his continuous support, mentorship, and encouragement during my Masters study. I will be forever grateful to him for his trust in me and for the opportunities he has provided me with.

I am thankful to my committee members Dr. David Watkins and Dr. Brian Barkdoll, as well as Dr. Martin T. Auer and Dr. Guy Meadows for their invaluable inputs and guidance over the years.

I would also like to thank Tim Hunter and Dr. Philip Chu from NOAA-GLERL for providing and assisting me with the Large Basin Runoff Model (LBRM); and Dr. Lauren Fry and Zoe Miller from USACE - Detroit District for providing and assisting me with the Coordinated Great Lakes Regulation and Routing Model (CGLRRM).

My sincere thanks to Chenfu Huang for assisting and guiding me from my very first day. Also, a sincere thank you to both Chenfu and Dr. Xinyu Ye for developing and performing GLARM simulations which laid the foundations for this study.

This work was supported by the Michigan Department of Environment, Great Lakes, and Energy (EGLE). 


\section{Abstract}

The Great Lakes of North America are the largest surface freshwater system in the world and many ecosystems, industries, and coastal processes are sensitive to the changes in their water levels. The recent changes in the Great Lakes climate and water levels have particularly highlighted the importance of water level prediction. The water levels of the Great Lakes are primarily governed by the net basin supplies (NBS) of each lake which are the sum of over-lake precipitation and basin runoff minus lake evaporation. Recent studies have utilized Regional Climate Models (RCMs) with a fully coupled onedimensional (1D) lake model to predict the future NBS, and the Coordinated Great Lakes Regulating and Routing Model (CGLRRM) has been used to predict the future water levels. However, multiple studies have emphasized the need for a three-dimensional (3D) lake model to accurately simulate the Great Lakes water budget. Therefore, in this study, we used the Great Lakes-Atmosphere Regional Model (GLARM) along with the Large Basin Runoff Model (LBRM) and CGLRRM to predict the changes in NBS and water levels by the mid- and late twenty-first century. GLARM is a 3D regional climate modeling system for the Great Lakes region that is fully coupled to a 3D hydrodynamic lake and ice model. This is the first study to use such an advanced model for water level prediction in the Great Lakes. We found that both annual over-lake precipitation and basin runoff are most likely to increase into the future. We also found that annual lake evaporation is most likely to decrease in Lake Superior but increase in all the other lakes. We posit that the decreases in evaporation are due to decreased wind speed over the lakes and decreased difference between saturated and actual specific humidity over the lakes. Our predicted changes in the three components of NBS would lead to mostly increased NBS and water levels in the future. The ensemble average of our predicted water level changes for Lake Superior, Michigan-Huron, and Erie are $+0.14 \mathrm{~m},+0.37 \mathrm{~m}$, and +0.23 $\mathrm{m}$ by the mid-twenty-first century, respectively, and $+0.47 \mathrm{~m},+1.29 \mathrm{~m}$, and $+0.80 \mathrm{~m}$ by the late twenty-first century, respectively. However, due to the multiple sources of uncertainties associated with climate modeling and predictions, the water level predictions from this study should not be viewed as exact predictions. These predictions are unique to our model configuration and methodology. Other studies can easily predict different water level changes through the use of different models and methodologies. Therefore, more predictions from advanced modeling systems like GLARM are needed to generate a consensus on future water level changes in the Great Lakes. 


\section{Introduction}

\subsection{The Great Lakes}

The Great Lakes of North America - Superior, Michigan, Huron, Erie, and Ontario - are the largest surface freshwater system in the world; collectively they have a surface area of about $244,000 \mathrm{~km}^{2}$ and contain around $23,000 \mathrm{~km}^{3}$ of water which accounts for $18 \%$ of the world's supply (U.S. Environmental Protection Agency \& Government of Canada, 1995). The Great Lakes basin spans large areas of both U.S. and Canada. More than 30 million people reside within the basin, and this makes up approximately $10 \%$ and $30 \%$ of the U.S. and Canadian populations, respectively (U.S. Environmental Protection Agency, 2019). The Great Lakes also supports several industries such as fishing, shipping, manufacturing, hydropower generation, agriculture, tourism, and recreation. Rau, Vaccaro, Riseng, and Read (2020) reported that in 2018, the Great Lakes were directly related to 1.3 million jobs and generated $\$ 82$ billion in wages.

\subsection{Great Lakes water level}

The water levels of the Great Lakes are partially controlled by regulating the major outflows from Lake Superior and Lake Ontario via manmade structures that are operated under separate regulation plans to achieve specific goals. The major outflow of Lake Superior is the St. Marys River, which flows into Lake Huron, and the major outflow of Lake Ontario is the St. Lawrence River, which drains into the Atlantic Ocean.

The current regulation plan in Lake Superior is named Plan 2012, and this plan tries to restore the natural variability in Lake Superior's water level while also considering Lake Michigan-Huron's water levels (The International Upper Great Lakes Study Board, 2012). Plan 2012 also incorporates socioeconomic and environmental goals such as preserving lake sturgeon habitats and providing benefits to hydropower generation and navigation (The International Upper Great Lakes Study Board, 2012).

The current regulation plan in Lake Ontario is named Plan 2014, and this plan tries to restore the natural variability in Lake Ontario's water level while moderating extreme water levels (International Joint Commission, 2014). Plan 2014 also acknowledges wetland restoration, hydropower production, navigation, and shoreline property protection (International Joint Commission, 2014).

All the other lakes (Michigan, Huron, and Erie) have unregulated outflows; however, due to their large surface areas and constricted outflows, their outflows are naturally regulated (Assel, Quinn, \& Sellinger, 2004). Consequently, the water levels of the Great Lakes fluctuate in a relatively small range, which makes industrial and recreational uses very sensitive to water level changes (Assel et al., 2004).

According to Hartmann (1990), changes in water level can have significant consequences in both socioeconomic and environmental aspects. Decreases in water level can deplete the marshes and wetlands necessary for wildlife and fisheries, decrease the hydropower production and affect the shipping costs (Hartmann, 1990). Lower water levels would 
force the cargo ships to be lighter which increases shipping costs and decreases profits (Lindeberg \& Alercook, 2000; Millerd, 2011; J. Wang et al., 2012). Diversion systems like the Chicago Diversion in Lake Michigan can also be significantly affected by lower water levels and the measures to restore the diversion system (e.g., dredging) could cost millions of dollars (Injerd, 1998). Furthermore, lake levels affect coastal processes such as bluff recession. For example, in the mid-1980s, Lake Michigan-Huron's water level rise caused extensive erosion-related damages (Andrew D. Gronewold \& Stow, 2014). Studies like Quigley, Gelinas, Bou, and Packer (1977) and Davidson-Arnott (2016) have noted the effects of long-term lake levels on toe erosion, bluff profiles, and retreat mechanisms.

Apart from their socioeconomic and environmental importance, the water levels of the Great Lakes are also a very important metric for understanding the impact of climate change on both freshwater and marine coastal systems due to its unusually long documented history and its similarities with some marine coastal systems (A. Gronewold et al., 2013). The water levels in the Great Lakes and some marine coasts have very similar magnitude of variability and are influenced by common factors like tides and storm surges (A. Gronewold et al., 2013). 


\section{Research Motivation}

\subsection{Observed changes in Great Lakes climate and water level due to climate change}

The water levels of the Great Lakes are significantly affected by the regional climate because the Great Lakes have a large water surface area (A. Gronewold et al., 2013). The recent changes in regional climate and the subsequent changes in water levels have highlighted the need for more extensive research into the potential impact of future climate on the Great Lakes water levels.

The U.S. portion of the Great Lakes basin experienced a $1.6^{\circ} \mathrm{F}$ increase in annual average temperature for the 1986-2016 period relative to 1901-1960, which was higher than the change over the contiguous United States (Wuebbles et al., 2019). During the 1973-2010 period, increasing winter air temperature caused the ice coverage of the Great Lakes to decrease by $71 \%$ (J. Wang et al., 2012). This decrease in ice coverage created a positive ice/water albedo feedback which caused Lake Superior's summer water temperature to increase more rapidly than the air temperature (Austin \& Colman, 2007).

The U.S. portion of the Great Lakes basin also experienced a 10\% increase in annual precipitation for the 1986-2016 period relative to 1901-1960 (Wuebbles et al., 2019). Warmer water and less ice cover caused increased lake-effect snowfall in specific areas of the Great Lakes region (Burnett, Kirby, Mullins, \& Patterson, 2003; Kunkel et al., 2009).

Looking at the changes in water level, during the late 1990s, the water levels in Lake Superior, Lake Michigan-Huron, and Lake Erie dropped dramatically because unusually high air temperature caused basin runoff to decrease and lake evaporation to increase (Assel et al., 2004). But in 2013-2014, after 15 years of below-average water level, Lake Superior and Lake Michigan-Huron experienced a record-setting water level rise due to decreased lake evaporation and increased over-lake precipitation and basin runoff (A. D. Gronewold et al., 2016). Following this rise, all the lakes experienced either monthly or all-time record highs (A. D. Gronewold, Do, Mei, \& Stow, 2021). For example, the August and September 2019 water levels in Lake Superior were at their highest monthly values since 1918, despite being at their lowest in 2007. Similarly, the January water level for Lake Michigan-Huron was at its highest in 2020 since 1918, despite being at its lowest in 2013. (USACE, 2020).

\subsection{Future climate and water level predictions from previous studies}

Previous studies have predicted different future climates for the Great Lakes region and more notably, have predicted conflicting future water level changes (i.e., both increases and decreases in water level). 
Multiple studies have consistently predicted continuous warming of air over the Great Lakes basin for the $21^{\text {st }}$ century, although the magnitude of the predicted warming varies (e.g., Notaro, Bennington, \& Lofgren, 2015; X. Wang, Huang, Baetz, \& Zhao, 2017; Xiao, Lofgren, Wang, \& Chu, 2018; Zhang et al., 2020). Zhang et al. (2020) predicted the annual mean air temperature over the Great Lakes basin to increase by $2.1^{\circ} \mathrm{C}$ to $4.0^{\circ} \mathrm{C}$ during $2040-2069$ and by $3.3^{\circ} \mathrm{C}$ to $6.0^{\circ} \mathrm{C}$ during $2070-2099$ relative to $1980-2009$ under the SRES A1B emission scenario (emission scenarios are explained in section 4.2), with the southern parts of the basin warming more in the summer, and northern parts warming more in the winter. X. Wang et al. (2017) predicted increases of $2.63^{\circ} \mathrm{C}, 3.77^{\circ} \mathrm{C}$, and $5.59^{\circ} \mathrm{C}$ in annual mean air temperature over the Great Lakes basin by $2030 \mathrm{~s}, 2050 \mathrm{~s}$, and 2080s, respectively, relative to 1961-1990 under the SRES A1B emission scenario. And Zhang, Zhao, Hein-Griggs, Barr, and Ciborowski (2019) predicted an increase in the maximum summer and minimum winter air temperature. They also predicted an increase in the yearly number of extremely hot days $\left(\geq 32^{\circ} \mathrm{C}\right)$ and a decrease in the yearly number of extremely cold days $\left(\leq-18^{\circ} \mathrm{C}\right)$.

Annual over-lake, over-land, and basin precipitation for the Great Lakes have also been predicted to increase in many studies (e.g., Notaro, Bennington, \& Lofgren, 2015; X. Wang et al., 2017; Mailhot, Music, Nadeau, Frigon, \& Turcotte, 2019; Zhang et al., 2019). However, the predicted seasonal changes are not always positive. For example, Zhang et al. (2019) predicted the annual basin precipitation to increase by $29-73 \mathrm{~mm} /$ year and 14-91 mm/year during 2030-2059 and 2060-2089, respectively, relative to 1980-2009 but predicted the summer precipitation to decrease in the future. Notaro, Bennington, and Lofgren (2015), Xiao et al. (2018), and Mailhot et al. (2019) have also predicted increases in annual precipitation and decreases in summer precipitation. d'Orgeville, Peltier, Erler, and Gula (2014) predicted the average rainfall intensity (also called the simple daily intensity index) to increase into the future by following the ClausiusClapeyron relationship i.e., 7\% increase per degree of surface warming; they also predicted an increase in the 50-year extreme rainfall's magnitude. In terms of snowfall, Notaro, Bennington, and Vavrus (2015) predicted a decrease in annual snowfall over the Great Lakes basin but an increase in lake-effect precipitation (increase in rainfall at the cost of snowfall) due to enhanced lake evaporation from reduced ice cover and greater wind fetch over the lakes in the future.

The sum of over-lake precipitation and basin runoff minus lake evaporation is known as the net basin supply (NBS), and many studies consider NBS to be the driver behind water level changes in the Great Lakes (e.g., Croley, 1990; Hartmann, 1990; Lofgren et al., 2002; Angel \& Kunkel, 2010; MacKay \& Seglenieks, 2013; Music, Frigon, Lofgren, Turcotte, \& Cyr, 2015; Notaro, Bennington, \& Lofgren, 2015). Thus, water level predictions for the Great Lakes heavily depend on the predicted changes for the over-lake precipitation, lake evaporation, and basin runoff. Lofgren et al. (2002)'s predicted water level changes ranged from $-1.38 \mathrm{~m}$ to $+0.35 \mathrm{~m}$ for Lake Michigan-Huron by 2081-2100 relative to 1954-1995; the potential for lower water levels was due to large evaporation increases and decreased basin runoff, whereas the potential for higher water levels was due to smaller increases in evaporation and basin runoff. Lofgren et al. (2002) predicted both increases and decreases in water levels because they used two different General 
Circulation Models (GCMs; GCMs are explained in section 4.1) to predict the future climate and one GCM had predicted a much hotter and drier future than the other one. This uncertainty in water level predictions due to different GCMs was highlighted by Angel and Kunkel (2010). They performed a total of 565 simulations with different GCMs, emissions scenarios, and initial conditions for the GCMs to come up with a wide range of water level predictions for the Great Lakes. For instance, their full range of predicted water level change for Lake Superior during 2080-2094 relative to 1970-1999 under the SRES A2 emission scenario was $+0.35 \mathrm{~m}$ to $-0.58 \mathrm{~m}$. Notaro, Bennington, and Lofgren (2015) also predicted both increases and decreases in future water level and more notably, they predicted increases in all of the NBS components (basin runoff, overlake precipitation, and lake evaporation). Thus, Notaro, Bennington, and Lofgren (2015) highlighted the importance of the relative changes in the NBS components by showing that water level could decrease if the increase in evaporation is able to offset the increase in basin runoff and over-lake precipitation.

\subsection{Shortcomings of previous studies}

Most studies before 2011 used some version of the suite of hydrologic models from Great Lakes Environmental Research Laboratory (GLERL) to predict the future NBS and subsequently the future water levels. The suite of models from GLERL consisted of the Large Basin Runoff Model (LBRM) to simulate basin runoff, the Large Lake Thermodynamics Model (LLTM) to simulate lake evaporation, and the Coordinated Great Lakes Regulation and Routing Model (CGLRRM) to simulate water levels. The inputs to LBRM and LLTM were the future predictions of multiple climate variables (such as air temperature, precipitation, and wind speed) that were created by applying each variable's predicted future changes onto its observed historical data. The predicted changes for these climate variables were based on a GCM's future and historical simulations, and the inputs to CGLRRM were the future NBS derived from the results of LBRM and LLTM. These studies suffered from flaws such as the possible misrepresentation of precipitation due to a GCM's coarse spatial resolution, and the inability to resolve small-scale processes such as lake-effect storms due to the one-way coupling of the GCMs and GLERL models (MacKay \& Seglenieks, 2013). In addition to these flaws, in 2011, Lofgren, Hunter, and Wilbarger (2011) found that LBRM violated the conservation of energy when used to predict future basin runoff (this flaw in LBRM is explained in section 5.2). This issue in LBRM led to higher evapotranspiration and predictions of lower water levels in almost all of the studies that used LBRM, putting the predictions from previous studies into question.

After the flaw in LBRM was identified, MacKay and Seglenieks (2013), and Notaro, Bennington, and Lofgren (2015) dynamically downscaled GCMs using high-resolution Regional Climate Models (RCMs; RCMs and dynamical downscaling are explained in section 4.1) to directly obtain the future NBS without the use of LBRM and LLTM. They fed the future NBS into CGLRRM to predict the future water levels. RCMs provided significant improvements over the GCMs and GLERL models, partly because RCMs could be fully coupled to lake models that allow small-scale processes to be captured by resolving lake-atmosphere interactions (MacKay \& Seglenieks, 2013). However, in these 
studies, RCMs were coupled to only one-dimensional (1D) lake models, and multiple studies have highlighted the need for fully coupling RCMs to three-dimensional (3D) lake models due to the 1D lake model's inability to simulate the Great Lakes, especially with regards to ice formation and stratification (e.g., Gula \& Peltier, 2012; Notaro, Zarrin, Vavrus, \& Bennington, 2013; Notaro, Bennington, \& Vavrus, 2015; Sharma et al., 2018). Although 3D lake models have been developed and used in the past, minimal progress has been made in terms of fully coupling them to RCMs (Sharma et al., 2018). However, Xue et al. (2017) recently developed a regional climate modeling system called the Great Lakes-Atmosphere Regional Model (GLARM) which was the first 3D regional modeling system for the Great Lakes with a fully coupled 3D hydrodynamic lake and ice model. Accordingly, this study uses GLARM in conjunction with LBRM and CGLRRM to predict the future water levels. 


\section{Objective}

The primary objective of this study is to predict the changes in water levels of the Great Lakes by using the climate predictions from GLARM. The climate predictions for this study are under the RCP 8.5 scenario (RCP scenarios are explained in section 4.2). Predictions are made for two future time periods: 2030-2049 (mid-twenty-first century) and 2080-2099 (late twenty-first century). The baseline period for this study is 20002019. Hence, the changes in climate for the future periods are relative to this baseline period. 


\section{General models and concepts used in climate prediction studies}

\subsection{General Circulation Models (GCMs) and Regional Climate Models (RCMs)}

GCMs and RCMs are the most commonly used tools in climate change predictions. GCMs are numerical models that simulate the future global climate under changing greenhouse gas (GHG) concentrations. Since their domain covers the whole earth, their horizontal resolution is usually around $150 \mathrm{~km}$ to $300 \mathrm{~km}$ and this low spatial resolution introduces limitations to GCM simulations such as lack of lake models to represent lakes, poor land-atmosphere feedback mechanisms, and an inability to capture local extreme storm events (Delaney \& Milner, 2019).

The World Climate Research Program (WCRP) has defined a set of internationally recognized GCMs that are included in the Coupled Model Intercomparison Project Phase 5 (CMIP5) to serve as a framework for climate change studies (IPCC, 2013). Delaney and Milner (2019) noted that out of the 55 CMIP5 GCMs, only 18 of them crudely capture the Great Lakes and the lake-atmosphere feedbacks, and the rest of them have either a more simplified representation of the lakes or none at all. Hence, GCMs have been superseded by RCMs in regional climate change studies.

RCMs are limited-area high-resolution models that use boundary conditions from GCMs to temporally and spatially refine GCM's large-scale information (Filippo Giorgi, 2019). This process of refinement is known as dynamical downscaling. RCMs provide highresolution climate predictions over a small area (e.g., the Great Lakes basin) and can simulate the effects of regional features like lakes or complex topography (Delaney \& Milner, 2019; Filippo Giorgi, 2019).

\subsection{Emissions scenarios}

The Fifth Assessment Report, which is the latest report by the Intergovernmental Panel on Climate Change (IPCC), has defined four new scenarios for the future based on future land use/cover and future concentrations of various gases and aerosols (IPCC, 2013). The four new scenarios are RCP 2.6, RCP 4.5, RCP 6.0, and RCP 8.5, where RCP stands for Representative Concentration Pathway. RCP scenarios span until 2100 and each of them represents a different future. For example, under the RCP 2.6 scenario, the $\mathrm{CO}_{2}$ equivalent concentration peaks at $\sim 490$ ppm before 2100 and then declines; whereas under the RCP 8.5 scenario, the $\mathrm{CO}_{2}$-equivalent concentration is $>1370 \mathrm{ppm}$ in 2100 (Moss et al., 2010). Among the four RCPs, RCP 8.5 represents the pathway with the highest greenhouse gas emissions (Riahi et al., 2011).

The GCMs are driven under one of these RCP scenarios to simulate a possible future climate. Prior to the introduction of RCPs, GCMs were driven under the SRES (Special Report on Emission Scenarios) scenarios which were used in the IPCC's Fourth Assessment Report (IPCC, 2007). RCP has now replaced SRES in the latest climate 
models because RCP recognizes the complexity of the carbon cycle by focusing on GHG concentrations rather than GHG emissions (Delaney \& Milner, 2019).

\subsection{Ensemble approach in climate change studies}

Climate change studies tend to use an ensemble of GCMs or RCMs to predict the future because there are multiple sources of uncertainty in climate predictions, and using a single climate model can increase errors and result in misinterpretation of predictions (Delaney \& Milner, 2019). F. Giorgi (2010) lists three sources of uncertainty in climate predictions. The first source of uncertainty is the emissions scenario considered in the prediction because no one knows the true future emissions scenario, and many assumptions are implicitly made when choosing an emissions scenario. The second source of uncertainty is the climate model itself. Due to our limited knowledge and understanding of the climate system, as well as the inability to model relevant physical processes across a wide range of scales, each climate model has its own configuration which reacts differently to even the same emissions scenario. Hence, each model has its own biases, and the internal variability of climate exacerbates this uncertainty. The third source of uncertainty is the downscaling approach used in predictions. Furthermore, since downscaling involves the use of GCM outputs, downscaling adds further uncertainty to an already uncertain GCM prediction. 


\section{Models and methods used in this study}

To predict the future water levels, the primary drivers behind the water level changes must be identified. For this study, the primary drivers were identified from the water budget equation for the Great Lakes. The water budget equation can be written as (Lee, 1992)

$$
\Delta \mathrm{S}=\mathrm{P}-\mathrm{E}+\mathrm{R}+\mathrm{I}-\mathrm{O}-\mathrm{C} \pm \mathrm{G} \pm \mathrm{D} \pm \Delta \mathrm{S}_{\mathrm{T}}
$$

where,

$\Delta \mathrm{S}=$ change in storage

$\mathrm{P}=$ over-lake precipitation

$\mathrm{E}=$ lake evaporation

$\mathrm{R}=$ basin runoff into the lake

$\mathrm{I}=$ inter-basin inflow through a natural channel

$\mathrm{O}=$ inter-basin outflow through a natural channel

$\mathrm{C}=$ consumptive use of lake water

$\mathrm{G}=$ groundwater flow into or out of the lake

$\mathrm{D}=$ inter-basin diversion into or out of the lake

$\Delta \mathrm{S}_{\mathrm{T}}=$ change in storage due to thermal expansion or contraction

All the terms in (Eq. 5.1) are in the same units and computed over the same time period (e.g., weekly, monthly).

The change in storage $(\Delta \mathrm{S})$ in (Eq. 5.1) is computed as the difference between the beginning-of-period and end-of-period water levels. Hence, the water budget equation essentially describes the change in water level as a function of water coming into the lake, water going out from the lake, and thermal expansion/contraction.

(Eq. 5.1) can be simplified by referring to the $(\mathrm{P}-\mathrm{E}+\mathrm{R})$ term as the Net Basin Supply (NBS).

$$
\Delta \mathrm{S}=\mathrm{NBS}+\mathrm{I}-\mathrm{O}-\mathrm{C} \pm \mathrm{G} \pm \mathrm{D} \pm \Delta \mathrm{S}_{\mathrm{T}}
$$

Additionally, instead of calculating NBS as (P - E + R), NBS can also be calculated by moving all the right-hand side terms in (Eq. 5.2) except NBS to the left-hand side. The NBS calculated in this way is known as the residual NBS. 
Nevertheless, in an ideal scenario, predicting future changes in water level involves accurately predicting the future magnitudes of each of the seven right-hand side terms of (Eq. 5.2). However, in this study, some of the terms in (Eq. 5.2) and their future changes or their contribution towards future changes in water level were ignored.

Firstly, $\mathrm{G}$ and $\Delta \mathrm{S}_{\mathrm{T}}$ were ignored. Groundwater flow $(\mathrm{G})$ was ignored herein because it is extremely small in magnitude and has not been adequately quantified yet (Assel et al., 2004). In addition, change in storage due to thermal expansion or contraction $\left(\Delta \mathrm{S}_{\mathrm{T}}\right)$ was ignored because its net effect is close to zero on an annual time scale (Fortin \& Gronewold, 2012). Meredith (1997) and Quinn (1986) have shown $\Delta \mathrm{S}_{\mathrm{T}}$ to be significant in monthly time scales, but more research and observational data are required before including the effect of thermal expansion in the water budget equation (Bruxer, 2011). Future changes in inter-basin diversion flow (D) and consumptive use (C) were also ignored in this study because according to Lenters (2001), they are relatively small in magnitude and can be disregarded as significant factors in the observed lake level trends. Finally, inter-basin inflow (I) and outflow (O) were also not considered as primary drivers behind water level changes because they are often governed by water levels and not vice versa (Lenters, 2001; Fortin \& Gronewold, 2012).

Following the arguments above, NBS is considered the only term in (Eq. 5.2) that had a major contribution towards the future changes in water level. Hence, NBS was identified as the primary driver behind the lake level changes for this study. Since NBS is a combination of $\mathrm{P}, \mathrm{E}$, and $\mathrm{R}$, it is apparent that climate change can significantly influence the future lake levels.

In this study, the general approach behind water level prediction was to first predict the change in each component of NBS, then obtain the future NBS and finally input the NBS to CGLRRM to generate the future water levels. The changes in over-lake precipitation and lake evaporation were predicted using GLARM, and the changes in basin runoff were predicted using LBRM. The methodology is explained in detail in section 5.4.

\subsection{Great Lakes-Atmosphere Regional Model (GLARM)}

GLARM is a regional climate modeling system for the Great Lakes that is composed of a regional climate model (RCM) that is fully coupled to a 3D hydrodynamic lake and ice model (Xue et al., 2017). GLARM was developed to address the limitations associated with the coupling of RCMs to 1D lake models (Xue et al., 2017). GLARM's modeling domain covers most of North America (Figure 5.1) with $18 \mathrm{~km}$ spaced horizontal grids and 18 vertical sigma layers (Xue et al., 2017). The RCM in GLARM is the fourth version of the International Centre for the Theoretical Physics (ICTP) Regional Climate Model (RegCM4), which simulates the land and atmospheric processes (F. Giorgi et al., 2012). The 3D hydrodynamic model in GLARM (Figure 5.2) is based on the Finite Volume Community Ocean Model (FVCOM) which is a prognostic, free-surface, 3D primitive equation coastal ocean circulation model that is numerically solved over an unstructured grid using the finite-volume method. (Chen, Beardsley, \& Cowles, 2006). The horizontal resolution of the hydrodynamic model's unstructured triangular grid 
ranges from $\sim 1-2 \mathrm{~km}$ near the coast to $\sim 2-4 \mathrm{~km}$ in the lake's offshore region, and the vertical resolution ranges from $<1 \mathrm{~m}$ in nearshore waters to $\sim 2-4 \mathrm{~m}$ in the lake's offshore region. The models and the design of GLARM are described in detail in Xue et al. (2017).

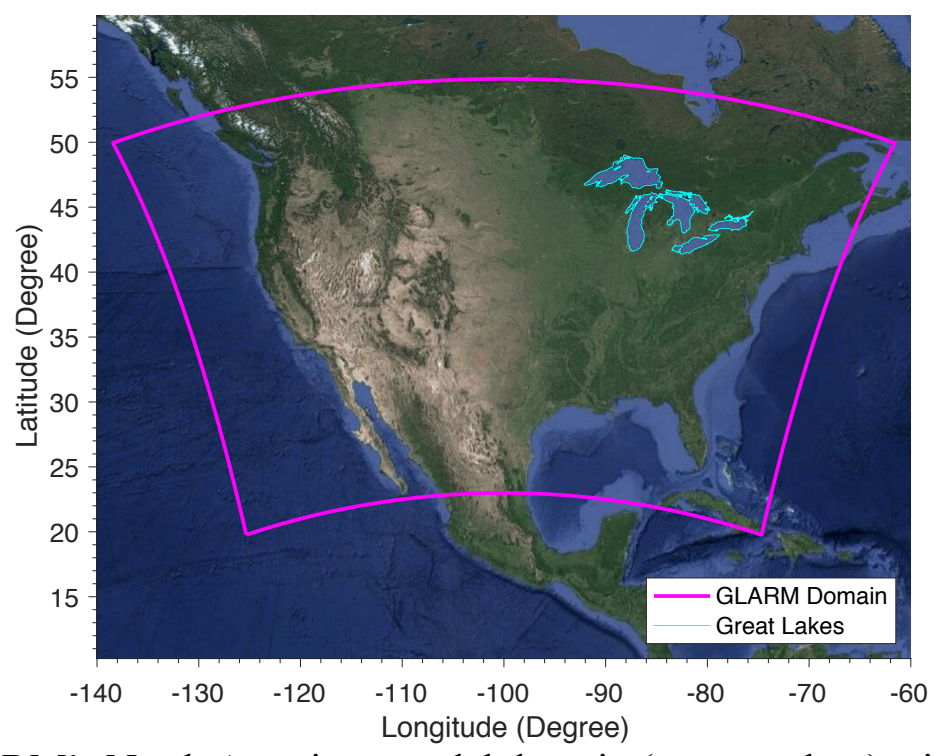

Figure 5.1 GLARM's North American model domain (magenta box) with the Great Lakes outlined in cyan (modified from Fig. 1 of Xue et al., 2017).

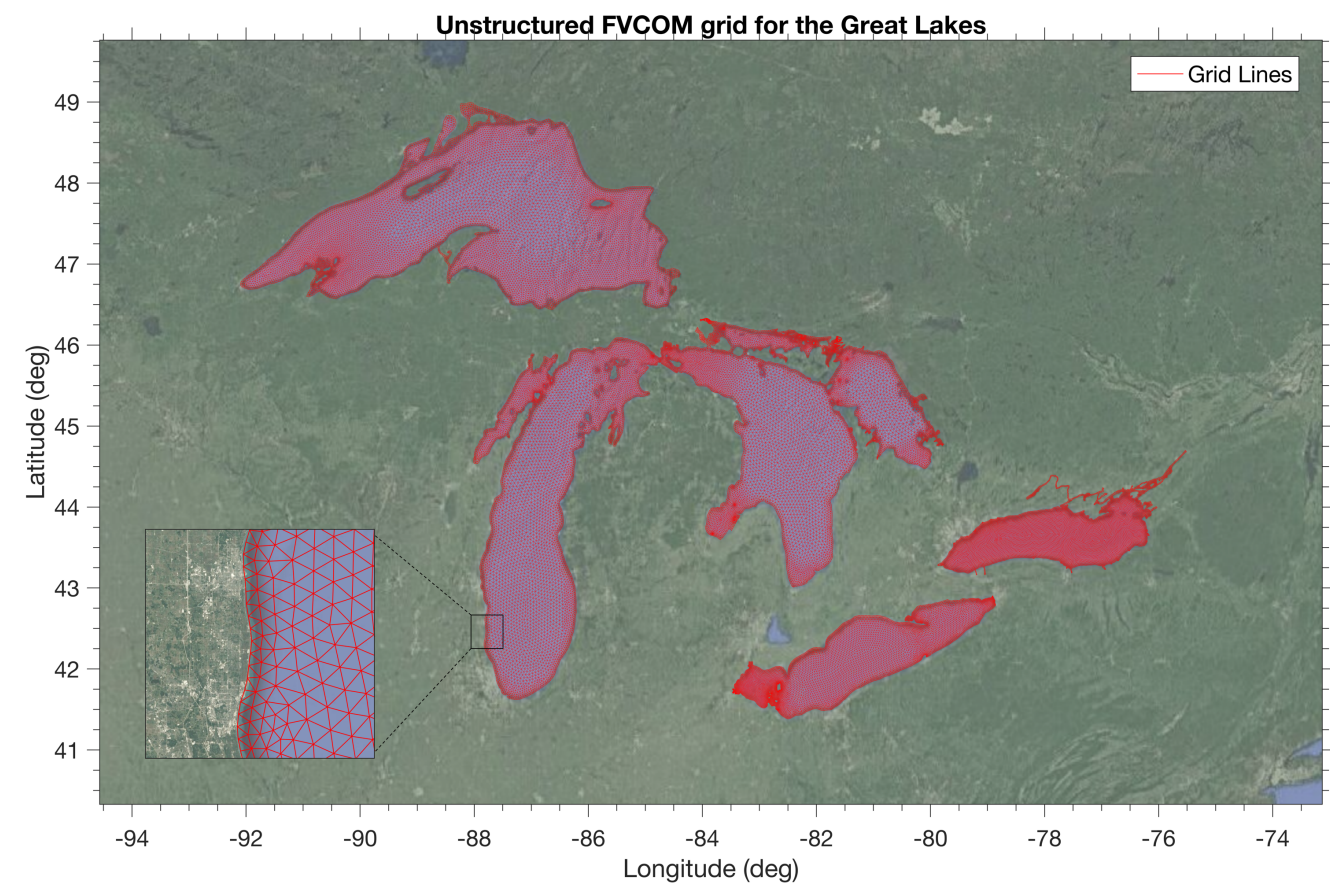

Figure 5.2 Unstructured triangular mesh (red lines) used in the Great Lakes 3D hydrodynamic model overlaid on a satellite image of the Great Lakes (modified from Fig. 
2 of Xue et al., 2017). For a better reprsentation of the mesh, the figure includes a closeup of the mesh in a southern region of Lake Michigan.

The validation efforts for GLARM have been comprehensively documented in Xue et al. (2017). GLARM was validated for surface air temperature and precipitation over North America and the Great Lakes region; precipitation and evaporation over the Great Lakes; surface water temperature of the Great Lakes; and ice coverage over the Great Lakes.

GLARM was shown to simulate the thermal structure and the surface water temperature (and the variables directly affected by it) of the Great Lakes significantly better than the simpler modeling systems used in previous studies (Xue et al., 2017).

In this study, a second variant of GLARM was also used. This variant's modeling domain covers just the Great Lakes area (Figure 5.3). However, the GLARM described in Xue et al. (2017) and this second variant of GLARM have the same exact model configurations. The second variant of GLARM was able to simulate the historical lake surface temperature, ice cover, and the precipitation and evaporation over the Great Lakes reasonably well and similar to the GLARM described in Xue et al. (2017). The validation plots for the second variant of GLARM are shown in Figure A.22, Figure A.23, and Figure A.24.

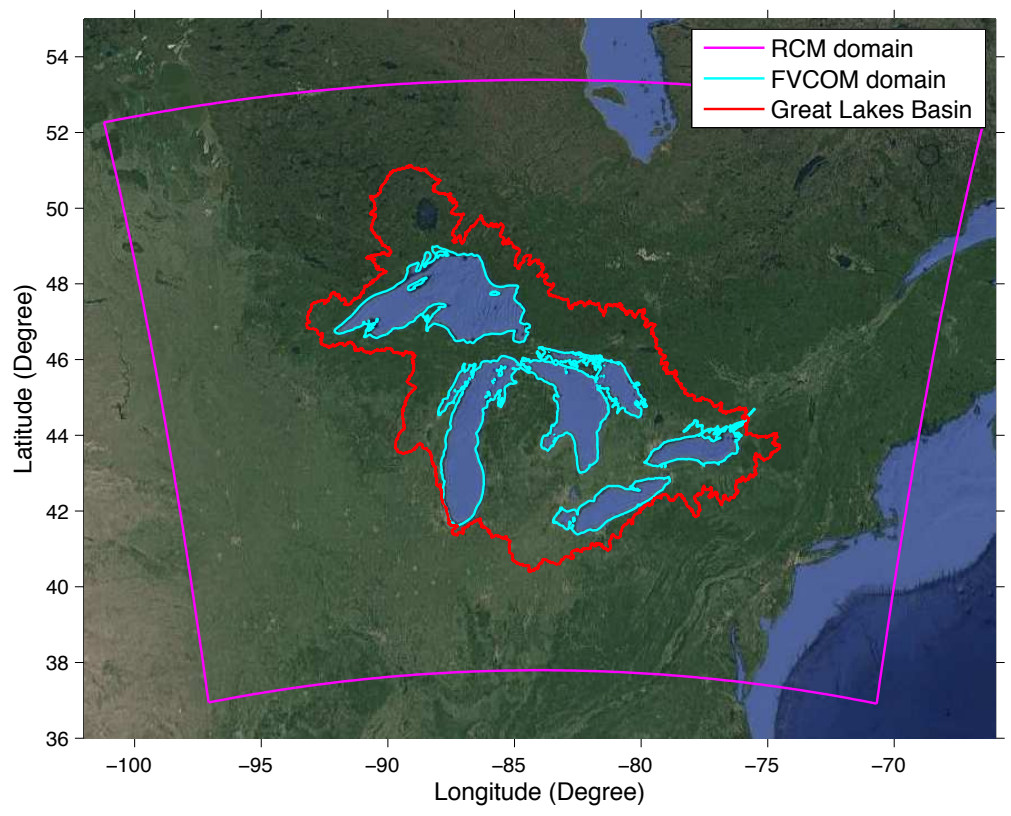

Figure 5.3 The domain of the second variant of GLARM is shown in magenta here. It encompasses the entire Great Lakes basin which is shown in red. The cyan line is the Great Lakes boundary which is also the boundary of the hydrodynamic model whose mesh is shown in Figure 5.2. 


\subsection{Large Basin Runoff Model (LBRM)}

The Large Basin Ruoff Model (LBRM), developed by the Great Lakes Environmental Research Laboratory (GLERL), is a physically based conceptual model that utilizes an interdependent tank cascade model (Figure 5.4) to simulate runoff from all 121 subbasins of the Great Lakes (Croley, 1983a, 1983b). LBRM's physically based concept assists the understanding of a subbasins response to natural forcings and its limited input data requirement proves useful for working within the Great Lakes basin where observational data are sparse (Croley, 1983b, 2002). The inputs to LBRM for this study, aside from the calibrated parameters, are the daily precipitation and daily minimum and maximum air temperature over the 121 subbasins.

Unlike some other models that employ the tank cascade concept, LBRM does not account for some of the nuances that occur in nature because even though the consideration of these nuances could improve the simulation of peak flows, they would only introduce complexities that would prohibit analytic solutions and increase the number of parameters required for calibration (Croley, 2002). Some of these nuances include the criteria for minimum tank fillings prior to inter-tank flows and the criteria for required evaporation before infiltration and similar flows are allowed. According to Croley (2002), these nuances can be ignored because they appear to be unnecessary for volumetric determinations over large time periods, and they are not observed over a large watershed due to the spatial integration of rainfall, snowmelt, and evapotranspiration processes.

LBRM's tank cascade model is shown in Figure 5.4. The model's principles and mechanisms are described in detail in Croley (2002) and are briefly discussed here.

Essentially, in the model, precipitation falls onto the surface and any present snowpack as rain if the daily average temperature is above zero; otherwise, it falls as snow. Snowmelt is set to occur only on days with above-zero air temperatures. Interception is considered as a part of evapotranspiration, and surface depression storage is neglected as it is transient. Additionally, the evaporation from, and condensation to, the snowpack is ignored. Snowmelt and rainfall are collectively referred to as the net supply and some portion of it infiltrates into the upper soil zone and some converts to surface runoff. The surface runoff is calculated using the partial-area concept and the infiltration is set to be proportional to the upper soil zone's moisture content. The percolation to the lower soil zone and evapotranspiration from the upper soil zone are also proportional to the upper soil zone's moisture content. Similarly, interflow, deep percolation, and evapotranspiration from the lower soil zone are proportional to the lower soil zone's moisture content. Also, groundwater flow and evapotranspiration from the groundwater zone are proportional to the groundwater zone's moisture content. It is important to note that in the LBRM, no provisions are made for water moving into or out of the watershed as groundwater. Finally, the basin runoff and evaporation from the surface storage are proportional to the surface storage's moisture content. In addition to the tank's moisture content, evapotranspiration and evaporation from the tanks are also proportional to the evapotranspiration and evaporation that is still possible from the tanks. 
In the LBRM, percolation, interflow, deep percolation, groundwater flow, and basin runoff are modeled using the linear reservoir concept. Following this concept, tank outflows are described as the product of a linear reservoir constant and the volume of water in the tank. Evaporation and evapotranspiration from the tanks are described by a slightly modified linear reservoir concept; they are equal to the product of a partial linear reservoir constant, rate of evaporation or evapotranspiration still possible from the tank, and the volume of water in the tank. The basin runoff, along with all the tank inflows and outflows (including evapotranspiration and evaporation), are calculated by solving a set of one-dimensional mass continuity equations.

Many studies such as Croley (1990), Lofgren et al. (2002), and Angel and Kunkel (2010) have used LBRM to predict future basin runoff for the Great Lakes. In these studies, the future basin runoff values were predicted by perturbing the historical inputs (observed daily precipitation and daily minimum and maximum air temperatures) with their predicted changes in the future as derived from GCM simulations. However, Lofgren et al. (2011) identified a problem in using LBRM in such a manner to simulate future basin runoff. They found the LBRM's calculation of total energy available for evaporation/evapotranspiration in the future was not constrained to an energy conservation criterion; it was found to be constrained only during the LBRM's calibration process. In an attempt to address this issue, in 2016, the formula for calculating the total energy available for evaporation/evapotranspiration was revised to incorporate the departure of a particular day's temperature from the long-term mean temperature of that day. This revision improved the LBRM's usability in climate change studies and this study uses this revised version of the LBRM.

The LBRM's source code and its calibrated parameters along with the observed historical daily precipitation and daily minimum and maximum air temperatures for each of the 121 subbasins were provided by NOAA GLERL (personal communication, Tim Hunter, January 7,2020$)$. Although the LBRM has been calibrated and validated multiple times by GLERL, we still validated the model simulated basin runoff for each lake for the 2000-2019 period against the observed historical monthly basin runoff obtained from the Great Lakes Dashboard (GLD; Hunter, Clites, Campbell, \& Gronewold, 2015). The validation statistics for each lake are shown in Table 5.1. These statistics were found to be very similar to the calibration and verification statistics of the LBRM mentioned in Croley (2002).

Table 5.1 Validation statistics for the LBRM

\begin{tabular}{|l|l|l|l|l|}
\hline Lake & $\begin{array}{l}\text { Number of } \\
\text { subbasins }\end{array}$ & $\begin{array}{l}\text { Pearson's linear } \\
\text { correlation } \\
\text { coefficient }\end{array}$ & p-value & $\begin{array}{l}\text { RMSE (mm } \\
\text { over the lake } \\
\text { per month) }\end{array}$ \\
\hline Superior & 22 & 0.876 & $1.927 \mathrm{e}-77$ & 15.318 \\
\hline Michigan-Huron & 56 & 0.916 & $2.411 \mathrm{e}-96$ & 16.030 \\
\hline St. Clair & 7 & 0.880 & $1.089 \mathrm{e}-78$ & 161.814 \\
\hline Erie & 21 & 0.860 & $2.089 \mathrm{e}-71$ & 45.152 \\
\hline Ontario & 15 & 0.935 & $5.627 \mathrm{e}-109$ & 50.487 \\
\hline
\end{tabular}




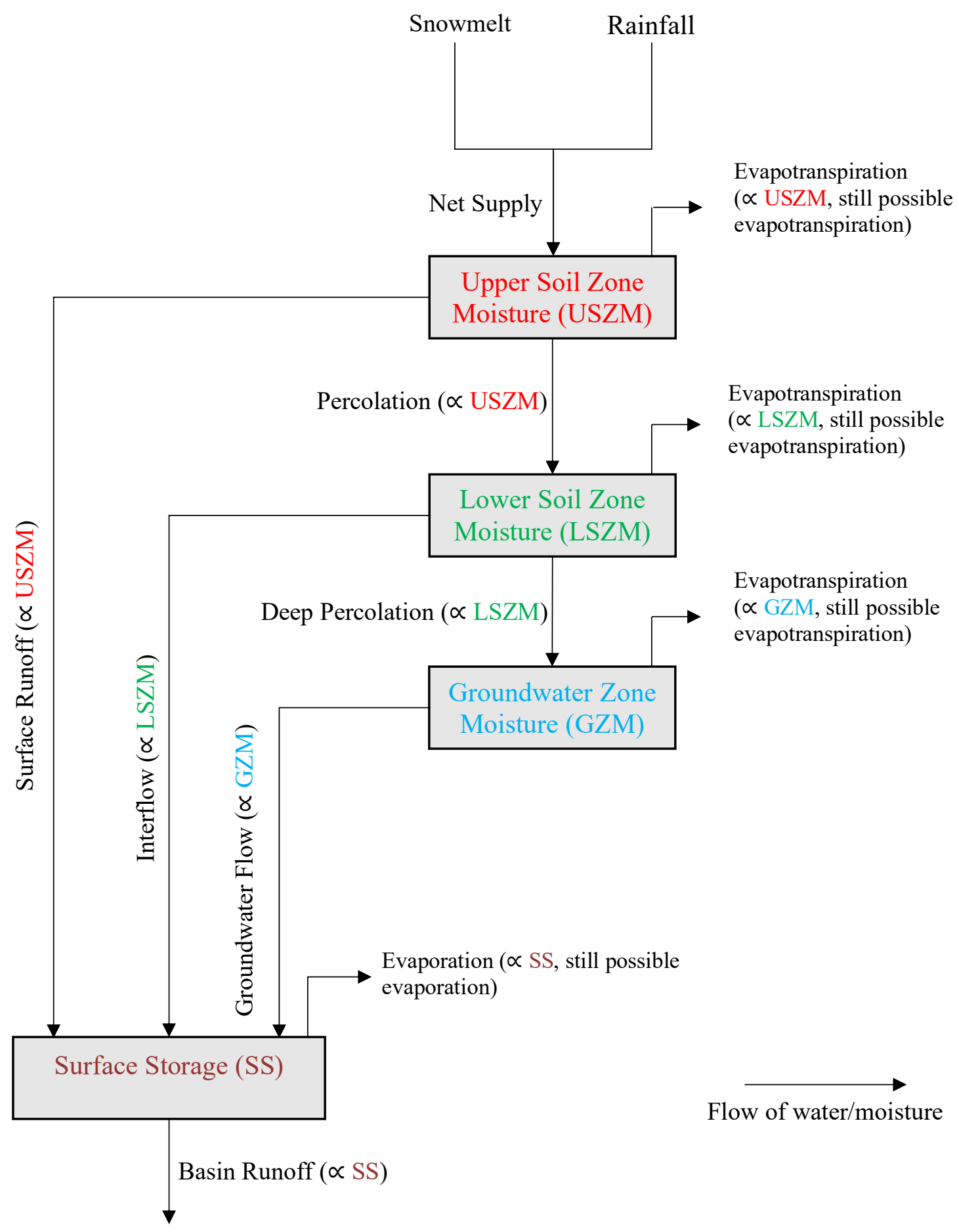

Note: Evapotranspiration in this figure refers to both evapotranspiration and evaporation

Figure 5.4 Tanks in the LBRM's tank cascade model (modified from Fig. 1 of Croley, 2002). The proportionality of the tank outflows is shown in the parentheses. 


\subsection{Coordinated Regulation and Routing Model (CGLRRM)}

CGLRRM is a hydrologic routing model, developed by NOAA GLERL, U.S. Army Corps of Engineers, and Environment Canada, that uses NBS to compute the water levels and the flows in the connecting channels for Lake Superior, Michigan-Huron, St. Clair, Erie, and Ontario.

CGLRRM consists of three linked modules (Draft User's Manual, 2001): the Lake Superior module, the middle lakes module, and the Lake Ontario module. The Lake Superior module computes the lake levels and outflow of Lake Superior via St. Mary's river. Since Lake Superior's outflow is regulated, the module can simulate the outflows under the pre-project relationship, the Plan 1977-A regulation plan, or the Plan 2012 regulation plan. The middle lakes module computes the lake levels and the outflows of the middle lakes which consist of Lake Michigan-Huron, St. Clair, and Erie. These middle lakes' outflows are via their connecting channels (St. Clair River, Detroit River, and Niagara River) which are all unregulated. Thus, the middle lakes module calculates the lake levels and routes the outflows based on continuity equations and stage-fall discharge relationships. The middle lakes module was developed initially by Quinn (1978) and Clites and Lee (1998). The Lake Ontario module computes the lake levels and outflow of Lake Ontario, and this module can be operated under the pre-project relationship, Plan 1958-D regulation plan, or the Plan 2014 regulation plan. However, at the time of this study, this module was non-functional, and thus water levels for Lake Ontario could not be predicted in this study.

In addition to NBS, CGLRRM also accounts for diversion flows and flow retardation in the connecting channels as additional inputs. The Ogoki and Lon Lac Diversion into Lake Superior, the Chicago Diversion from Lake Michigan, and the Welland Canal Diversion from Lake Erie were considered in this study. The flows for each diversion were the monthly climatology of flows (i.e., 12 values) calculated using the observed monthly flows between 1945 to 2012, 1945 to 2008, and 1945 to 2012 respectively. The observed monthly flows for these diversions were obtained from GLD. Flow retardation due to ice and weeds in the St. Clair River, the Detroit River, and the Niagara River was also considered in this study. The retardation values for each river were the monthly climatology of retardation values from 1900 to 2016. The retardation values for each river were obtained from USACE (personal communication, Zoe Miller, July 15, 2020).

The following are some of the practical limitations of CGLRRM (Draft User's Manual, 2001):

1. Since the model is limited to just water balance calculations, it does not consider any short-term hydrodynamic anomalies such as ice jams or peaking and ponding.

2. Any input that is outside the ranges used in the development of the regulation plans may result in unrealistic outputs. 
3. The stage-fall discharge equations used in the model are configured for a certain range of flow and water level. Hence, anything beyond these ranges results in erroneous flow estimates.

For this study, the NBS inputs and the lake level outputs were both on a monthly time scale. Furthermore, all the CGLRRM simulations in this study were performed using the Plan 1977A regulation plan for Lake Superior because the Plan 2012 regulation plan requires two additional inputs which are difficult to define/predict: (1) the previous number of gates opened and (2) the last sturgeon year. In this study, the residual net basin supplies from the Great Lakes Coordinating Committee were used as inputs to simulate the historical water levels. The model was validated for the 2000-2019 period against the observed monthly mean lake levels from the Great Lakes Coordinating Committee (Great Lakes Coordinating Committee, 2019) (Table 5.2).

Table 5.2 Validation statistics for CGLRRM

\begin{tabular}{|l|l|l|l|}
\hline Lake & $\begin{array}{l}\text { Pearson's linear } \\
\text { correlation } \\
\text { coefficient }\end{array}$ & p-value & RMSE (m) \\
\hline Superior & 0.996 & $5.273 \mathrm{e}-252$ & 0.030 \\
\hline Michigan-Huron & 0.999 & $3.924 \mathrm{e}-311$ & 0.030 \\
\hline St. Clair & 0.983 & $4.491 \mathrm{e}-178$ & 0.059 \\
\hline Erie & 0.987 & $2.562 \mathrm{e}-189$ & 0.051 \\
\hline
\end{tabular}

\subsection{Methodology}

The future water levels in this study were predicted by following these four major steps:

\section{Dynamically downscale GCMs using GLARM}

GLARM with the Great Lakes domain was used to dynamically downscale the historical and future simulations from three different GCMs, namely GISS-E2-H, IPSL-CM5A-HR, and MPI-ESM-MR (hereafter referred to as GISS, IPSL, and MPI respectively). These three GCMs were selected from 19 CMIP5 GCMs based on their high reliability factor under the Reliability Ensemble Averaging (REA) method (Ye, 2019). Additionally, GLARM with the North America domain was used to once again dynamically downscale IPSL. Thus, in total, four dynamical downscalings were performed to produce four sets of historical and future simulations for the Great Lakes region, one for each GLARM-GCM combination. The historical simulations span the baseline period (2000-2019). The future simulations span the mid-twenty-first century period (2030-2049) and the late twentyfirst century period (2080-2099).

The downscaling simulations for this study were performed by Chenfu Huang (for the Great Lakes domain GLARM) and by Dr. Xinyu Ye (for the North America domain GLARM) using Michigan Tech's high-performance computing cluster "Superior." 
2. Calculate the monthly changes in basin runoff for each future period relative to the baseline period in each of the four downscaling cases for each lake

First, the monthly basin runoff for the baseline period was obtained by using the observed historical daily precipitation and daily minimum and maximum air temperature values as inputs into LBRM. Then, future monthly changes in daily precipitation and daily minimum and maximum air temperature over the 121 Great Lakes subbasins were calculated using GLARM's historical and future simulations. These changes were applied to the observed historical dataset to create a perturbed dataset which was subsequently used as inputs into LBRM to obtain the future monthly basin runoff. Finally, the monthly changes in basin runoff were calculated by subtracting the baseline monthly basin runoff from the future monthly basin runoff.

3. Calculate the monthly changes in over-lake precipitation and lake evaporation for each future period relative to the baseline period in each of the four downscaling cases for each lake

Over-lake precipitation and lake evaporation are direct outputs of GLARM; hence, the baseline and future monthly data were directly obtained from GLARM. Their monthly changes relative to the baseline period were calculated by simply subtracting the baseline monthly data from the future monthly data.

4. Calculate the monthly changes in NBS and predict future lake levels for each future period relative to the baseline period in each of the four downscaling cases for each lake

The preliminary monthly changes in NBS were first calculated by adding the monthly changes in basin runoff and over-lake precipitation and then subtracting the monthly changes in lake evaporation. Then the mean and standard deviation of each month from the preliminary monthly changes in NBS (i.e., 12 mean and 12 standard deviations using the 20 monthly values for each month corresponding to the 20 -year time period) were used to create 10 random time series of monthly changes in NBS that are within \pm 1 standard deviation. The \pm 1 limit was chosen because it allowed the more significant and unlikely NBS changes to be excluded. Ten random time series were created because this was determined to be enough to approximately capture the mean future lake levels. The random time series of monthly changes in NBS were created to partly address the uncertainty from our preceding model simulations by capturing a wider range of monthly changes in NBS. These random time series of monthly changes in NBS were finally added to the historical monthly residual NBS time series from the Great Lakes Coordinating Committee to create 10 future NBS time series for each future period in each downscaling case for each lake.

These 10 future NBS time series were ultimately used as inputs to CGLRRM to predict 10 future water level time series for each future period in each downscaling case for each lake. However, the first 10 years of future water levels were ignored in this study because the starting water levels in CGLRRM for the future simulations were set to the observed 
historical levels (which is highly unlikely), and the effects of starting water levels were found to be negligible after 10 years of simulation. Hence, the baseline period for water levels results is 2010-2019 and the future time periods are 2040-2049 and 2090-2099. The NBS and water level predictions presented in this study (in sections 6.4 and 6.5) are calculated using the average of the 10 future NBS and the 10 future water level time series. 


\section{Results}

\subsection{Over-lake precipitation}

Our predicted changes in annual over-lake precipitation for each lake are shown in Figure A.1 and the predictions were very different amongst the four downscaling cases. Hence, the ensemble averages were calculated to combine the predictions from the four downscaling cases. According to the ensemble averages, all the lakes are predicted to experience increases in annual over-lake precipitation, with bigger increases in the late twenty-first century. The ensemble average of predicted changes for Lake Superior, Michigan-Huron, Erie, and Ontario are $+13.65 \mathrm{~mm},+40.1 \mathrm{~mm},+55.19 \mathrm{~mm}$, and +28.61 $\mathrm{mm}$ by the mid-twenty-first century, respectively, and $+95.78 \mathrm{~mm},+167.3 \mathrm{~mm},+174.9$ $\mathrm{mm}$, and $+127.5 \mathrm{~mm}$ by the late twenty-first century, respectively. The individual downscaling predictions ranged from $-42.5 \mathrm{~mm}$ in Lake Superior to $+88.94 \mathrm{~mm}$ in Lake Michigan-Huron by the mid-twenty-first century and from $-53.48 \mathrm{~mm}$ in Lake Erie to $+440.8 \mathrm{~mm}$ in Lake Erie by the late-twenty-first century. IPSL (GL) and IPSL (US) were the only downscaling cases to predict decreases by the mid-twenty-first century. In the case of Lake Superior, IPSL (GL) and IPSL (US) predicted a decrease in the mid-twentyfirst century but an increase in the late twenty-first century, which suggests a significant shift in precipitation trend in the future.

At the time of this study, Notaro, Bennington, and Lofgren (2015) and Music et al. (2015) were the only studies that used RCMs to predict the changes in annual over-lake precipitations for individual lakes. However, the time periods (both baseline and future) of the previous studies do not match the time periods of this study. Thus, to facilitate a more direct comparison between the previous and this study's predictions, the baseline period of the previous studies were shifted to match the baseline period of this study. This was done by first subtracting the average annual value of their baseline period from the average annual value of this study's baseline period. This difference was then subtracted from their predictions to obtain their predictions with respect to this study's baseline period. The average annual values of the previous and this study's baseline periods were calculated using the observed historical data from GLD. This method of shifting the previous studies' baseline period to match this study's baseline inherently assumes that the climate models in the previous studies would have produced the same difference between the average annual values of the two time periods as the one produced by the GLD data, which is not necessarily true. Hence, the predictions obtained after shifting the baseline should not be seen as actual predictions from the previous studies. This methodology of shifting the baseline of the previous studies was applied to the other variables as well.

The over-lake precipitation predictions from previous studies after shifting their baselines are shown in Figure A.2 and are all increases except for one case in Lake Ontario. Furthermore, the predicted changes in the late twenty-first century after shifting the baseline are very similar to our ensemble average predictions. 
Figure A.3 and Figure A.4 show our predicted changes in monthly over-lake precipitation. From our ensemble average, the biggest changes in over-lake precipitation are predicted to be during the late spring and late fall, and the smallest changes are seen during the early months of the year. Mailhot et al. (2019), Music et al. (2015), and Notaro, Bennington, and Lofgren (2015) predicted all seasons to become wetter in the future except for summer which could become slightly drier; however, our predictions showed slight increases in the summer and some slight decreases in the winter.

\subsection{Lake evaporation}

Our predicted changes in annual lake evaporation are shown in Figure A.5. The ensemble average of predicted changes for Lake Superior, Michigan-Huron, Erie, and Ontario are $29.32 \mathrm{~mm},+1.036 \mathrm{~mm},+42.52 \mathrm{~mm}$, and $+6.61 \mathrm{~mm}$ by the mid-twenty-first century, respectively, and $-64.19 \mathrm{~mm},+22.32 \mathrm{~mm},+160.8 \mathrm{~mm}$, and $+33.58 \mathrm{~mm}$ by the latetwenty-first century, respectively. The individual downscaling predictions ranged from $42.14 \mathrm{~mm}$ in Lake Superior to $+63.85 \mathrm{~mm}$ in Lake Michigan-Huron by the mid-twentyfirst century and from $-76.34 \mathrm{~mm}$ in Lake Superior to $+176.2 \mathrm{~mm}$ in Lake Erie by the late twenty-first century. The most noticeable prediction was for Lake Superior, with our predictions showing a lower future lake evaporation. The original predictions from previous studies showed increases into the future; however, once the baseline was shifted, some predictions of a decrease were produced as shown in Figure A.6. A lower future lake evaporation is in agreement with the current state of lake evaporation in the Great Lakes as described by A. D. Gronewold et al. (2021). A. D. Gronewold et al. (2021) showed that the lake evaporation in the Great Lakes from 2013 to 2018 was below average and this low evaporation along with an increased precipitation were the reason for water level rise during 2013-2014.

The predicted monthly changes in lake evaporation are shown in Figure A.7 and Figure A.8. For all the lakes, evaporation was predicted to decrease during the early months of the year, and, in the case of Lake Superior, it was predicted to decrease during the end of the year as well. Since the future air temperature and ice cover over the Great Lakes have been predicted to increase and decrease respectively (Notaro, Bennington, \& Lofgren, 2015), the decreases in lake evaporation during the early months of the year seemed counterintuitive. Thus, to explain this lower evaporation during the early months of the year in the future, a simple analysis was performed by focusing on the two variables that affect evaporation based on the bulk transfer equation.

The bulk transfer formula for evaporation is (Arya, 2001):

$$
\text { Evaporation }=\rho C_{e} U_{r}\left(Q_{s}-Q_{r}\right)
$$

where $\rho$ is density of air, $C_{e}$ is bulk transfer coefficient of water vapor, $U_{r}$ is the wind speed at a reference level r, $Q_{s}$ is the saturated specific humidity, and $Q_{r}$ is the actual specific humidity at reference level $\mathrm{r}$. 
In (Eq. 6.1), we considered the density of air and the bulk transfer coefficient to be constants over time; hence, the only variables that could affect the future evaporation were wind speed and the difference between the saturated and actual specific humidity. We predicted the future changes in these two variables, as shown in Figure A.9 for wind speed and Figure A.10 for the difference between the saturated and actual specific humidity. From our predictions, wind speed decreases in all the months, but the difference in saturated and actual specific humidity decreases in just the early months of the year and increases near the end of the year (except for Lake Superior where it decreases near the end of the year as well). Therefore, the predicted decreases in evaporation are most likely due to the decreases in wind speed and the difference between saturated and actual specific humidity.

\subsection{Basin runoff}

Our predicted changes in annual basin runoff are shown in Figure A.11. The ensemble average of predicted changes for Lake Superior, Michigan-Huron, Erie, and Ontario are $+26.1 \mathrm{~mm},+40.36 \mathrm{~mm},+37.65 \mathrm{~mm}$, and $+96.81 \mathrm{~mm}$ by the mid-twenty-first century, respectively, and $+88.26 \mathrm{~mm},+138.9 \mathrm{~mm},+171.7 \mathrm{~mm}$, and $+271.1 \mathrm{~mm}$ by the late twenty-first century, respectively. The individual downscaling predictions ranged from $24.31 \mathrm{~mm}$ in Lake Michigan-Huron to $+265.4 \mathrm{~mm}$ in Lake Ontario by the mid-twentyfirst century and from $-31.53 \mathrm{~mm}$ in Lake Erie to $+410.6 \mathrm{~mm}$ in Lake Ontario by the late twenty-first century. Most downscaling cases predicted an increase in basin runoff into the future, although IPSL (GL) and IPSL (US) predicted decreases for some lakes.

Previous studies predicted increases in almost all instances, but after shifting the baseline, some of their predictions changed into decreases as well (Figure A.12).

The monthly changes in basin runoff are shown in Figure A.13 and Figure A.14. There is a clear trend in the predicted monthly changes. The basin runoff is predicted to increase during the winter months and then undergo a minimal change in the spring. The trend of the predicted monthly changes is very similar to those predicted by Notaro, Bennington, and Lofgren (2015), Music et al. (2015), and Mailhot et al. (2019). The predicted increase in winter basin runoff is likely due to the increased and early snowmelt and the subsequent drop in runoff is likely due to the diminished snowpack (Notaro, Bennington, \& Lofgren, 2015).

\subsection{Net Basin Supply}

The cumulative effect of our predicted changes in over-lake precipitation, lake evaporation, and basin runoff can be seen in the predicted annual changes of NBS (Figure A.15). Similar to its components, predicted NBS changes vary amongst the downscaling cases, but the ensemble average predicted an increase in future NBS for all the lakes. The ensemble average of predicted changes for Lake Superior, Michigan-Huron, Erie, and Ontario are $+61.31 \mathrm{~mm},+83.67 \mathrm{~mm},+46.37 \mathrm{~mm}$, and $+117.3 \mathrm{~mm}$ by the mid-twenty-first century, respectively, and $+249 \mathrm{~mm},+284 \mathrm{~mm},+188.8 \mathrm{~mm}$, and $+362.3 \mathrm{~mm}$ by the late twenty-first century, respectively. The individual downscaling predictions ranged from $48.36 \mathrm{~mm}$ in Lake Superior to $+331.6 \mathrm{~mm}$ in Lake Ontario by the mid-twenty-first 
century and from $-278.5 \mathrm{~mm}$ in Lake Erie to $+634.2 \mathrm{~mm}$ in Lake Ontario by the late twenty-first century. IPSL (GL) and IPSL (US) were the only downscaling cases that predicted decreases into the future. In terms of seasonal changes, NBS was predicted to increase in all the seasons, but the least in the summer (Figure A.17 and Figure A.18).

The predictions from previous studies after shifting the baseline are shown in Figure A.16 and they predicted both increases and decreases in the NBS. However, our predicted increases in NBS from GLARM are much larger than the predictions from previous studies due to the large predicted increases in over-lake precipitation and basin runoff coupled with our smaller increases (or decreases in the case of Lake Superior) in lake evaporation.

\subsection{Water level}

Our predicted changes in average water level are shown in Figure A.19. Our simulations predicted both increases as well as decreases into the future, but the predicted increases are much larger than the predicted decreases. Lake Superior's levels are predicted to increase the least and Lake Michigan-Huron's levels are predicted to increase the most. The ensemble average of predicted changes for Lake Superior, Michigan-Huron, and Erie are $+0.1435 \mathrm{~m},+0.3701 \mathrm{~m}$, and $+0.2267 \mathrm{~m}$ by the mid-twenty-first century, respectively, and $+0.4721 \mathrm{~m},+1.2940 \mathrm{~m}$, and $+0.7979 \mathrm{~m}$ by the late twenty-first century, respectively. The individual downscaling predictions ranged from $-0.0913 \mathrm{~m}$ in Lake Michigan-Huron to $+1.0310 \mathrm{~m}$ in Lake Michigan-Huron by the mid-twenty-first century and from -0.0445 $\mathrm{m}$ in Lake Erie to $+2.4510 \mathrm{~m}$ in Lake Michigan-Huron by the late twenty-first century. IPSL (GL) predicted decreases in the mid-twenty-first century but increases in the late twenty-first century, which suggests a large and rapid rise in water levels in the future. In addition, except for one case in Lake Erie, all the downscaling cases predicted increases in water levels by the late twenty-first century. The predicted changes from GLARM were significantly larger than the predictions from previous studies, which are shown in Figure A.20, because the predicted NBS increases from GLARM are significantly larger.

Figure A.21 shows the monthly climatology of water levels for both the historical time period and the two future time periods. The seasonality of water levels were predicted to undergo no discernible changes by the mid-twenty-first century. However, by the late twenty-first century, the peak month in Lake Superior was predicted to occur either late or early, depending on the downscaled GCM. 


\section{Discussion and conclusion}

The predictions from this study suggests that Great Lakes water levels are more likely to increase into the future with minimal changes in seasonality. This increase is likely to be caused by an increase in over-lake precipitation and basin runoff along with a relatively smaller increase (or a decrease in the case of Lake Superior) in lake evaporation. Lake Superior's water level was predicted to increase the least and Lake Michigan-Huron's water level was predicted to increase the most.

It should be noted that the predictions from this study have some uncertainties within them (described in section 4.3). Thus, the predicted water level increases should not be taken as exact predictions and should rather be viewed as one of many possible scenarios. However, the predictions from this study should motivate the development of a new regulation plan that can handle high water levels as well as a new hydraulic model that is optimized to simulate the water level of the Great Lakes under high NBS conditions. Furthermore, this study motivates the use of two-way coupled 3D atmosphere, land, and lake models in more climate change studies for the Great Lakes.

In this study, lake evaporation in Lake Superior was predicted to decrease into the future and this exacerbated the water level increase. The main reasons for the evaporation decrease were the decrease in wind speed over the lakes and the decrease in the difference between the saturated and actual specific humidity over the lakes. Desai, Austin, Bennington, and McKinley (2009) hypothesized that the summer winds over Lake Superior increased during the last two decades because the summer lake surface temperature (LST) was rising faster than the air temperature above it. But in almost all our predictions, air temperature is predicted to increase faster than LST, except for the summer months (Figure A.25 to Figure A.30). Hence, the slower rate of LST increase relative to air temperature could be one explanation for our predicted decrease in wind speed. However, more research is needed to comprehensively explain the predicted decrease in lake evaporation.

Furthermore, the basin runoff in this study was simulated by driving LBRM with GLARM's output. Future work should focus on obtaining the basin runoff data directly from GLARM. This would eliminate the limitations of LBRM and would provide more consistent predictions between the three components of NBS. Future studies can also complement this study by choosing a different ensemble of GCMs to downscale. The GCMs for this study were chosen based on the REA method, but other GCM ensembles and selection methods have been developed for use in the Great Lakes region (Delaney \& Milner, 2019). Finally, future work should also focus on incorporating thermal expansion into the water budget equation as it can have a significant impact on the water level in certain seasons. 


\section{Reference List}

Angel, J., \& Kunkel, K. (2010). The Response of Great Lakes Water Levels to Future Climate Scenarios with an Emphasis on Lake Michigan-Huron. Journal of Great Lakes Research - J GREAT LAKES RES, 36, 51-58. doi:10.1016/j.jglr.2009.09.006

Arya, S. P. (2001). Introduction to Micrometeorology (Second ed.): Academic Press.

Assel, R. A., Quinn, F. H., \& Sellinger, C. E. (2004). Hydroclimatic Factors of the Recent Record Drop in Laurentian Great Lakes Water Levels. Bulletin of the American Meteorological Society, 85(8), 1143-1152. doi:10.1175/bams-85-81143

Austin, J. A., \& Colman, S. M. (2007). Lake Superior summer water temperatures are increasing more rapidly than regional air temperatures: A positive ice-albedo feedback. Geophysical Research Letters, 34(6). doi:10.1029/2006gl029021

Bruxer, J. (2011). Uncertainty Analysis of Lake Erie Net Basin Supplies as Computed Using the Residual Method. (Master of Applied Science). McMaster University, Retrieved from https://canadaresearch.mcmaster.ca/handle/11375/9907

Burnett, A. W., Kirby, M. E., Mullins, H. T., \& Patterson, W. P. (2003). Increasing Great Lake-Effect Snowfall during the Twentieth Century: A Regional Response to Global Warming? Journal of Climate, 16(21), 3535-3542. doi:10.1175/15200442(2003)016<3535:Iglsdt $>2.0$. Co;2

Chen, C., Beardsley, R., \& Cowles, G. (2006). An Unstructured-Grid Finite-Volume Coastal Ocean Model (FVCOM) System. Oceanography, 19, 78-89. doi:10.5670/oceanog.2006.92

Clites, A. H., \& Lee, D. H. (1998). MIDLAKES: A coordinated hydrologic response model for the middle Great Lakes. Retrieved from https://www.glerl.noaa.gov/ftp/publications/tech_reports/glerl-109/tm-109.pdf

Coordinated Great Lakes Regulation and Routing Model - Draft User's Manual. (2001). Retrieved from https://www.glerl.noaa.gov/ahps/HunterWork/DraftManual_April2001.pdf

Croley, T. E. (1983a). Great Lake basins (U.S.A.-Canada) runoff modeling. Journal of Hydrology, 64(1), 135-158. doi:https://doi.org/10.1016/0022-1694(83)90065-3

Croley, T. E. (1983b). Lake Ontario Basin (U.S.A.-Canada) runoff modeling. Journal of Hydrology, 66(1), 101-121. doi:https://doi.org/10.1016/0022-1694(83)90179-8

Croley, T. E. (1990). Laurentian Great Lakes double-CO2 climate change hydrological impacts. Climatic Change, 17(1), 27-47. doi:10.1007/BF00148999

Croley, T. E. (2002). Large basin runoff model. In V. P. Singh \& D. K. Frevert (Eds.), Mathematical Models of Large Watershed Hydrology (Vol. 1, pp. 717-768). Littleton, Colorado: Water Resources Publications.

d'Orgeville, M., Peltier, W. R., Erler, A. R., \& Gula, J. (2014). Climate change impacts on Great Lakes Basin precipitation extremes. Journal of Geophysical Research: Atmospheres, 119(18), 10,799-710,812. doi:10.1002/2014jd021855

Davidson-Arnott, R. (2016). Erosion of Cohesive Bluff Shorelines - A discussion paper on processes controlling erosion and recession of cohesive shorelines with particular reference to the Ausable Bayfield Conservation Authority (ABCA) shoreline north of Grand Bend University of Guelph. Retrieved from 
https://bsra.ca/download/Discussion-Paper-on-Erosion-of-Cohesive-BluffShorelines-FINAL.pdf

Delaney, F., \& Milner, G. (2019). The State of Climate Modeling in the Great Lakes Basin - A Synthesis in Support of a Workshop held on June 27, 2019 in Arr Arbor, $M I$. Retrieved from https://climateconnections.ca/app/uploads/2020/05/The-Stateof-Climate-Modeling-in-the-Great-Lakes-Basin Sept132019.pdf

Desai, A. R., Austin, J. A., Bennington, V., \& McKinley, G. A. (2009). Stronger winds over a large lake in response to weakening air-to-lake temperature gradient. Nature Geoscience, 2(12), 855-858. doi:10.1038/ngeo693

Fortin, V., \& Gronewold, A. (2012). Water Balance of the Laurentian Great Lakes. In (pp. 864-869).

Giorgi, F. (2010). Uncertainties in climate change projections, from the global to the regional scale. EPJ Web of Conferences, 9, 115-129. Retrieved from https://doi.org/10.1051/epjconf/201009009

Giorgi, F. (2019). Thirty Years of Regional Climate Modeling: Where Are We and Where Are We Going next? Journal of Geophysical Research: Atmospheres, 124(11), 5696-5723. doi:https://doi.org/10.1029/2018JD030094

Giorgi, F., Coppola, E., Solmon, F., Mariotti, L., Sylla, M. B., Bi, X., . . Brankovic, C. (2012). RegCM4: model description and preliminary tests over multiple CORDEX domains. Climate Research, 52, 7-29. Retrieved from https://www.intres.com/abstracts/cr/v52/p7-29/

Great Lakes Coordinating Committee. (2019, 2019-07-15). Coordinating Committee Products and Datasets. Retrieved from http://www.greatlakescc.org/wp36/home/coordinating-committee-products-anddatasets/

Gronewold, A., Fortin, V., Lofgren, B., Clites, A., Stow, C., \& Quinn, F. (2013). Coasts, water levels, and climate change: A Great Lakes perspective. Climatic Change, 120. doi:10.1007/s10584-013-0840-2

Gronewold, A. D., Bruxer, J., Durnford, D., Smith, J. P., Clites, A. H., Seglenieks, F., . . . Fortin, V. (2016). Hydrological drivers of record-setting water level rise on Earth's largest lake system. Water Resources Research, 52(5), 4026-4042. doi: $10.1002 / 2015 \mathrm{wr} 018209$

Gronewold, A. D., Do, H. X., Mei, Y., \& Stow, C. A. (2021). A tug-of-war within the hydrologic cycle of a continental freshwater basin. Geophysical Research Letters, n/a(n/a), e2020GL090374. doi:https://doi.org/10.1029/2020GL090374

Gronewold, A. D., \& Stow, C. A. (2014). Water Loss from the Great Lakes. Science, 343(6175), 1084. doi:10.1126/science.1249978

Gula, J., \& Peltier, W. R. (2012). Dynamical Downscaling over the Great Lakes Basin of North America Using the WRF Regional Climate Model: The Impact of the Great Lakes System on Regional Greenhouse Warming. Journal of Climate, 25(21), 7723-7742. doi:10.1175/jcli-d-11-00388.1

Hartmann, H. C. (1990). Climate change impacts on Laurentian Great Lakes levels. Climatic Change, 17(1), 49-67. doi:10.1007/BF00149000

Hunter, T. S., Clites, A. H., Campbell, K. B., \& Gronewold, A. D. (2015). Development and application of a North American Great Lakes hydrometeorological database 
- Part I: Precipitation, evaporation, runoff, and air temperature. Journal of Great Lakes Research, 41(1), 65-77. doi:https://doi.org/10.1016/j.jglr.2014.12.006

Injerd, D. (1998). Impacts and risks of climate change and variability: stakeholder perspectives. Paper presented at the Adapting to Climate Change and Variability in the Great Lakes-St. Lawrence Basin: Proceedings of a Binational Symposium, Environment Canada, Downsview, Ontario.

International Joint Commission. (2014). Lake Ontario St. Lawrence River Plan 2014:Protecting against extreme water levels, restoring wetlands and preparing for climate change. Retrieved from

IPCC. (2007). Climate Change 2007: Synthesis Report. Contribution Group I, II and III to the Fourth Assessment Report of the Intergovernmental Panel on Climate Change. Retrieved from Geneva, Switzerland:

IPCC. (2013). Summary for policymakers. In T. F. Stocker, D. Qin, G. K. Plattner, M. Tignor, S. K. Allen, J. Boschung, A. Nauels, Y. Xia, V. Bex, \& P. M. Midgley (Eds.), Climate Change 2013: The Physical Science Basis. Contribution of Working Group I to the Fifth Assessment Report of the Intergovernmental Panel on Climate Change. Cambridge, United Kingdom and New York, NY, USA: Cambridge University Press.

Kunkel, K. E., Ensor, L., Palecki, M., Easterling, D., Robinson, D., Hubbard, K. G., \& Redmond, K. (2009). A new look at lake-effect snowfall trends in the Laurentian Great Lakes using a temporally homogeneous data set. Journal of Great Lakes Research, 35(1), 23-29. doi:https://doi.org/10.1016/j.jglr.2008.11.003

Lee, D. H. (1992). Computation of Net Basin Supplies: A comparison of two methods. Retrieved from

Lenters, J. D. (2001). Long-term Trends in the Seasonal Cycle of Great Lakes Water Levels. Journal of Great Lakes Research, 27(3), 342-353. doi:https://doi.org/10.1016/S0380-1330(01)70650-8

Lindeberg, J. D., \& Alercook, G. M. (2000). Climate change and Great Lakes shipping/boating. Retrieved from https://project.geo.msu.edu/glra/PDF files/Regional\%20Summary/04F_WRES_F boating.pdf

Lofgren, B. M., Hunter, T., \& Wilbarger, J. (2011). Effects of Using Air Temperature as a Proxy for Potential Evapotranspiration in Climate Change Scenarios of Great Lakes Basin Hydrology. Lancet, 37. doi:10.1016/j.jglr.2011.09.006

Lofgren, B. M., Quinn, F. H., Clites, A. H., Assel, R. A., Eberhardt, A. J., \& Luukkonen, C. L. (2002). Evaluation of Potential Impacts on Great Lakes Water Resources Based on Climate Scenarios of Two GCMs. Journal of Great Lakes Research, 28(4), 537-554. doi:https://doi.org/10.1016/S0380-1330(02)70604-7

MacKay, M., \& Seglenieks, F. (2013). On the simulation of Laurentian Great Lakes water levels under projections of global climate change. Climatic Change, 117(1), 55-67. doi:10.1007/s10584-012-0560-z

Mailhot, E., Music, B., Nadeau, D. F., Frigon, A., \& Turcotte, R. (2019). Assessment of the Laurentian Great Lakes' hydrological conditions in a changing climate. Climatic Change, 157(2), 243-259. doi:10.1007/s10584-019-02530-6 
Millerd, F. (2011). The potential impact of climate change on Great Lakes international shipping. Climatic Change, 104(3), 629-652. doi:10.1007/s10584-010-9872-z

Moss, R. H., Edmonds, J. A., Hibbard, K. A., Manning, M. R., Rose, S. K., van Vuuren, D. P., . . Wilbanks, T. J. (2010). The next generation of scenarios for climate change research and assessment. Nature, 463(7282), 747-756. doi:10.1038/nature08823

Music, B., Frigon, A., Lofgren, B., Turcotte, R., \& Cyr, J.-F. (2015). Present and future Laurentian Great Lakes hydroclimatic conditions as simulated by regional climate models with an emphasis on Lake Michigan-Huron. Climatic Change, 130(4), 603-618. doi:10.1007/s10584-015-1348-8

Notaro, M., Bennington, V., \& Lofgren, B. (2015). Dynamical Downscaling-Based Projections of Great Lakes Water Levels*+. Journal of Climate, 28(24), 97219745. doi:10.1175/jcli-d-14-00847.1

Notaro, M., Bennington, V., \& Vavrus, S. (2015). Dynamically Downscaled Projections of Lake-Effect Snow in the Great Lakes Basin*,+. Journal of Climate, 28, 16611684. doi:10.1175/JCLI-D-14-00467.1

Notaro, M., Zarrin, A., Vavrus, S., \& Bennington, V. (2013). Simulation of Heavy LakeEffect Snowstorms across the Great Lakes Basin by RegCM4: Synoptic Climatology and Variability*,+. Monthly Weather Review, 141(6), 1990-2014. doi:10.1175/mwr-d-11-00369.1

Quigley, R. M., Gelinas, P. J., Bou, W. T., \& Packer, R. W. (1977). Cyclic erosioninstability relationships: Lake Erie north shore bluffs. Canadian Geotechnical Journal, 14(3), 310-323. doi:10.1139/t77-037

Quinn, F. H. (1978). Hydrologic response model of the North American Great Lakes. Journal of Hydrology, 37(3), 295-307. doi:https://doi.org/10.1016/00221694(78)90021-5

Rau, E., Vaccaro, L., Riseng, C., \& Read, J. G. (2020). The Dynamic Great Lakes Economy Employment Trends from 2009 to 2018. Retrieved from https://www.michiganseagrant.org/wp-content/uploads/2020/10/MICHU-20-203Great-Lakes-Jobs-Report.pdf

Riahi, K., Rao, S., Krey, V., Cho, C., Chirkov, V., Fischer, G., . . Rafaj, P. (2011). RCP 8.5-A scenario of comparatively high greenhouse gas emissions. Climatic Change, 109(1), 33. doi:10.1007/s10584-011-0149-y

Sharma, A., Hamlet, A. F., Fernando, H. J. S., Catlett, C. E., Horton, D. E., Kotamarthi, V. R., ... Wuebbles, D. J. (2018). The Need for an Integrated Land-LakeAtmosphere Modeling System, Exemplified by North America's Great Lakes Region. Earth's Future, 6(10), 1366-1379. doi:10.1029/2018ef000870

The International Upper Great Lakes Study Board. (2012). LAKE SUPERIOR REGULATION: ADDRESSING UNCERTAINTY IN UPPER GREAT LAKES WATER LEVELS. Retrieved from

U.S. Environmental Protection Agency. (2019, 4/4/2019). Facts and Figures about the Great Lakes. Retrieved from https://www.epa.gov/greatlakes/facts-and-figuresabout-great-lakes

U.S. Environmental Protection Agency, \& Government of Canada. (1995). The Great Lakes. An Environmental Atlas and Resource Book (Third ed.). 
Wang, J., Bai, X., Hu, H., Clites, A., Colton, M., \& Lofgren, B. (2012). Temporal and Spatial Variability of Great Lakes Ice Cover, 1973-2010*. Journal of Climate, 25(4), 1318-1329. doi:10.1175/2011jcli4066.1

Wang, X., Huang, G., Baetz, B. W., \& Zhao, S. (2017). Probabilistic projections of regional climatic changes over the Great Lakes Basin. Climate Dynamics, 49(7), 2237-2247. doi:10.1007/s00382-016-3450-7

Wuebbles, D., Cardinale, B., Cherkauer, K., Davidson-Arnott, R., Hellmann, J., Infante, D., . . Ballinger, A. (2019). An Assessment of the Impacts of Climate Change on the Great Lakes. Retrieved from https://elpc.org/wpcontent/uploads/2020/04/2019-ELPCPublication-Great-Lakes-Climate-ChangeReport.pdf

Xiao, C., Lofgren, B., Wang, J., \& Chu, P. (2018). A Dynamical Downscaling Projection of Future Climate Change in the Laurentian Great Lakes Region Using a Coupled Air-Lake Model.

Xue, P., Pal, J. S., Ye, X., Lenters, J. D., Huang, C., \& Chu, P. Y. (2017). Improving the Simulation of Large Lakes in Regional Climate Modeling: Two-Way LakeAtmosphere Coupling with a 3D Hydrodynamic Model of the Great Lakes. Journal of Climate, 30(5), 1605-1627. doi:10.1175/jcli-d-16-0225.1

Ye, X. (2019). THE GREAT LAKES CLIMATE ANALYSIS USING A TWO-WAY COUPLED 3-D GREAT LAKES -ATMOSPHERE REGIONAL MODEL WITH DATA ASSIMILATION METHODOLOGY. (PhD). Michigan Technological University, Campus Access Dissertation. Retrieved from https://digitalcommons.mtu.edu/etdr/847

Zhang, L., Zhao, Y., Hein-Griggs, D., Barr, L., \& Ciborowski, J. J. H. (2019). Projected extreme temperature and precipitation of the Laurentian Great Lakes Basin. Global and Planetary Change, 172, 325-335. doi:https://doi.org/10.1016/j.gloplacha.2018.10.019

Zhang, L., Zhao, Y., Hein-Griggs, D., Janes, T., Tucker, S., \& Ciborowski, J. J. H. (2020). Climate change projections of temperature and precipitation for the great lakes basin using the PRECIS regional climate model. Journal of Great Lakes Research, 46(2), 255-266. doi:https://doi.org/10.1016/j.jglr.2020.01.013 


\section{A Figures showing the predictions}

\section{A.1 Over-lake precipitation predictions}
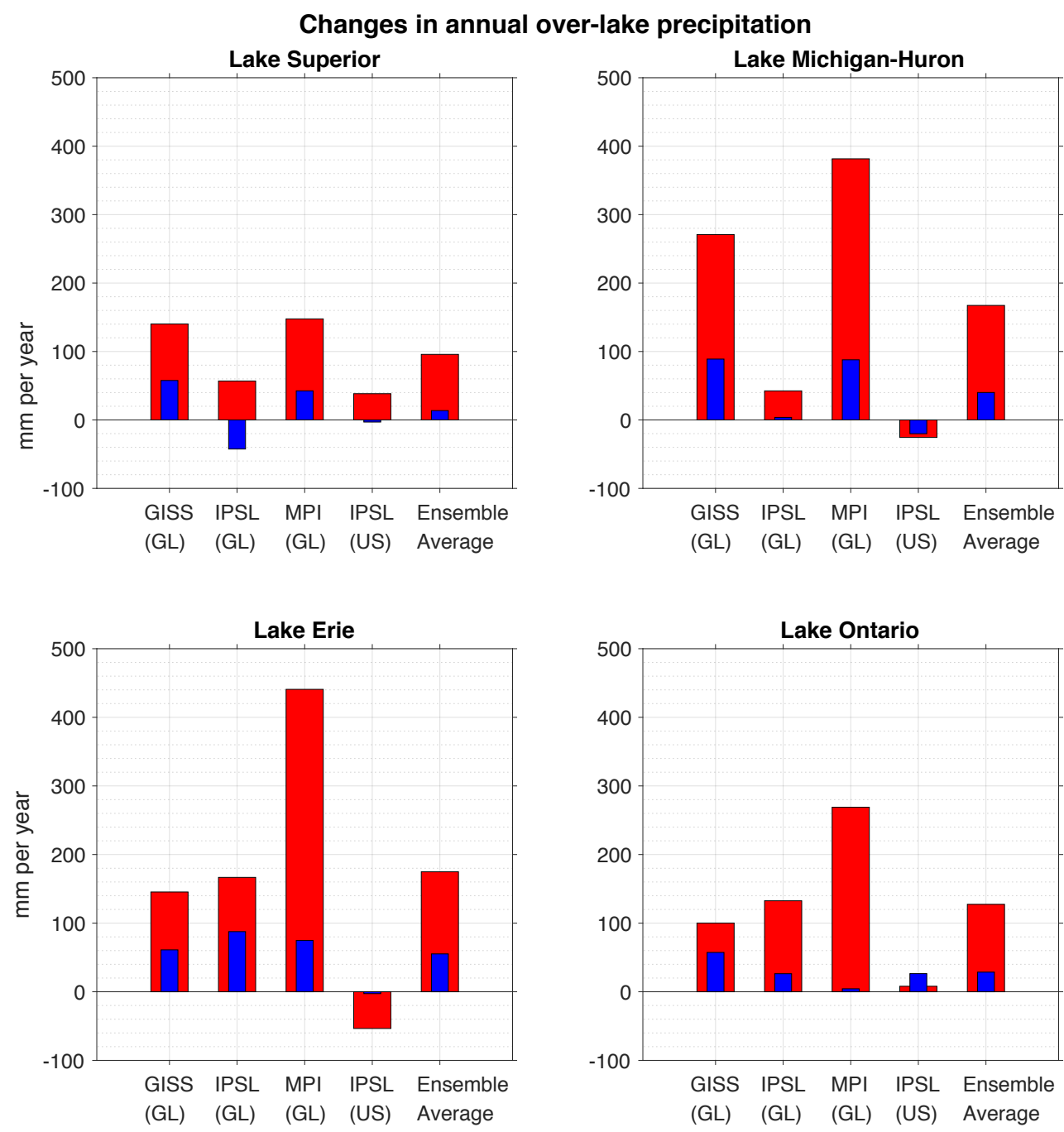

Late twenty-first century changes

Mid-twenty-first century changes

Figure A.1 Average predicted change in annual over-lake precipitation for each lake relative to the 2000-2019 from GLARM. Changes by 2030-2049 are shown in blue and changes by 2080-2099 are shown in red. Each bar represents millimeters over the respective lake area. The X-axis labels represent the GCM and the GLARM domain used for downscaling. '(GL)' is the GLARM with the Great Lakes region as its domain and '(US)' is the GLARM with North America as its domain. The ensemble average is the average of the four predictions. 

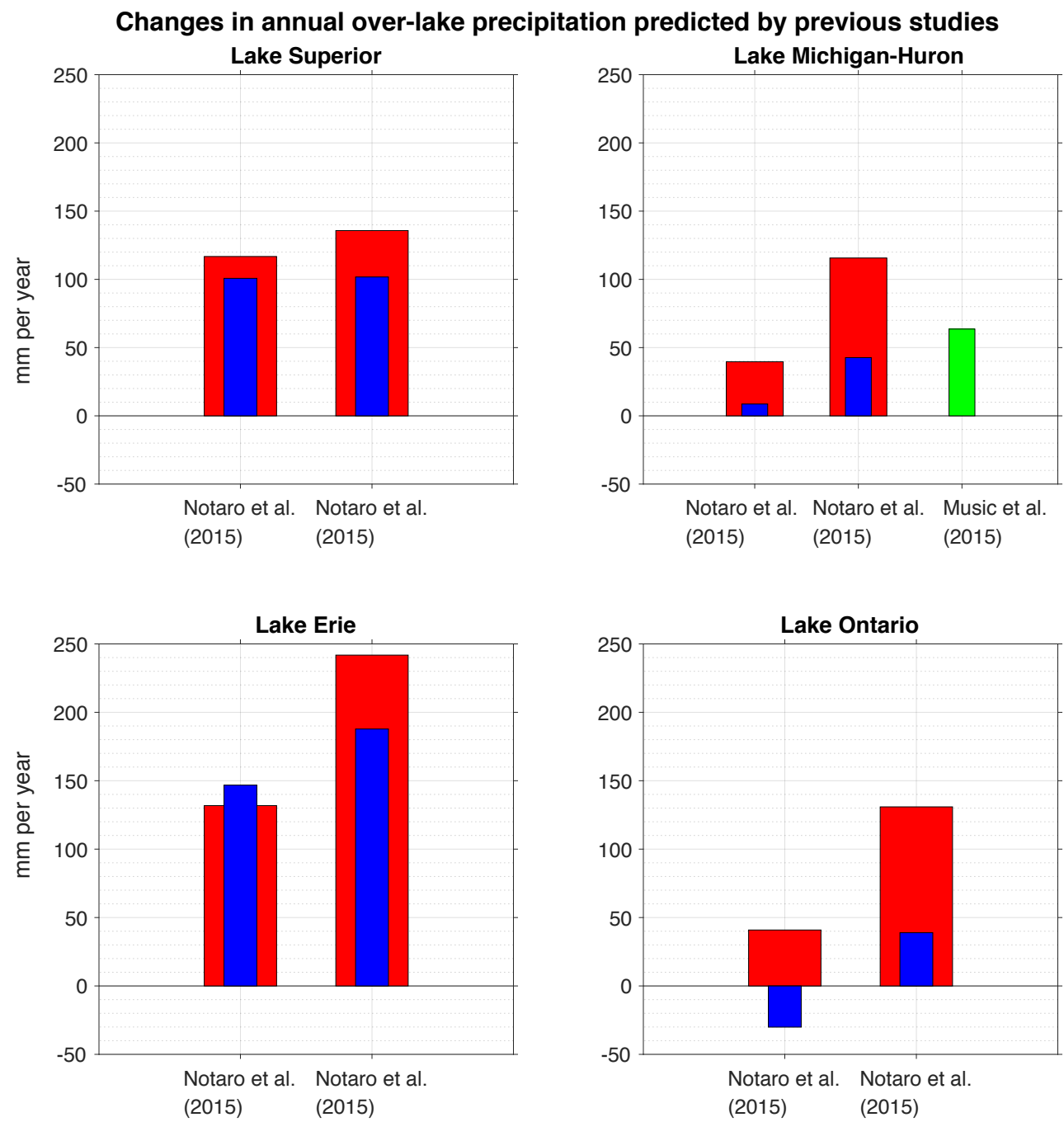

Future: 2080-99 (RCP 8.5) $\square$ Future: 2040-59 (RCP 8.5) $\square$ Future: 2041-70 (SRES A2)

Figure A.2 Predicted changes in average annual over-lake precipitation for each lake relative to the 2000-2019 average from previous studies. The X-axis labels show the names of the studies. Notaro, Bennington, and Lofgren (2015) used two different RCMs; hence, there are two labels for Notaro, Bennington, and Lofgren (2015), one for each $\mathrm{RCM}$. The future time period and the emission scenario of the studies are shown in the legend. Each bar represents millimeters over the respective lake area. 

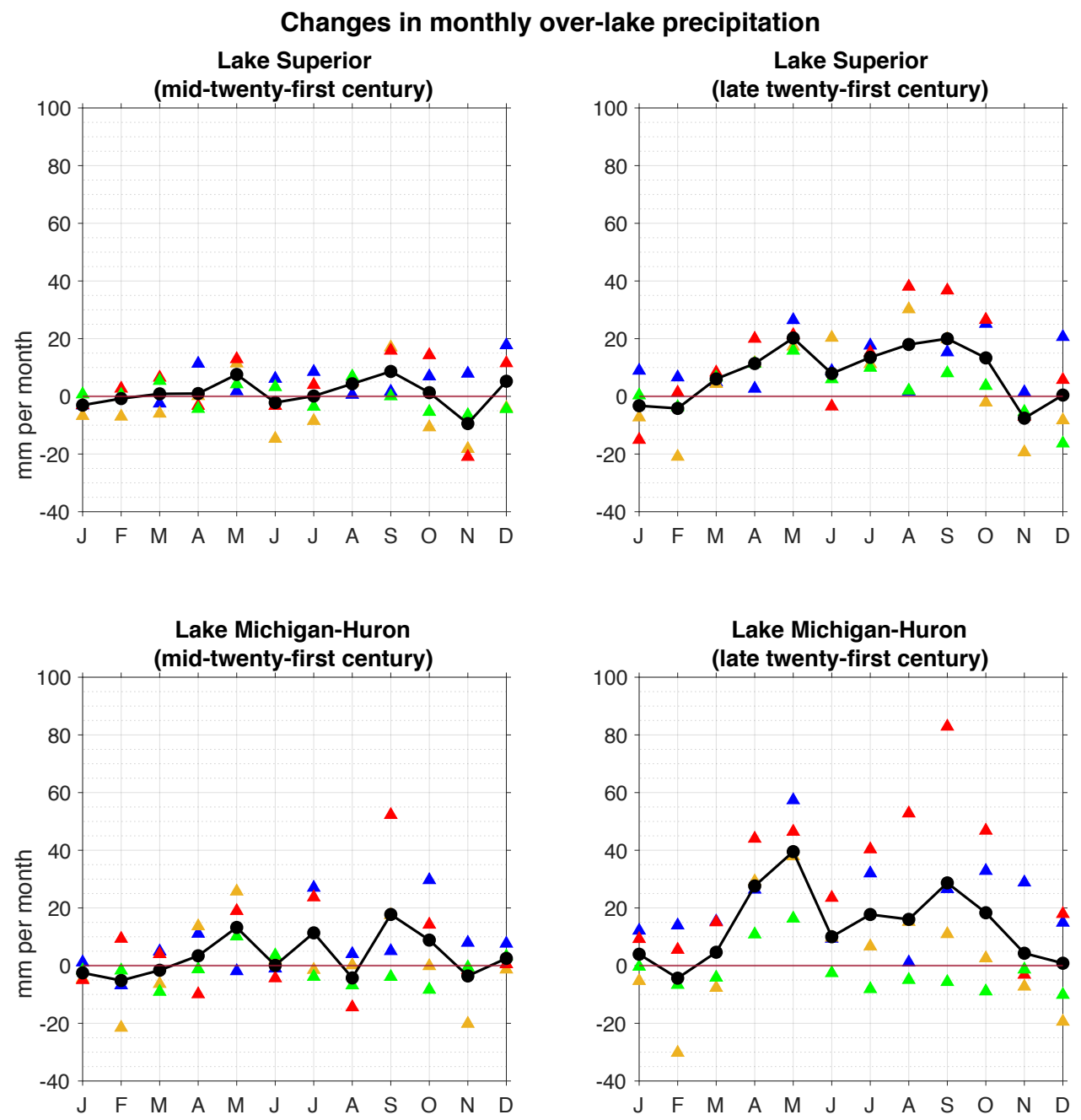

$\Delta$ GISS $(\mathrm{GL}) \wedge \mathrm{IPSL}(\mathrm{GL}) \wedge \mathrm{MPI}(\mathrm{GL}) \wedge \mathrm{IPSL}(\mathrm{US})$ - - Ensemble average

Figure A.3 Average predicted change in monthly over-lake precipitation for Lake Superior (top row) and Lake Michigan-Huron (bottom row) relative to the 2000-2019 from GLARM. Changes by 2030-2049 are in the first column and changes by 2080-2099 are in the second column. Each point represents millimeters over the respective lake area. The colors represent the GCM and the GLARM domain used for downscaling. '(GL)' represents the GLARM with Great Lakes region as its domain and '(US)' represents the GLARM with North America as its domain. The ensemble average (black line) is the average of the four predictions. 
Changes in monthly over-lake precipitation
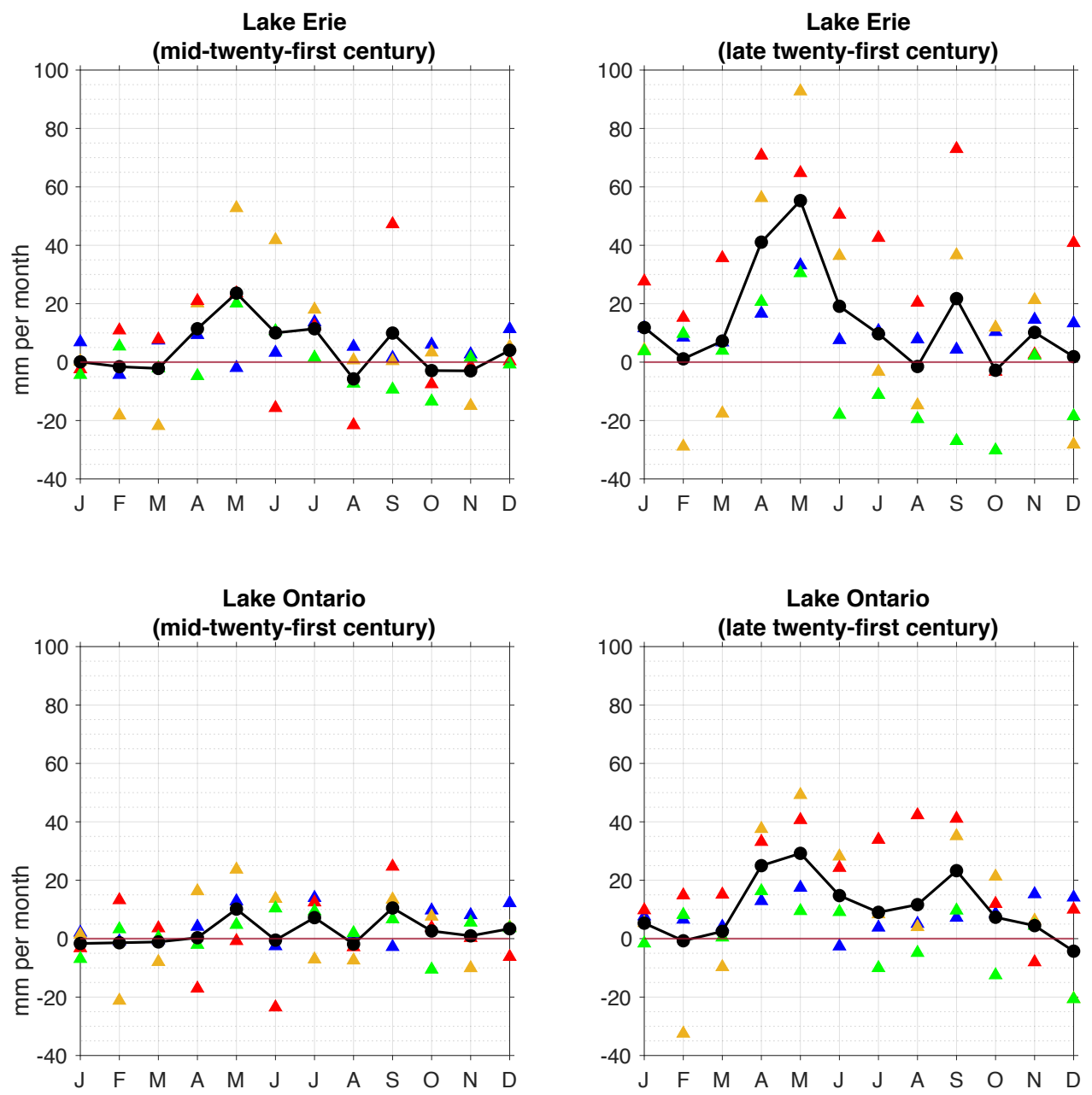

$\Delta \mathrm{GISS}(\mathrm{GL}) \wedge \mathrm{IPSL}(\mathrm{GL}) \Delta \mathrm{MPI}(\mathrm{GL}) \wedge \mathrm{IPSL}(\mathrm{US})-\bullet-$ Ensemble average

Figure A.4 Average predicted change in monthly over-lake precipitation for Lake Erie (top row) and Lake Ontario (bottom row) relative to the 2000-2019 from GLARM. Changes by 2030-2049 are in the first column and changes by 2080-2099 are in the second column. Each point represents millimeters over the respective lake area. The colors represent the GCM and the GLARM domain used for downscaling. '(GL)' represents the GLARM with Great Lakes region as its domain and '(US)' represents the GLARM with North America as its domain. The ensemble average (black line) is the average of the four predictions. 


\section{A.2 Lake evaporation predictions}
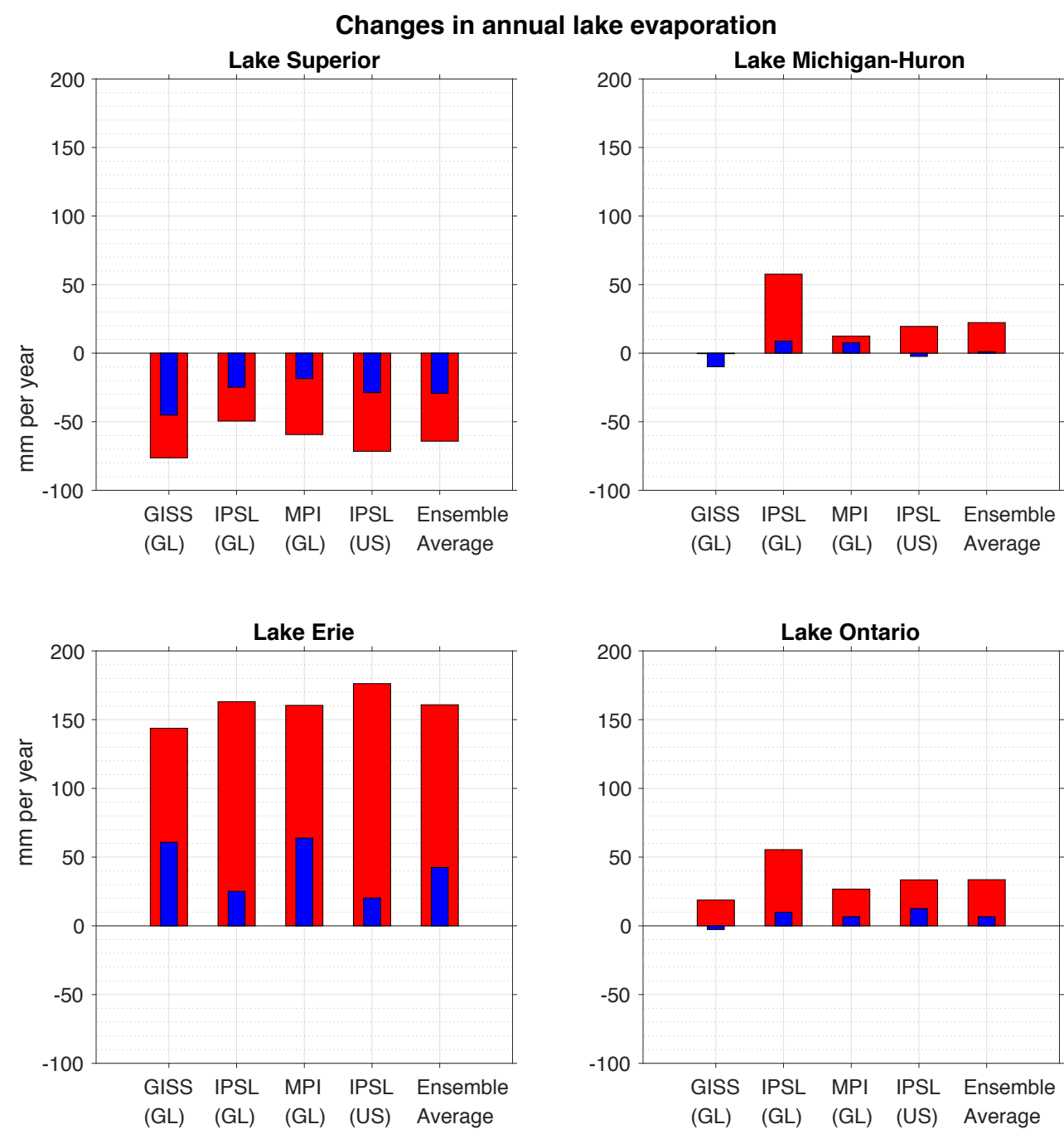

Late twenty-first century changes $\square$ Mid-twenty-first century changes

Figure A.5 Average predicted change in annual lake evaporation for each lake relative to the 2000-2019 from GLARM. Changes by 2030-2049 are shown in blue and changes by 2080-2099 are shown in red. Each bar represents millimeters over the respective lake area. The X-axis labels represent the GCM and the GLARM domain used for downscaling. '(GL)' is the GLARM with the Great Lakes region as its domain and '(US)' is the GLARM with North America as its domain. The ensemble average is the average of the four predictions. 

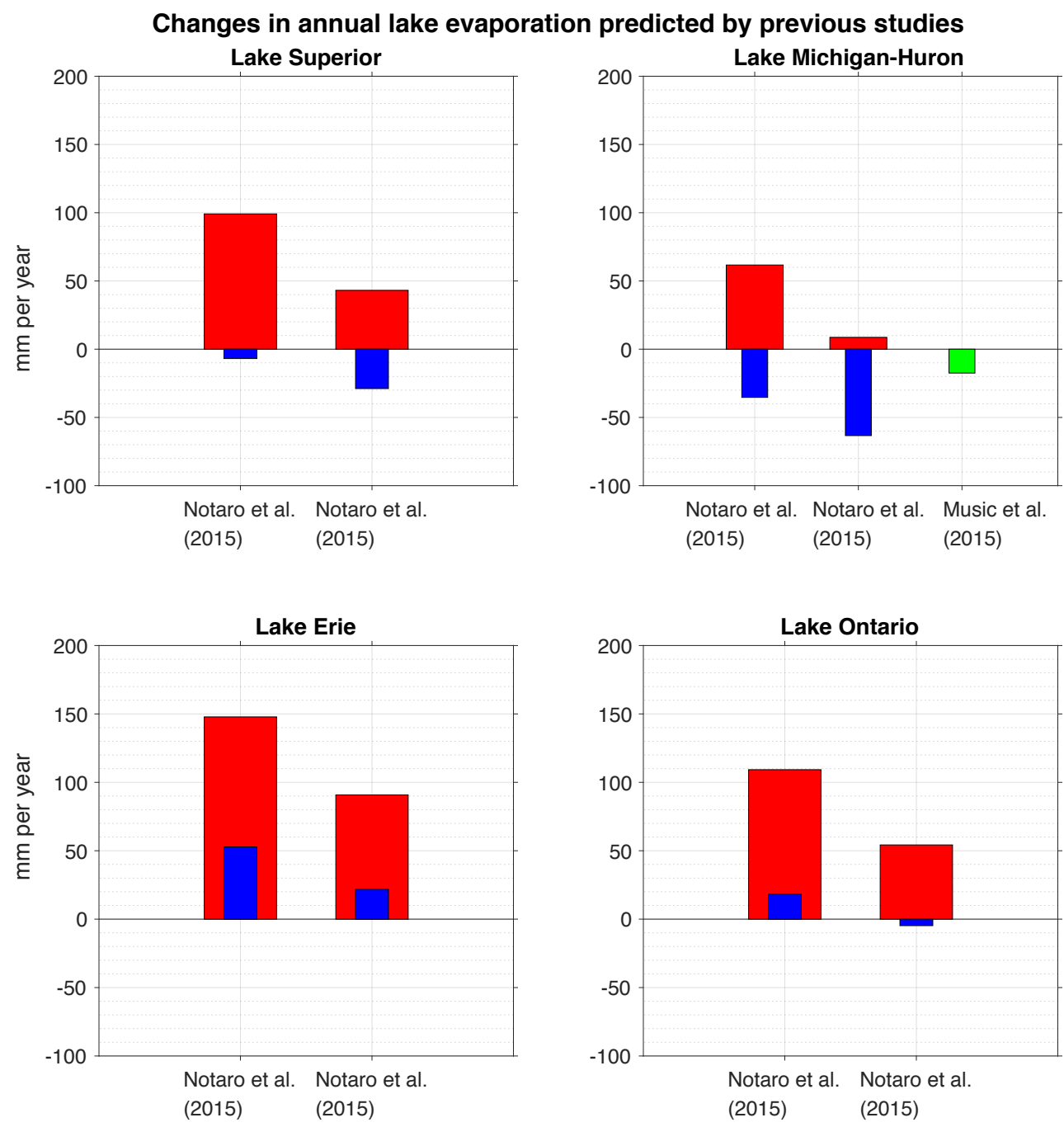

Future: 2080-99 (RCP 8.5) $\square$ Future: 2040-59 (RCP 8.5) $\square$ Future: 2041-70 (SRES A2)

Figure A.6 Predicted changes in average annual lake evaporation for each lake relative to the 2000-2019 average from previous studies. The X-axis labels show the names of the studies. Notaro, Bennington, and Lofgren (2015) used two different RCMs; hence, there are two labels for Notaro, Bennington, and Lofgren (2015), one for each RCM. The future time period and the emission scenario of the studies are shown in the legend. Each bar represents millimeters over the respective lake area. 

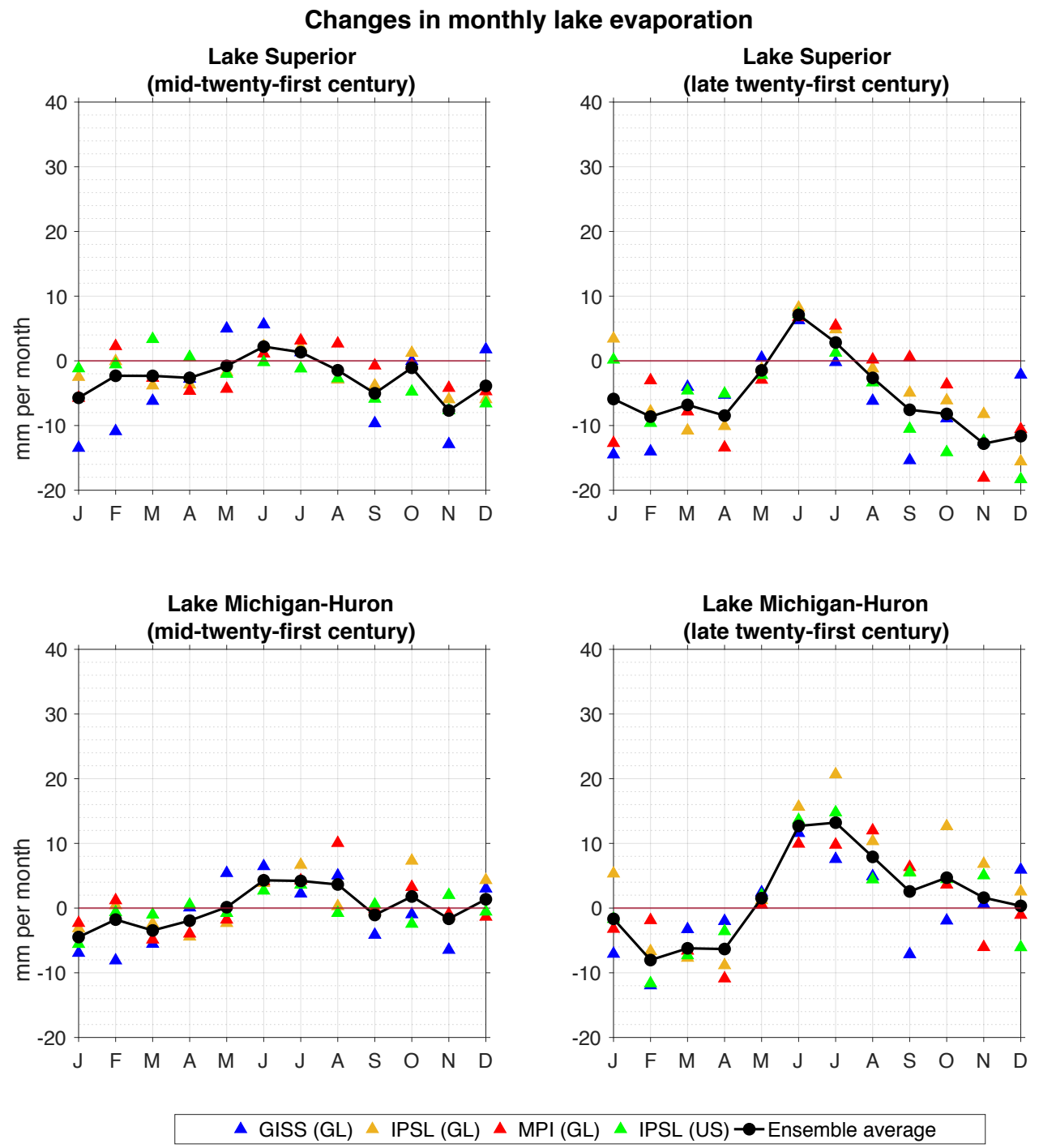

Figure A.7 Average predicted change in monthly lake evaporation for Lake Superior (top row) and Lake Michigan-Huron (bottom row) relative to the 2000-2019 from GLARM. Changes by 2030-2049 are in the first column and changes by 2080-2099 are in the second column. Each point represents millimeters over the respective lake area. The colors represent the GCM and the GLARM domain used for downscaling. '(GL)' represents the GLARM with Great Lakes region as its domain and '(US)' represents the GLARM with North America as its domain. The ensemble average (black line) is the average of the four predictions. 

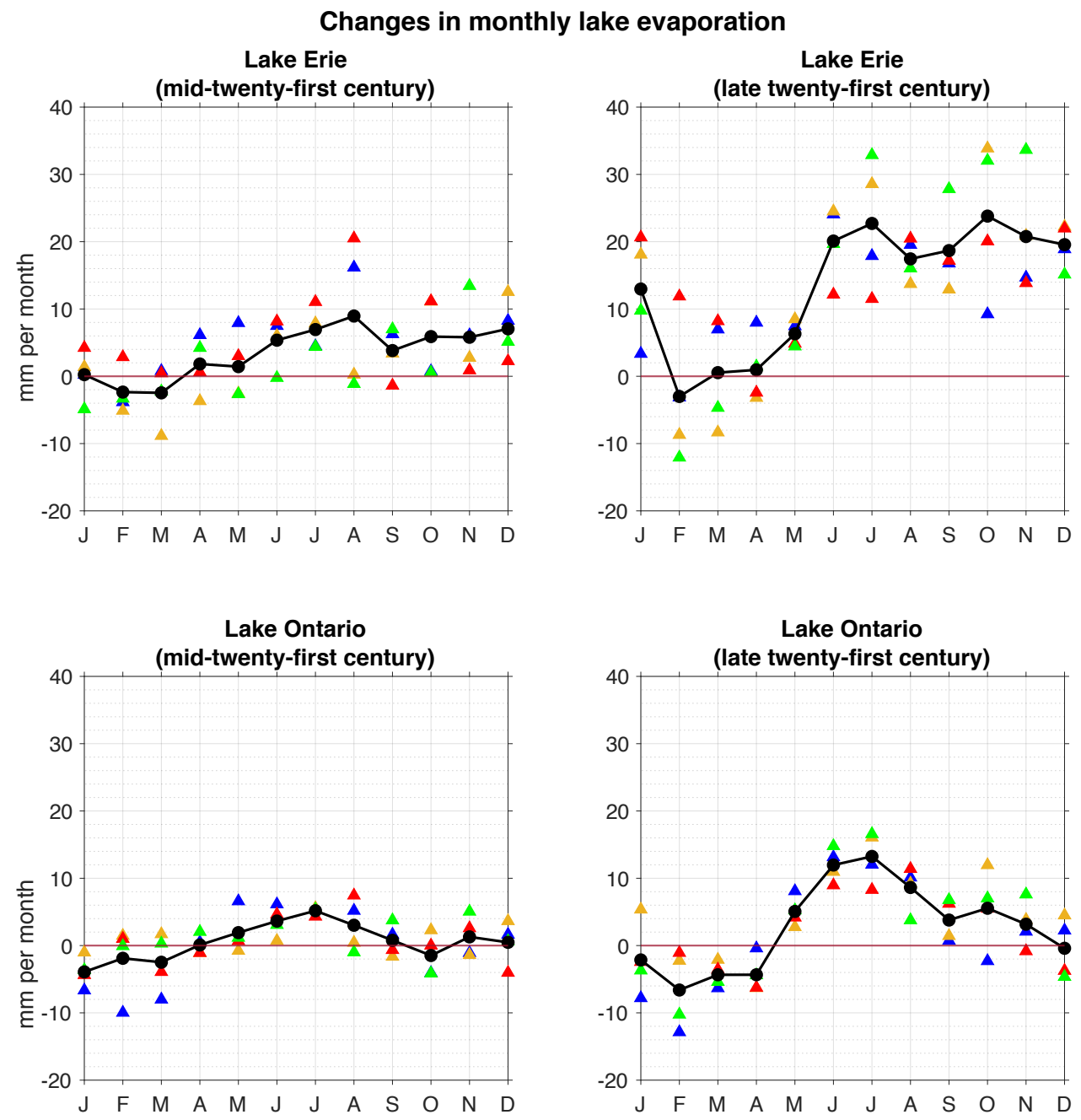

$\Delta \mathrm{GISS}(\mathrm{GL}) \wedge \mathrm{IPSL}(\mathrm{GL}) \wedge \mathrm{MPI}(\mathrm{GL}) \wedge \mathrm{IPSL}(\mathrm{US})$ - - Ensemble average

Figure A.8 Average predicted change in monthly lake evaporation for Lake Erie (top row) and Lake Ontario (bottom row) relative to the 2000-2019 from GLARM. Changes by 2030-2049 are in the first column and changes by 2080-2099 are in the second column. Each point represents millimeters over the respective lake area. The colors represent the GCM and the GLARM domain used for downscaling. '(GL)' represents the GLARM with Great Lakes region as its domain and '(US)' represents the GLARM with North America as its domain. The ensemble average (black line) is the average of the four predictions. 


\section{A.3 Wind speed predictions}
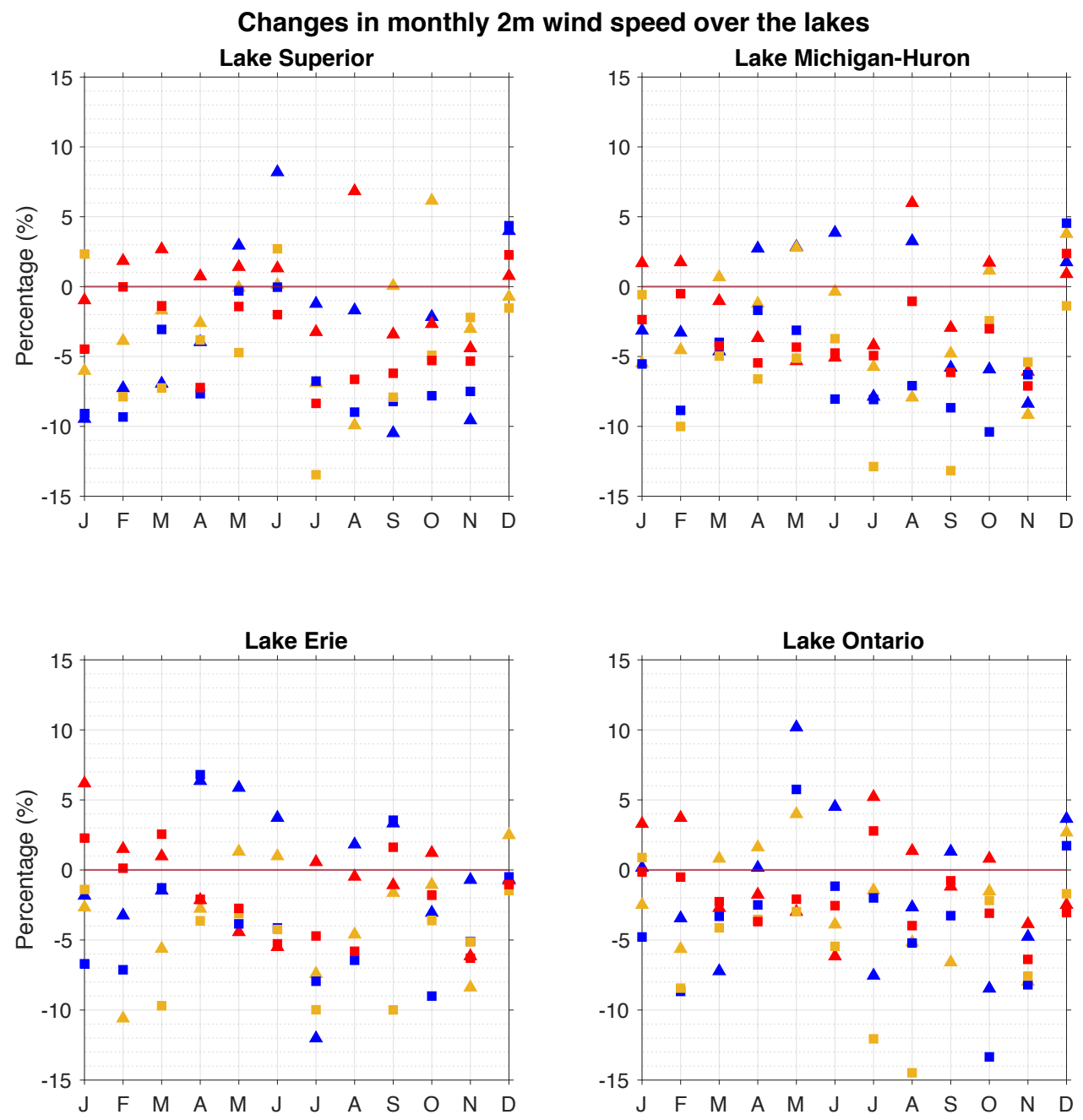

$\Delta$ GISS (GL) mid-twenty-first changes $\triangle$ IPSL (GL) mid-twenty-first changes $\triangle$ MPI (GL) mid-twenty-first changes - GISS (GL) late twenty-first changes — IPSL (GL) late twenty-first changes — MPI (GL) late twenty-first changes

Figure A.9 Average predicted change in monthly wind speed relative to the 2000-2019 from GLARM. Changes by 2030-2049 are represented as triangles and changes by 20802099 are represented as squares. The colors represent the GCM and the GLARM domain used for downscaling. '(GL)' represents the GLARM with Great Lakes region as its domain and '(US)' represents the GLARM with North America as its domain. 


\section{A.4 Specific humidity predictions}

Changes in monthly difference between saturated and actual specific humidity over the lakes
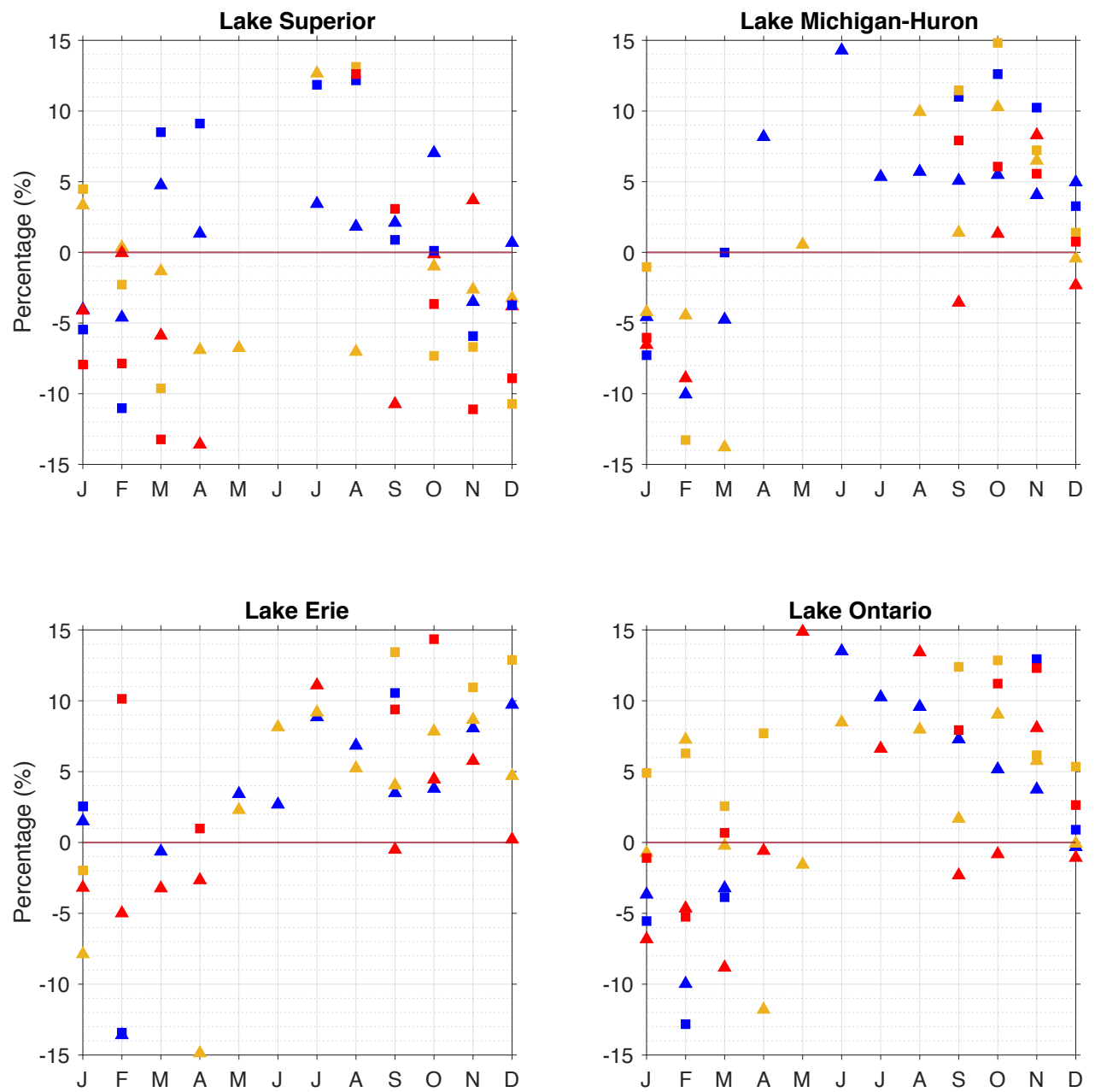

\ GISS (GL) mid-twenty-first changes $\triangle$ IPSL (GL) mid-twenty-first changes $\triangle$ MPI (GL) mid-twenty-first changes

- GISS (GL) late twenty-first changes = IPSL (GL) late twenty-first changes - MPI (GL) late twenty-first changes

Figure A.10 Average predicted change in monthly difference between saturated and actual specific humidity relative to the 2000-2019 from GLARM. Changes by 2030-2049 are represented as triangles and changes by 2080-2099 are represented as squares. The colors represent the GCM and the GLARM domain used for downscaling. '(GL)' represents the GLARM with Great Lakes region as its domain and '(US)' represents the GLARM with North America as its domain. 


\section{A.5 Basin runoff predictions}
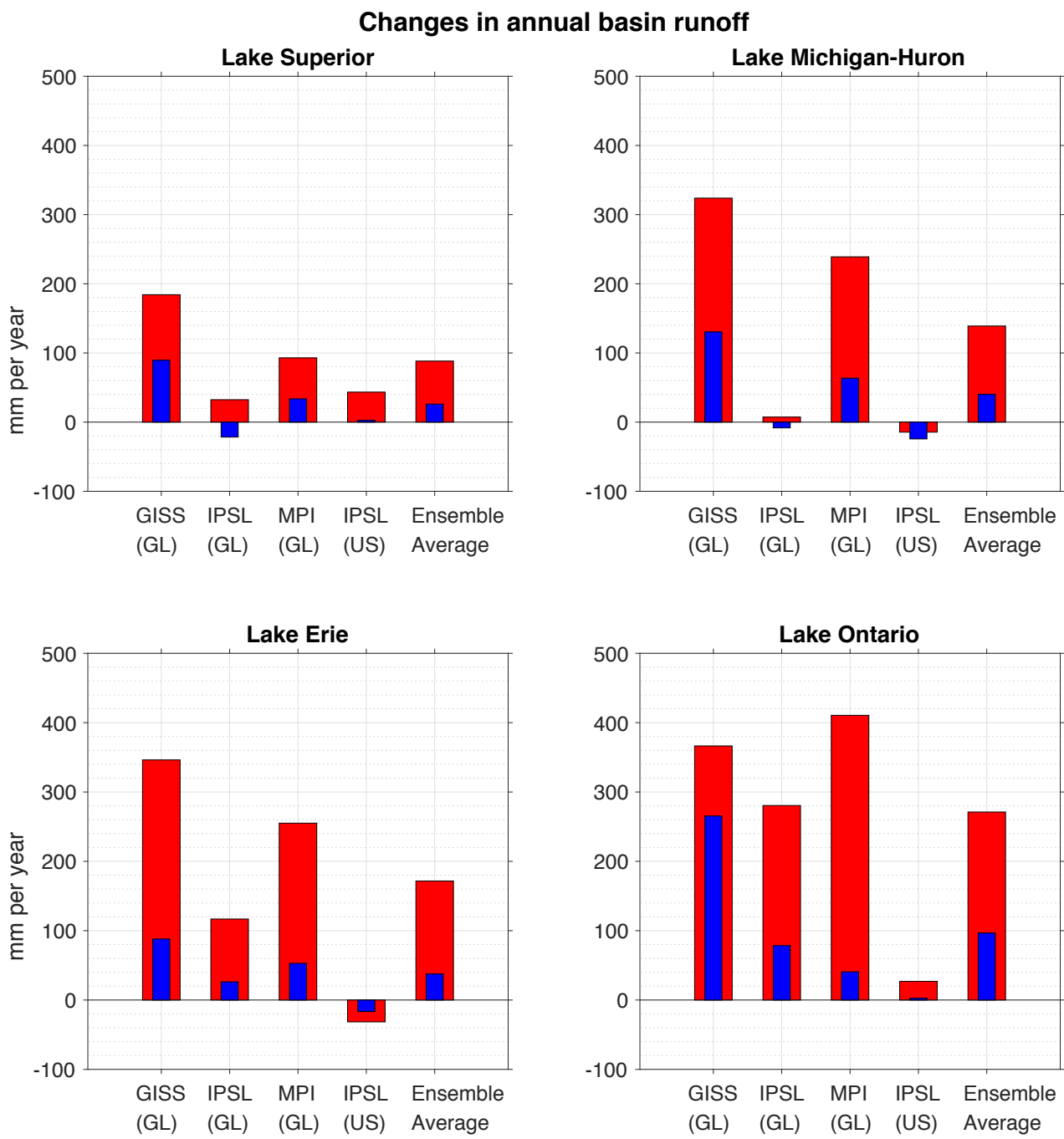

Late twenty-first century changes

Mid-twenty-first century changes

Figure A.11 Average predicted change in annual basin runoff for each lake relative to the 2000-2019 from GLARM. Changes by 2030-2049 are shown in blue and changes by 2080-2099 are shown in red. Each bar represents millimeters over the respective lake area. The X-axis labels represent the GCM and the GLARM domain used for downscaling. '(GL)' is the GLARM with the Great Lakes region as its domain and '(US)' is the GLARM with North America as its domain. The ensemble average is the average of the four predictions. 

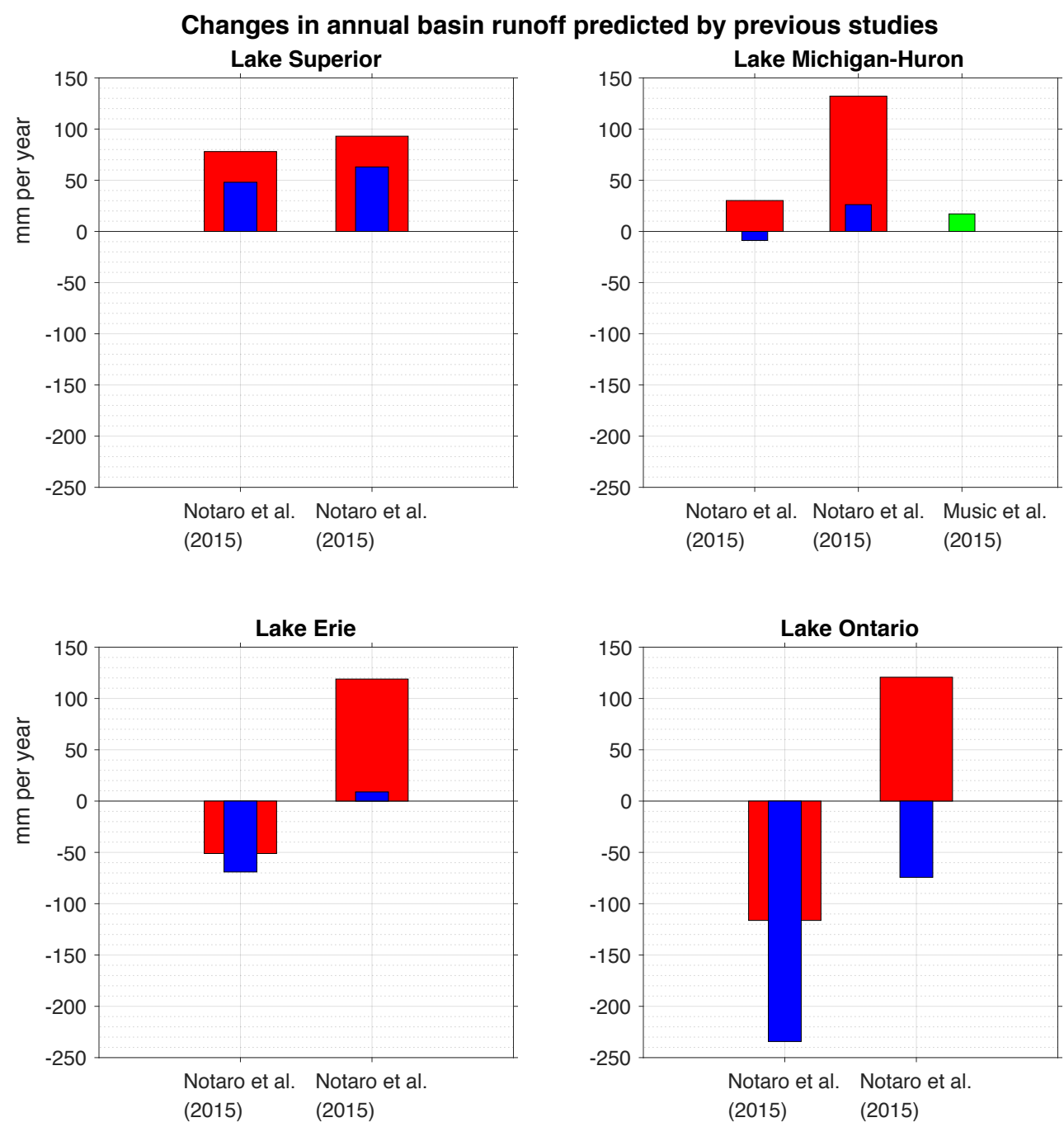

Future: 2080-99 (RCP 8.5) $\square$ Future: 2040-59 (RCP 8.5) $\square$ Future: 2041-70 (SRES A2)

Figure A.12 Predicted changes in average annual basin runoff for each lake relative to the 2000-2019 average from previous studies. The X-axis labels show the names of the studies. Notaro, Bennington, and Lofgren (2015) used two different RCMs; hence, there are two labels for Notaro, Bennington, and Lofgren (2015), one for each RCM. The future time period and the emission scenario of the studies are shown in the legend. Each bar represents millimeters over the respective lake area. 

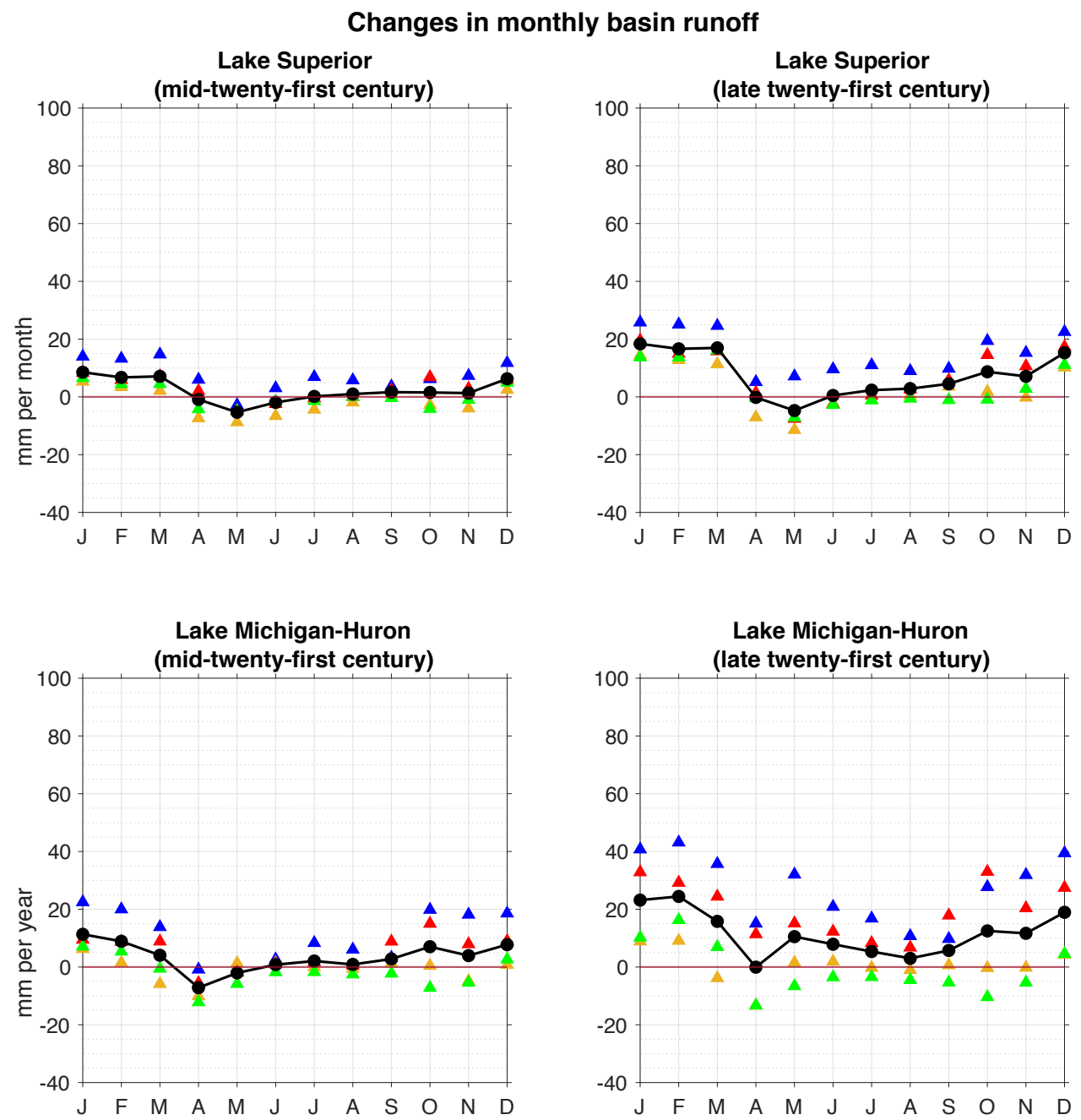

$\Delta \mathrm{GISS}(\mathrm{GL}) \wedge \mathrm{IPSL}(\mathrm{GL}) \wedge \mathrm{MPI}(\mathrm{GL}) \wedge \mathrm{IPSL}(\mathrm{US})-\bullet-$ Ensemble average

Figure A.13 Average predicted change in monthly basin runoff for Lake Superior (top row) and Lake Michigan-Huron (bottom row) relative to the 2000-2019 from GLARM. Changes by 2030-2049 are in the first column and changes by 2080-2099 are in the second column. Each point represents millimeters over the respective lake area. The colors represent the GCM and the GLARM domain used for downscaling. '(GL)' represents the GLARM with Great Lakes region as its domain and '(US)' represents the GLARM with North America as its domain. The ensemble average (black line) is the average of the four predictions. 

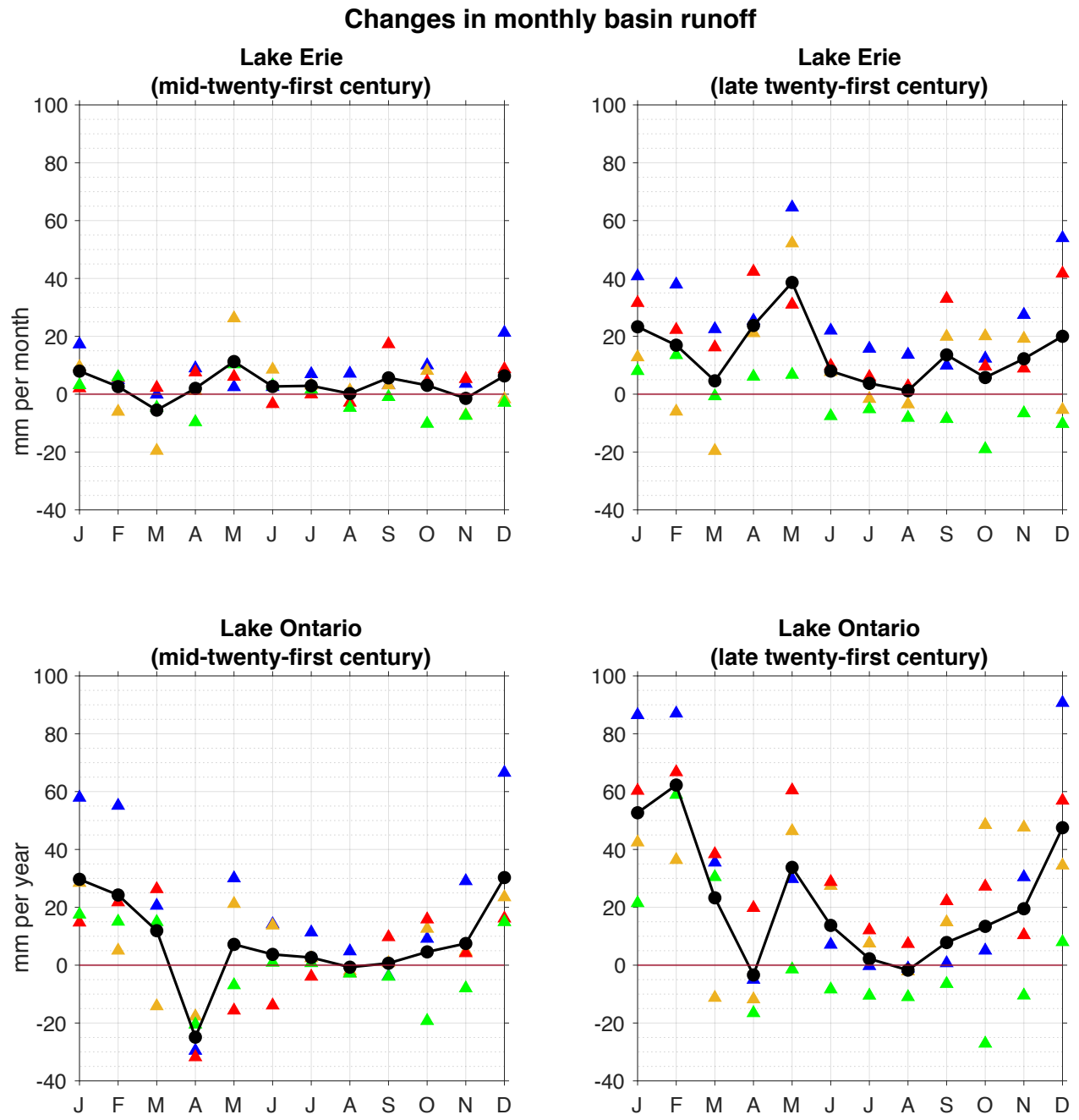

$\Delta \mathrm{GISS}(\mathrm{GL}) \Delta \mathrm{IPSL}(\mathrm{GL}) \Delta \mathrm{MPI}(\mathrm{GL}) \Delta \mathrm{IPSL}(\mathrm{US})-\bullet-$ Ensemble average

Figure A.14 Average predicted change in monthly lake evaporation for Lake Erie (top row) and Lake Ontario (bottom row) relative to the 2000-2019 from GLARM. Changes by 2030-2049 are in the first column and changes by 2080-2099 are in the second column. Each point represents millimeters over the respective lake area. The colors represent the GCM and the GLARM domain used for downscaling. '(GL)' represents the GLARM with Great Lakes region as its domain and '(US)' represents the GLARM with North America as its domain. The ensemble average (black line) is the average of the four predictions. 


\section{A.6 NBS predictions}
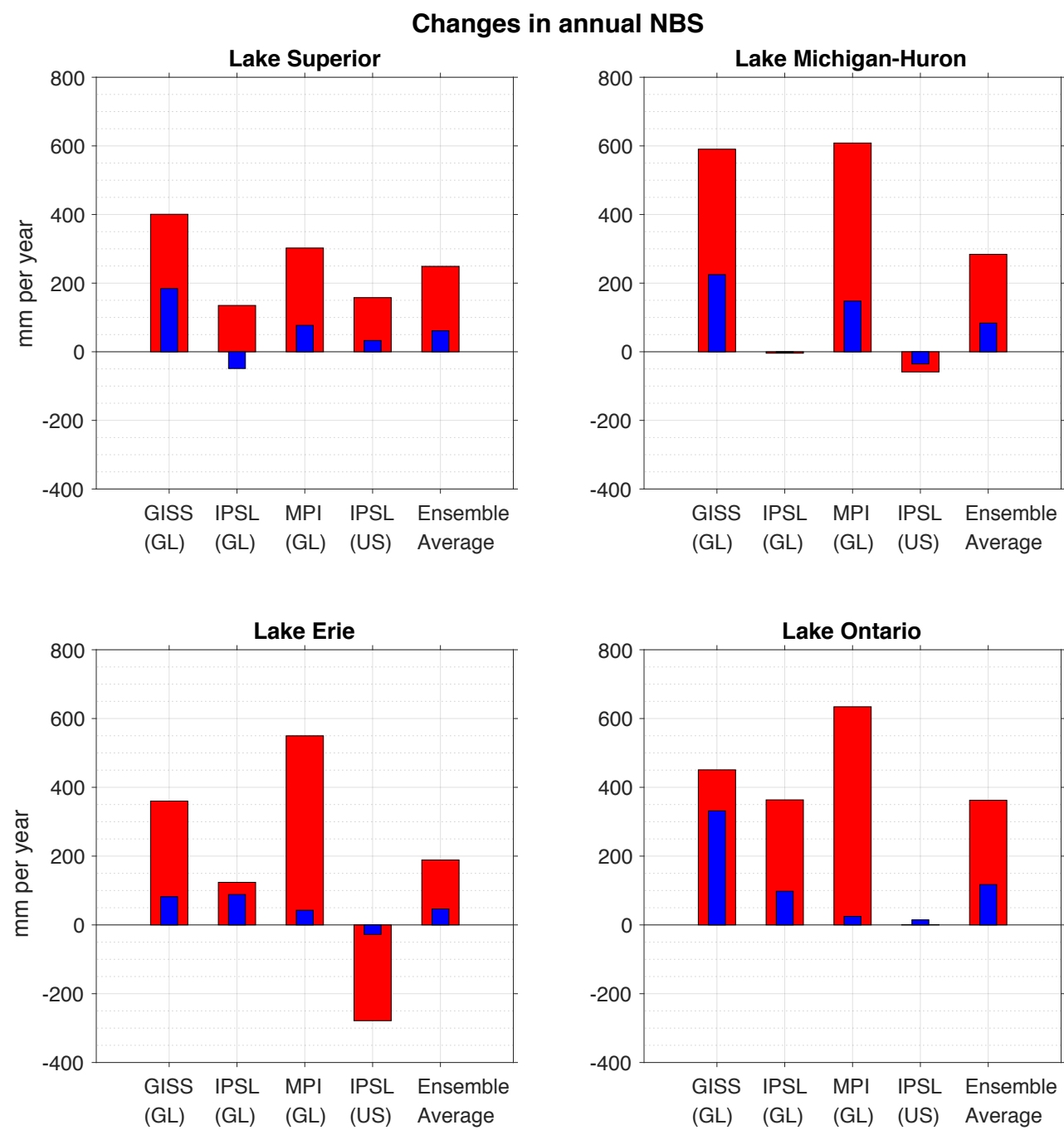

Late twenty-first century changes

Mid-twenty-first century changes

Figure A.15 Average predicted change in annual NBS for each lake relative to the 20002019 from GLARM. Changes by 2030-2049 are shown in blue and changes by 20802099 are shown in red. Each bar represents millimeters over the respective lake area. The $\mathrm{X}$-axis labels represent the GCM and the GLARM domain used for downscaling. '(GL)' is the GLARM with the Great Lakes region as its domain and '(US)' is the GLARM with North America as its domain. The ensemble average is the average of the four predictions. 

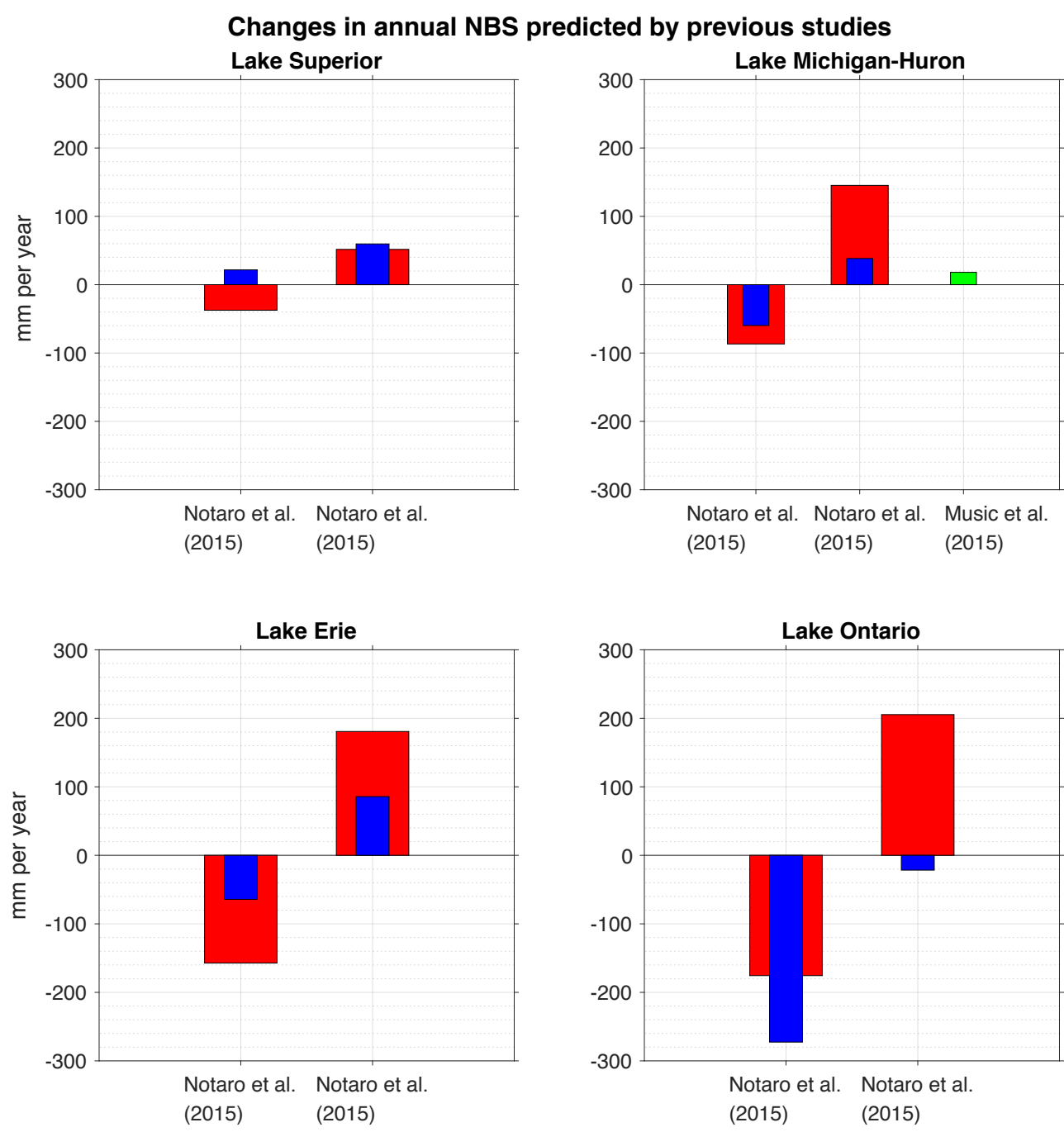

Future: 2080-99 (RCP 8.5) $\square$ Future: 2040-59 (RCP 8.5) $\square$ Future: 2041-70 (SRES A2)

Figure A.16 Predicted changes in average annual NBS for each lake relative to the 20002019 average from previous studies. The X-axis labels show the names of the studies. Notaro, Bennington, and Lofgren (2015) used two different RCMs; hence, there are two labels for Notaro, Bennington, and Lofgren (2015), one for each RCM. The future time period and the emission scenario of the studies are shown in the legend. Each bar represents millimeters over the respective lake area. 

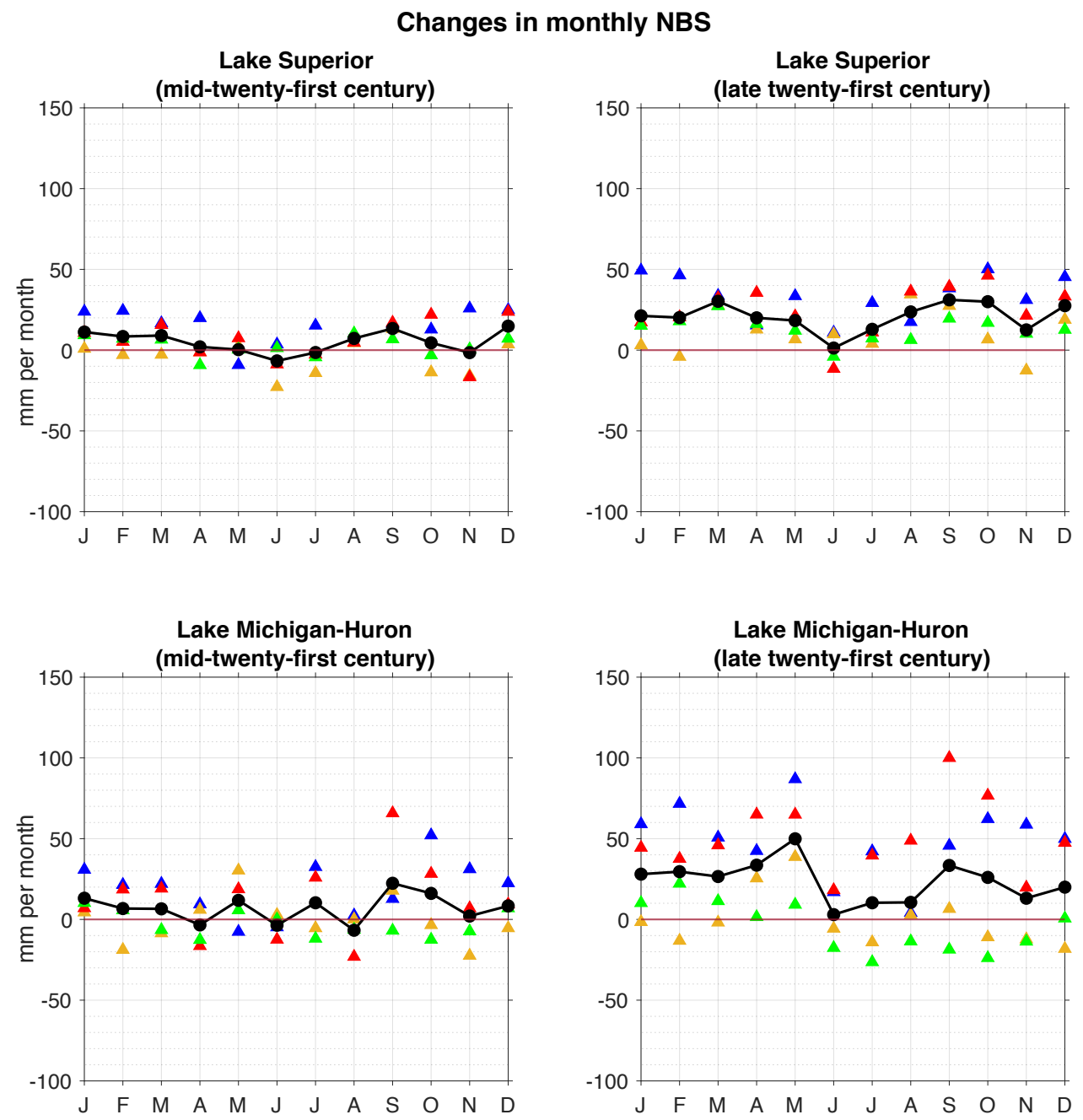

$\Delta \mathrm{GISS}(\mathrm{GL}) \wedge \mathrm{IPSL}(\mathrm{GL}) \wedge \mathrm{MPI}(\mathrm{GL}) \wedge \mathrm{IPSL}(\mathrm{US})-\bullet-$ Ensemble average

Figure A.17 Average predicted change in monthly NBS for Lake Superior (top row) and Lake Michigan-Huron (bottom row) relative to the 2000-2019 from GLARM. Changes by 2030-2049 are in the first column and changes by 2080-2099 are in the second column. Each point represents millimeters over the respective lake area. The colors represent the GCM and the GLARM domain used for downscaling. '(GL)' represents the GLARM with Great Lakes region as its domain and '(US)' represents the GLARM with North America as its domain. The ensemble average (black line) is the average of the four predictions. 

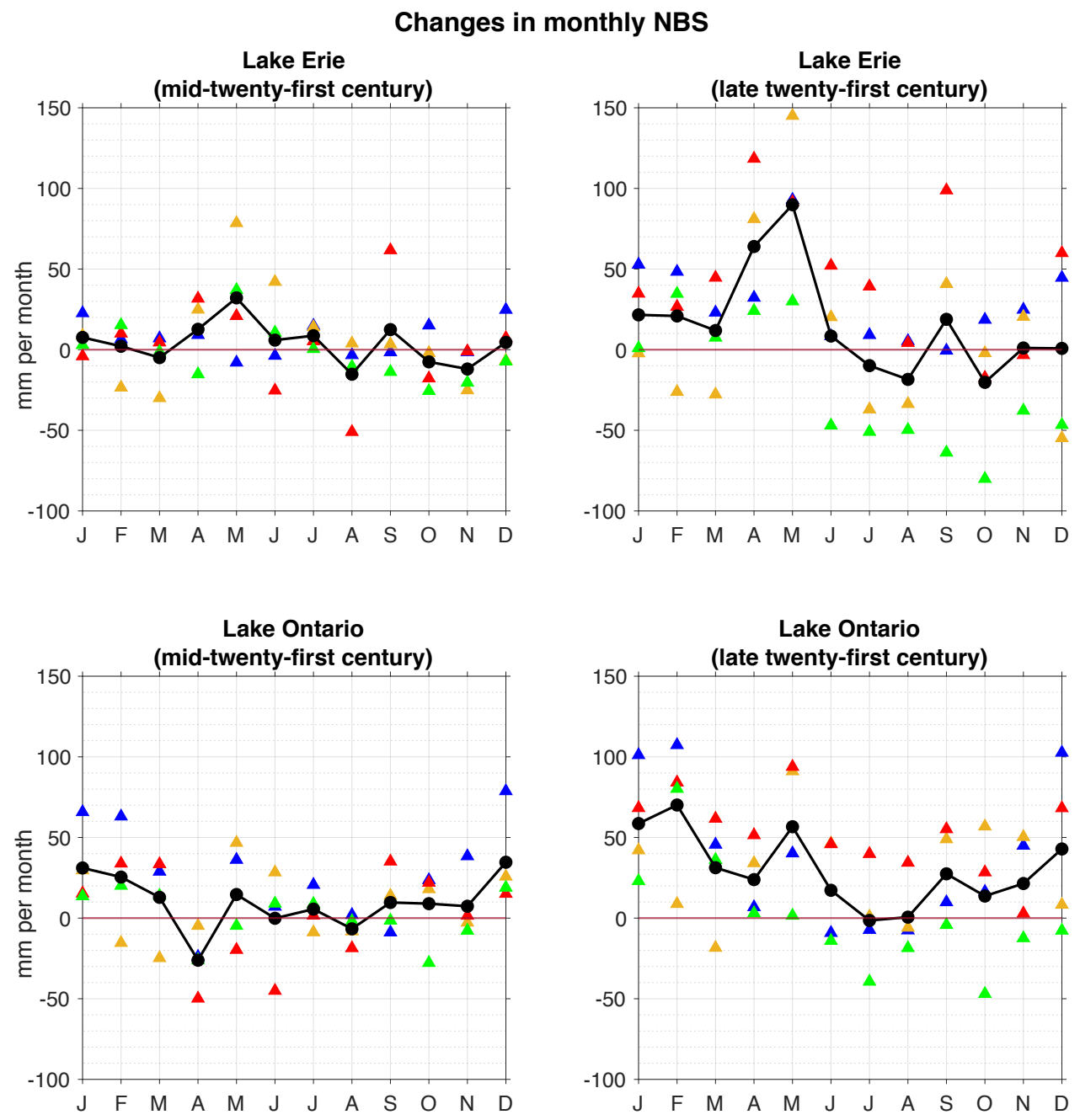

$\Delta \mathrm{GISS}(\mathrm{GL}) \wedge \mathrm{IPSL}(\mathrm{GL}) \Delta \mathrm{MPI}(\mathrm{GL}) \wedge \mathrm{IPSL}(\mathrm{US})$ - - Ensemble average

Figure A.18 Average predicted change in monthly NBS for Lake Erie (top row) and Lake Ontario (bottom row) relative to the 2000-2019 from GLARM. Changes by 2030-2049 are in the first column and changes by 2080-2099 are in the second column. Each point represents millimeters over the respective lake area. The colors represent the GCM and the GLARM domain used for downscaling. '(GL)' represents the GLARM with Great Lakes region as its domain and '(US)' represents the GLARM with North America as its domain. The ensemble average (black line) is the average of the four predictions. 


\section{A.7 Water level predictions}
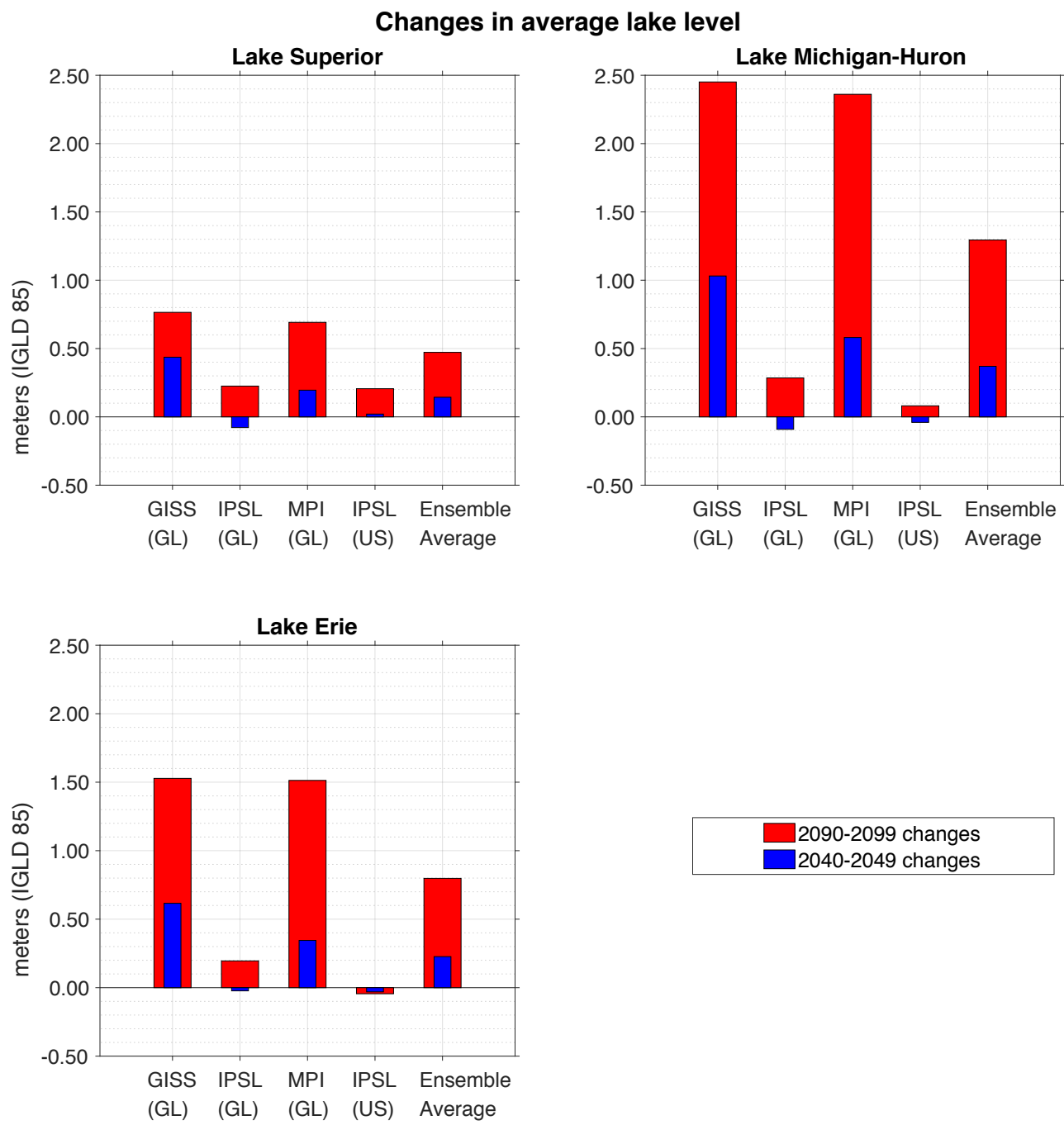

2090-2099 changes

Figure A.19 Predicted change in average monthly lake level for each lake relative to the 2010-2019 average from GLARM. Changes by 2040-2049 are shown in blue and changes by 2090-2099 are shown in red. The X-axis labels represent the GCM and the GLARM domain used for downscaling. '(GL)' represents the GLARM with Great Lakes region as its domain and '(US)' represents the GLARM with North America as its domain. The ensemble average is the average of the four predictions. 

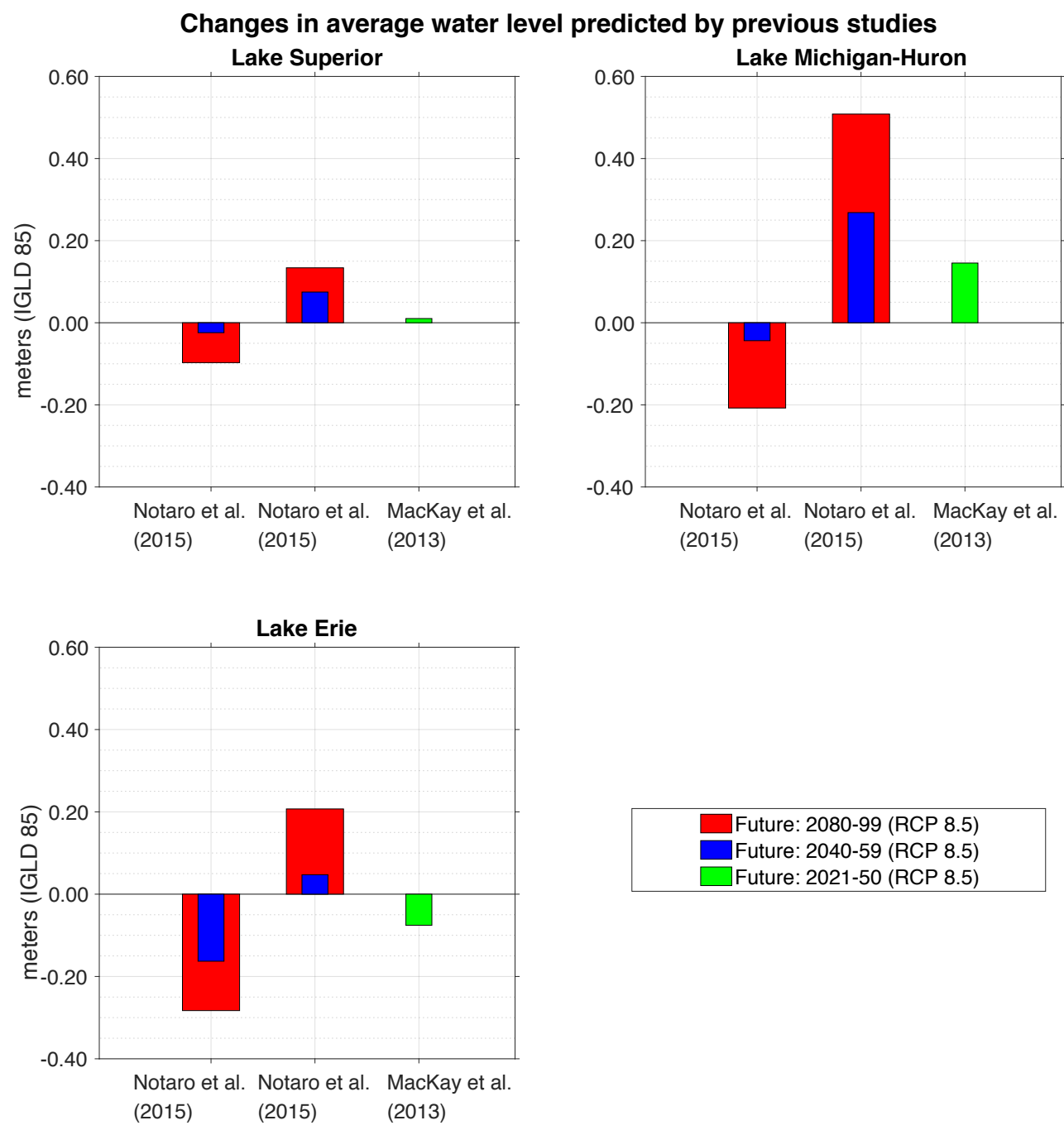

Figure A.20 Predicted changes in average monthly water level for each lake relative to the 2010-2019 average from previous studies. The X-axis labels show the names of the studies. Notaro, Bennington, and Lofgren (2015) used two different RCMs; hence, there are two labels for Notaro, Bennington, and Lofgren (2015), one for each RCM. The future time period and the emission scenario of the studies are shown in the legend. 


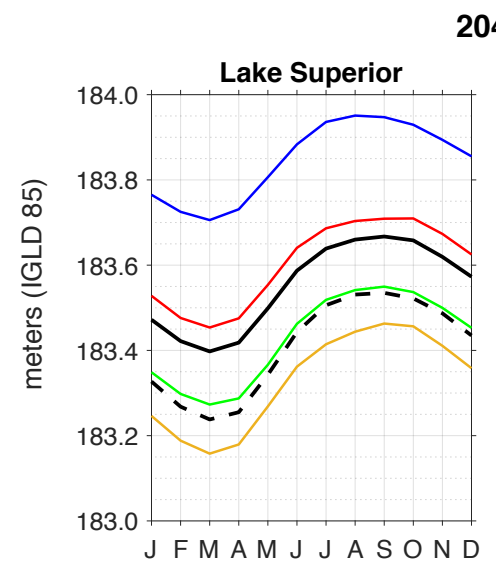

2040-2049 and 2010-2019 monthly lake levels
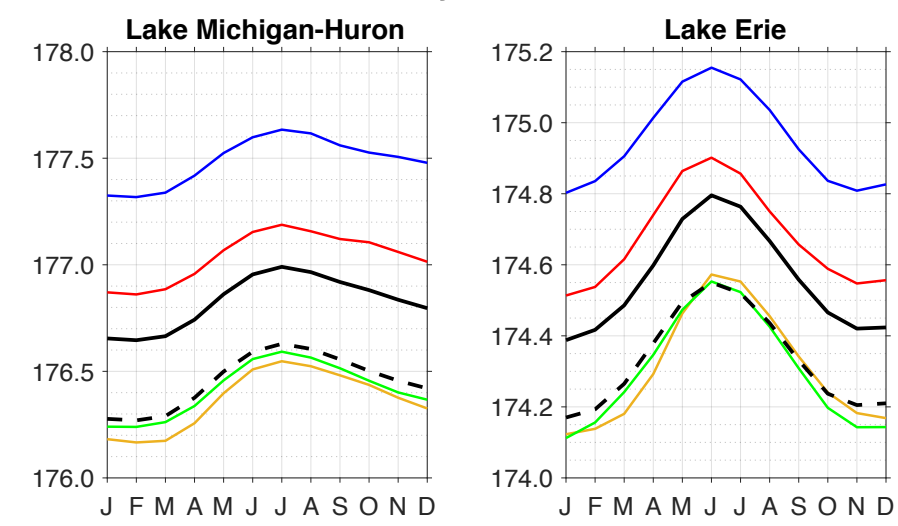

2090-2099 and 2010-2019 monthly lake levels
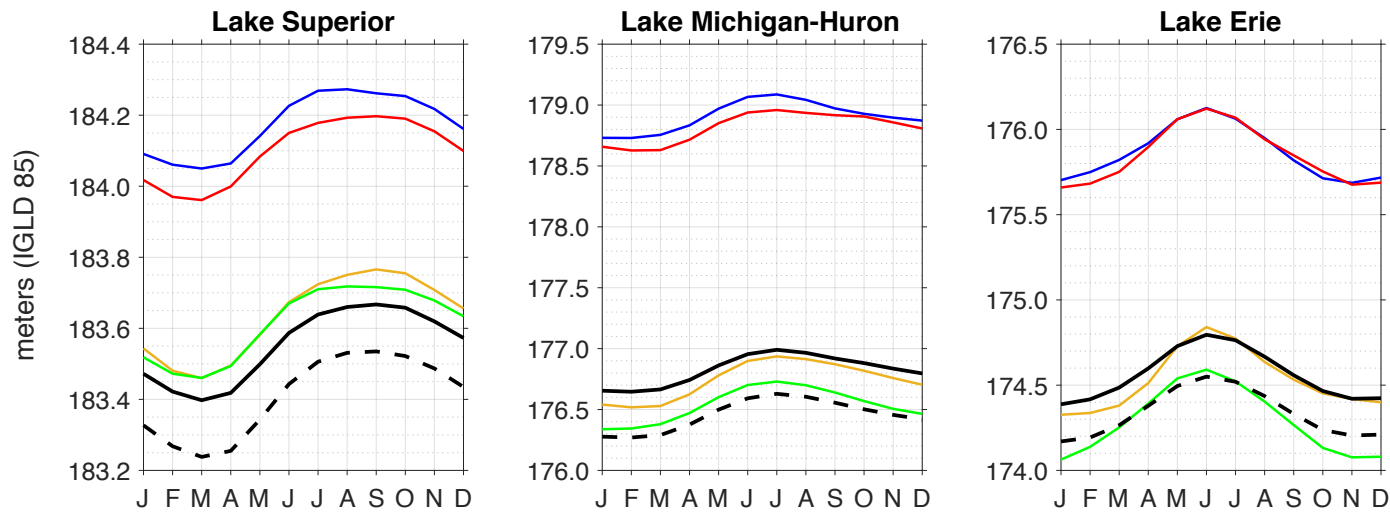

—GISS (GL) — IPSL (GL) — MPI (GL) — IPSL (US) —Ensemble Average - -2010-2019

Figure A.21 Monthly climatology of lake levels for 2040-2049 (top row) and 2090-2099 (bottom row). The 2010-2019 climatology is shown in black dotted lines. The colors represent the GCM and the GLARM domain used for downscaling. '(GL)' represents the GLARM with Great Lakes region as its domain and '(US)' represents the GLARM with North America as its domain. 


\section{A.8 GLARM validation}
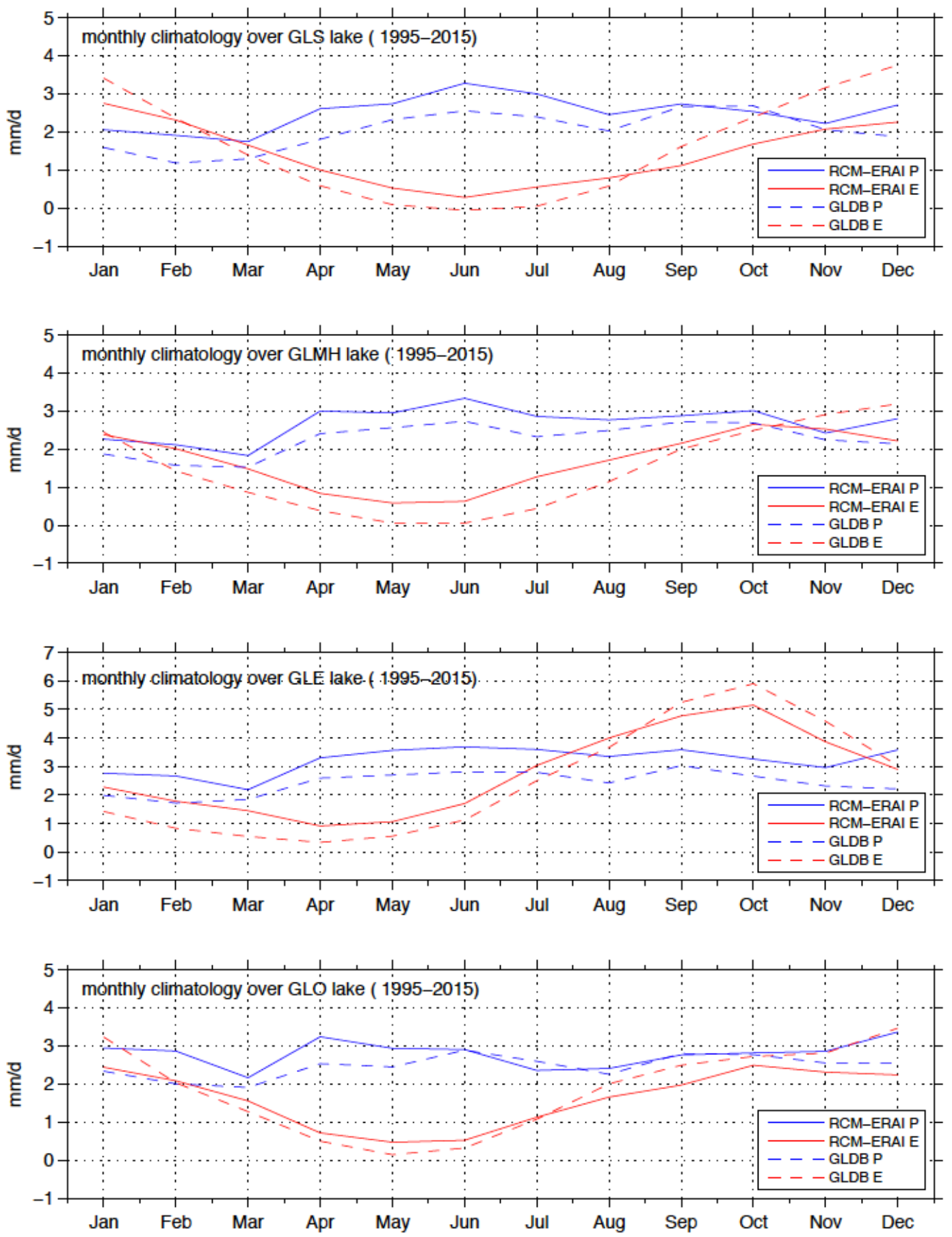

Figure A.22 Seasonal climatology of monthly mean over-lake precipitation (blue) and lake evaporation (red) from Great Lakes Dashboard observation and GLARM simulation results. The GLARM here has the Great Lakes region as the model domain. 

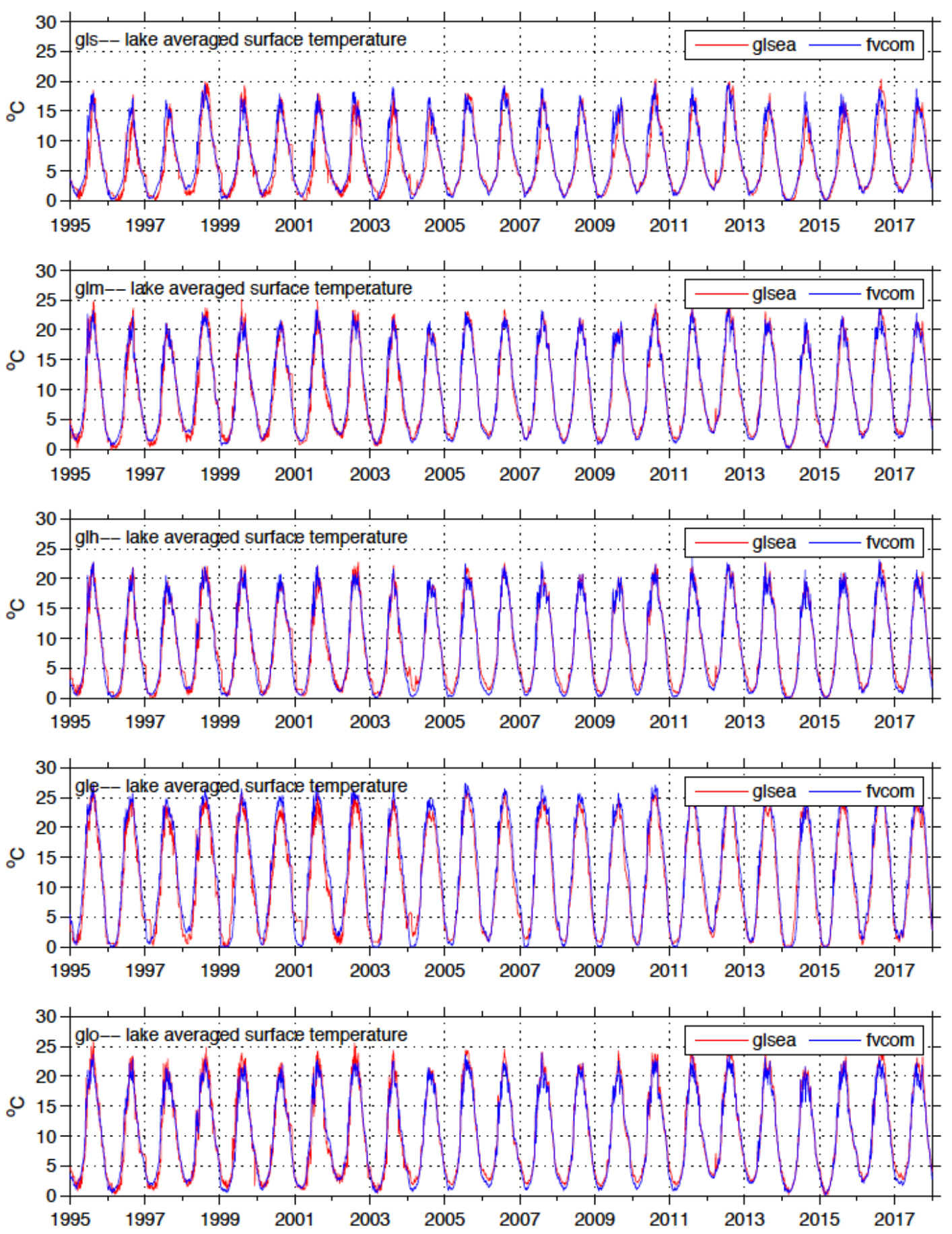

Figure A.23 Time series of surface water temperature simulated by the FVCOM hydrodynamic model from GLARM (blue) and the observation data from the Great Lakes Surface Environmental Analysis (GLSEA) (red). The GLARM here has the Great Lakes region as the model domain. 

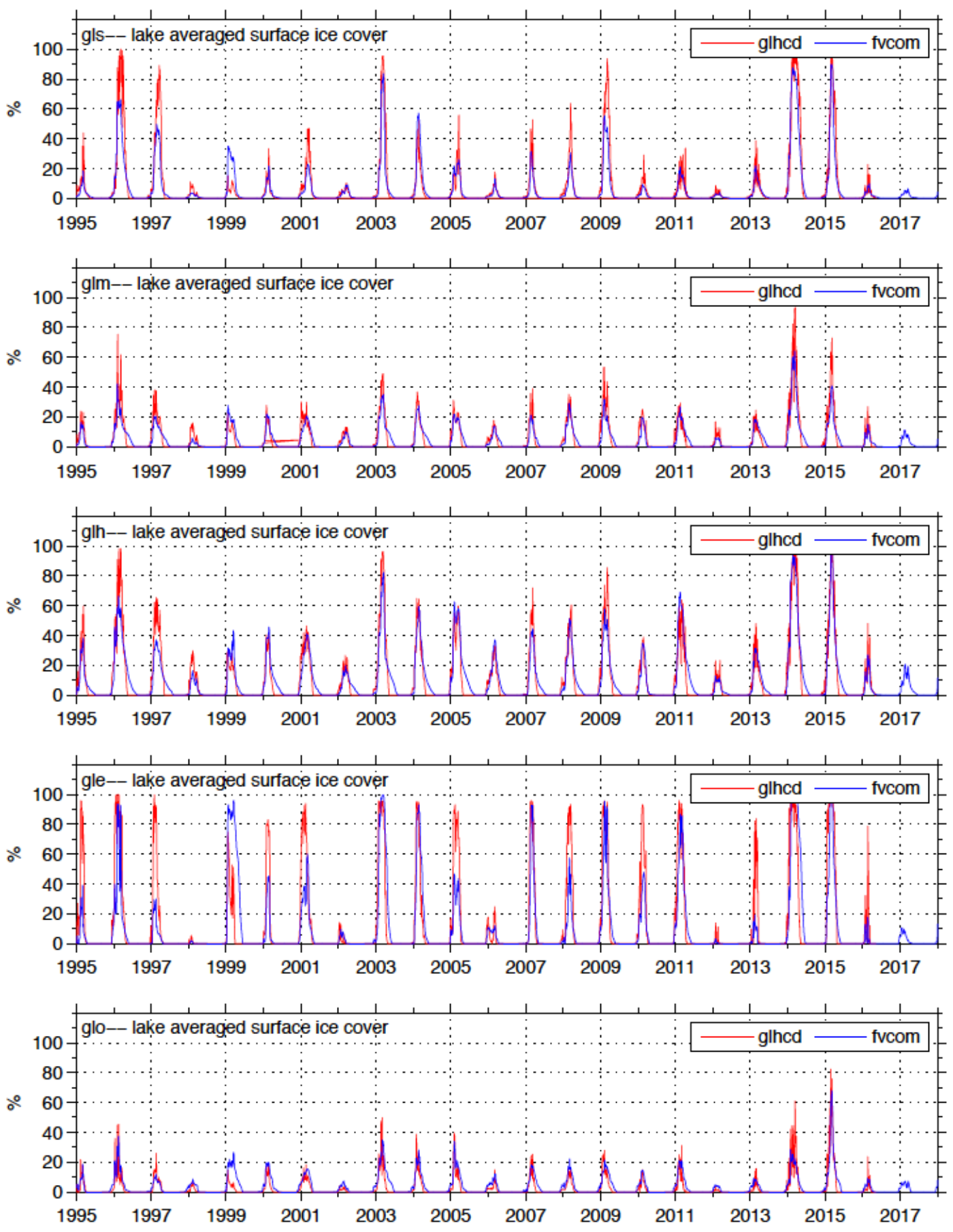

Figure A.24 Time series of surface ice cover over the lakes simulated by the FVCOM hydrodynamic model from GLARM (blue) and the observation data from the Great Lakes Hydroclimatic Dashboard (GLHCD) (red). The GLARM here has the Great Lakes region as the model domain. 


\section{A.9 Air temperature and LST predictions}

Changes in LST and air temperature by $2030-49$ relative to $2000-19$ using GISS (GL)

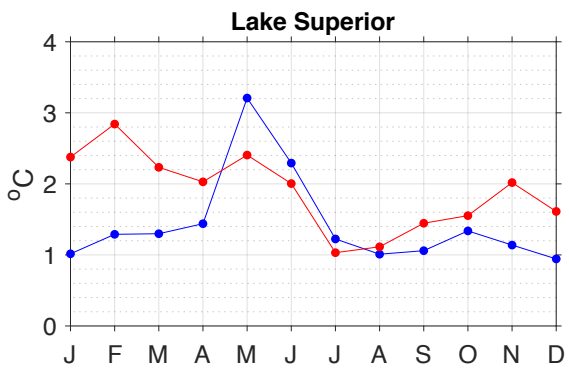

Lake Michigan-Huron

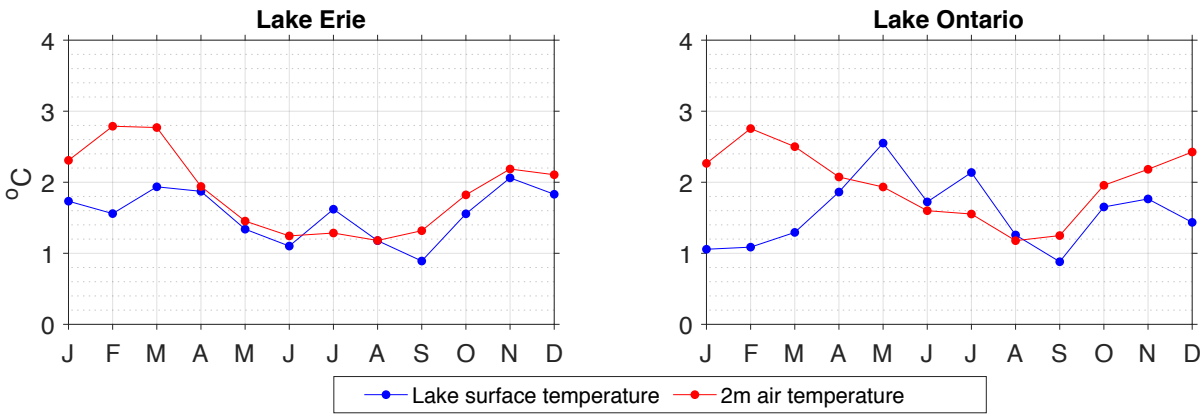

Figure A.25 Monthly changes in lake surface temperature and air temperature over the lakes by 2030-2049 relative to 2000-2019 by downscaling GISS using GLARM with the Great Lakes domain.

Changes in LST and air temperature by 2030-49 relative to 2000-19 using IPSL (GL)
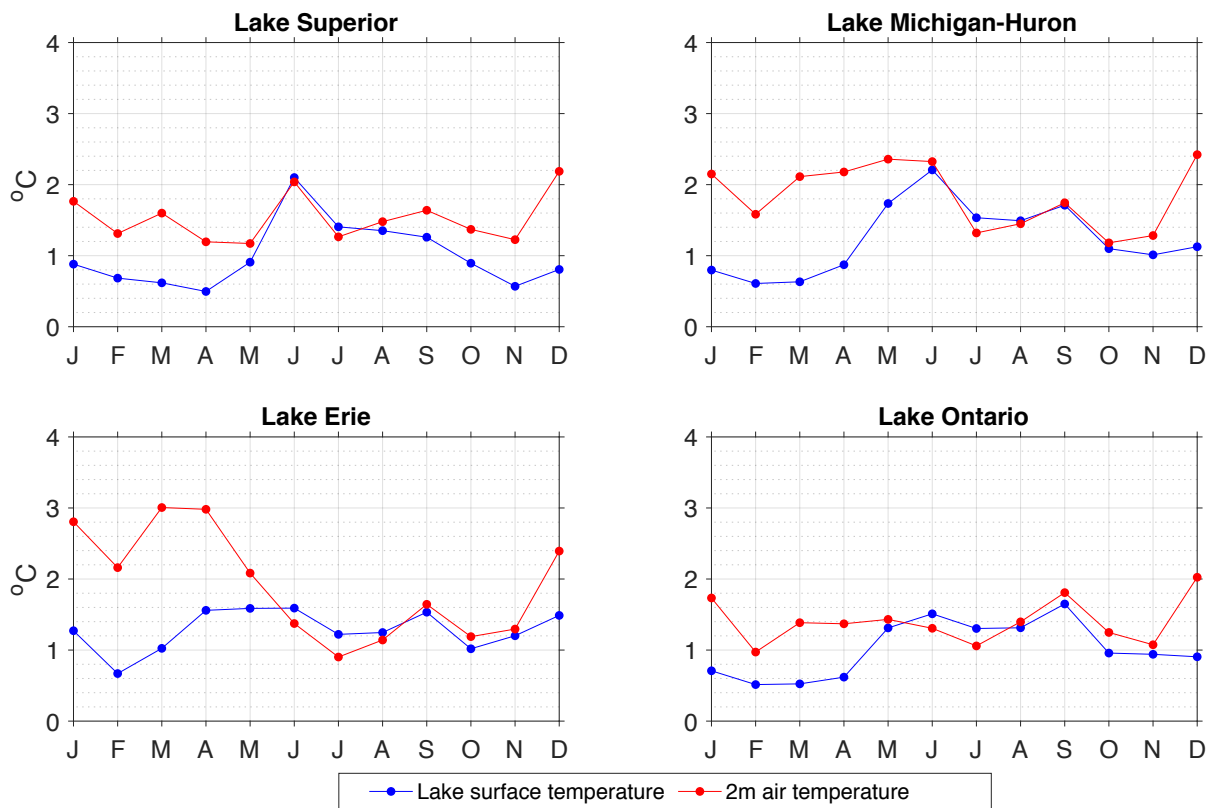

Figure A.26 Monthly changes in lake surface temperature and air temperature over the lakes by 2030-2049 relative to 2000-2019 by downscaling IPSL using GLARM with the Great Lakes domain. 
Changes in LST and air temperature by 2030-49 relative to 2000-19 using MPI (GL)
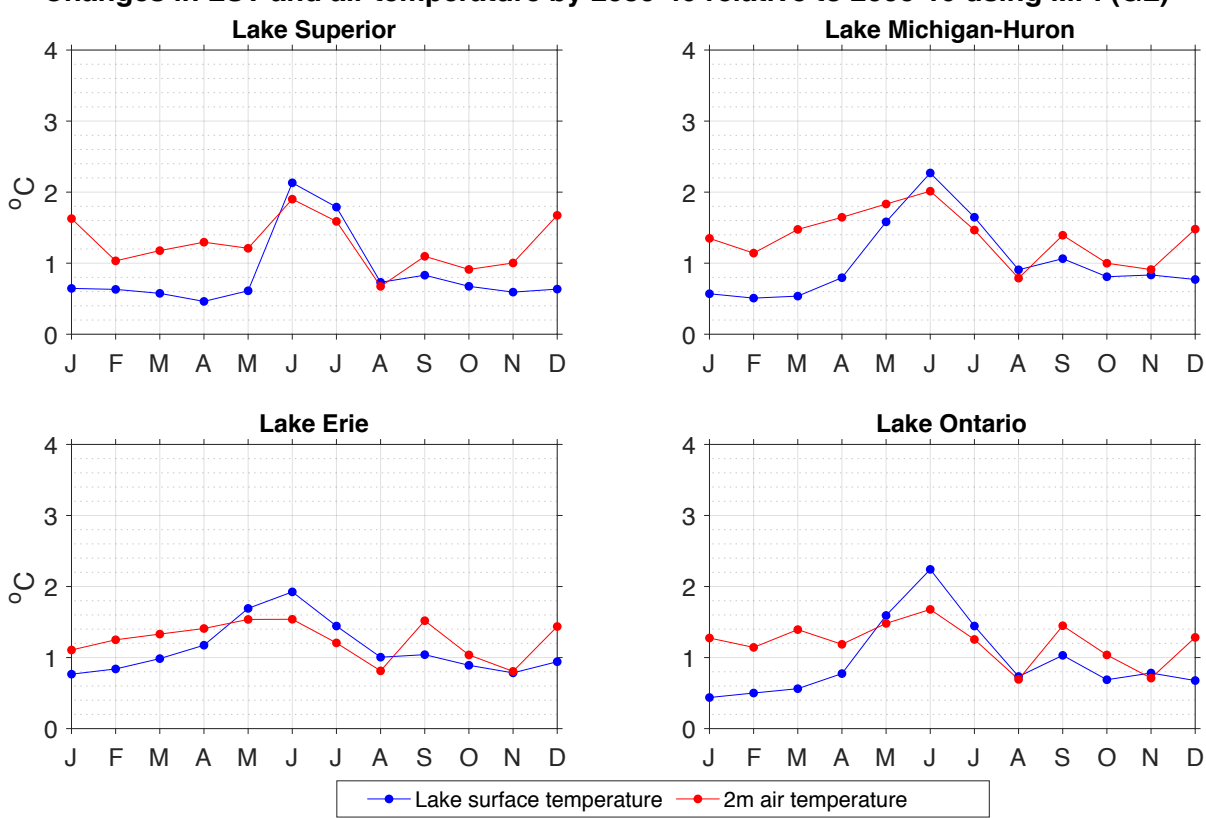

Figure A.27 Monthly changes in lake surface temperature and air temperature over the lakes by 2030-2049 relative to 2000-2019 by downscaling MPI using GLARM with the Great Lakes domain.

Changes in LST and air temperature by 2080-99 relative to 2000-19 using GISS (GL)
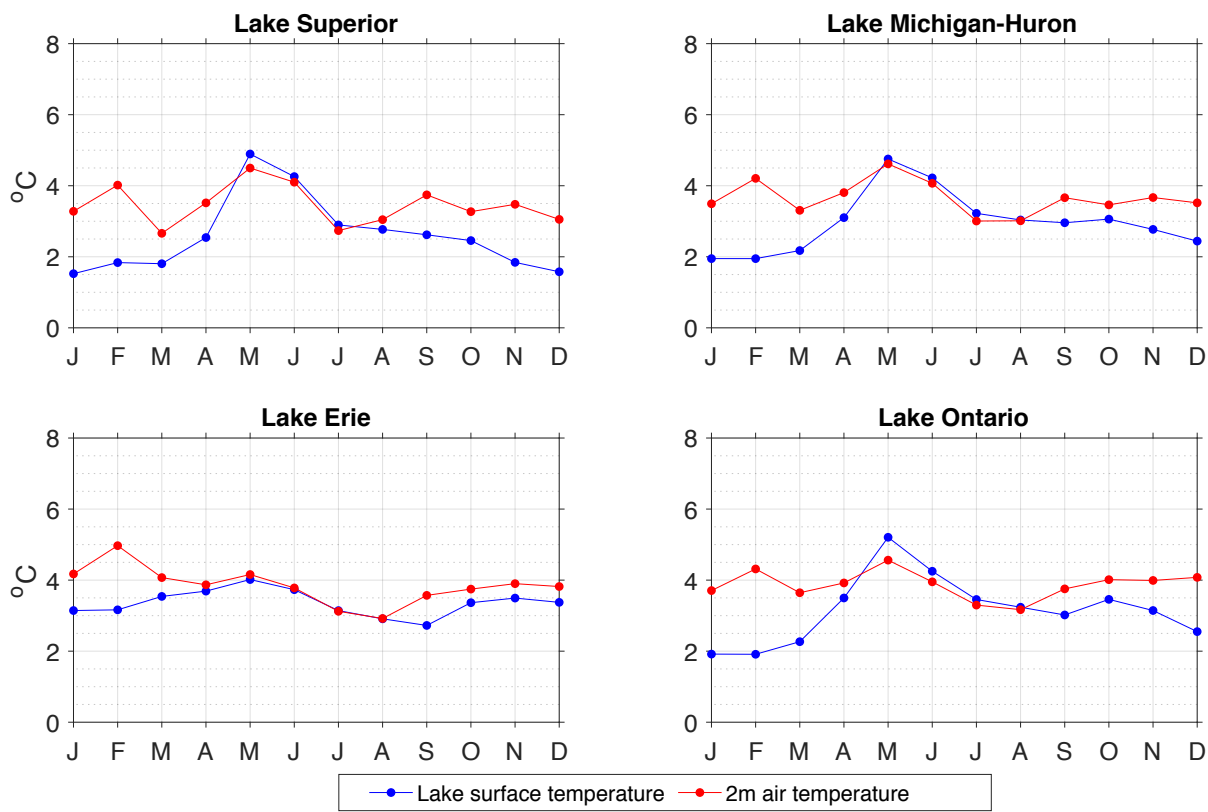

Figure A.28 Monthly changes in lake surface temperature and air temperature over the lakes by 2080-2099 relative to 2000-2019 by downscaling GISS using GLARM with the Great Lakes domain. 
Changes in LST and air temperature by 2080-99 relative to 2000-19 using IPSL (GL)
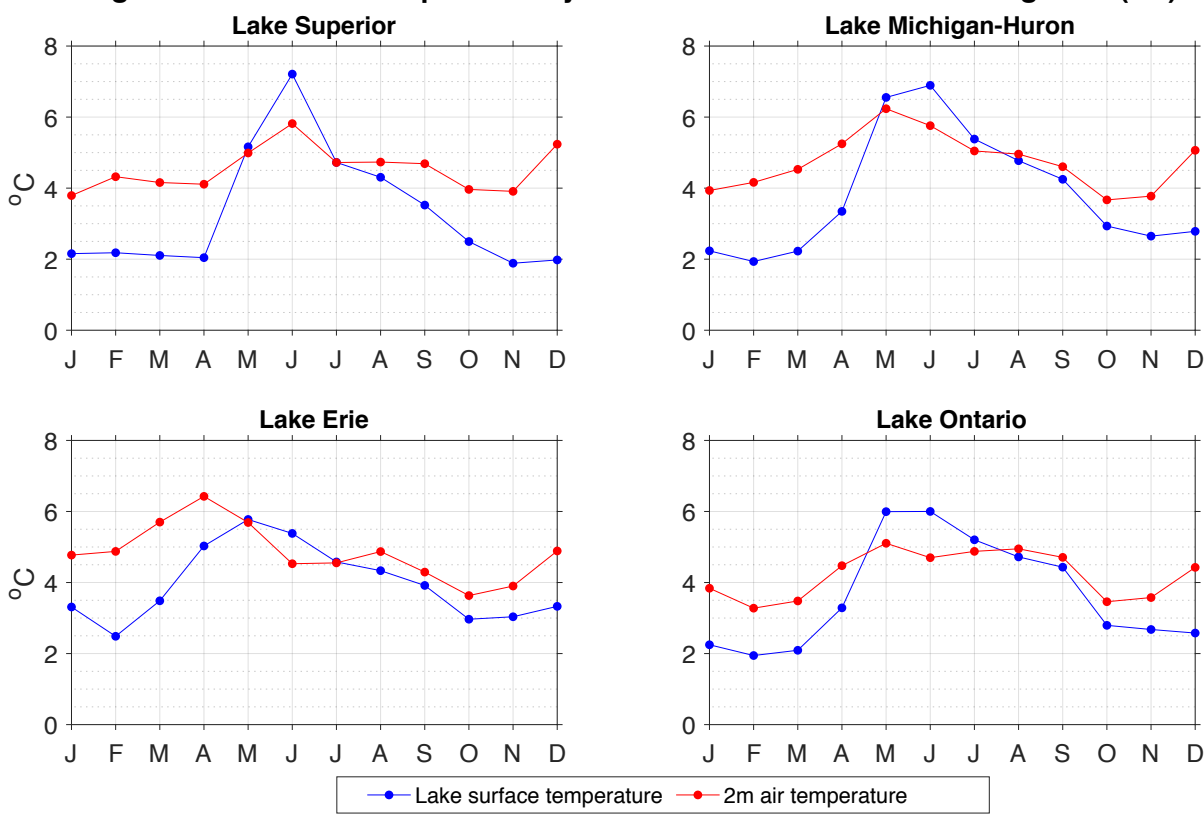

Figure A.29 Monthly changes in lake surface temperature and air temperature over the lakes by 2080-2099 relative to 2000-2019 by downscaling IPSL using GLARM with the Great Lakes domain.

Changes in LST and air temperature by 2080-99 relative to 2000-19 using MPI (GL)

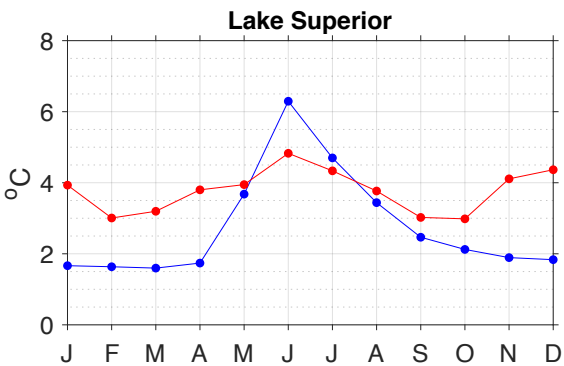

Lake Michigan-Huron

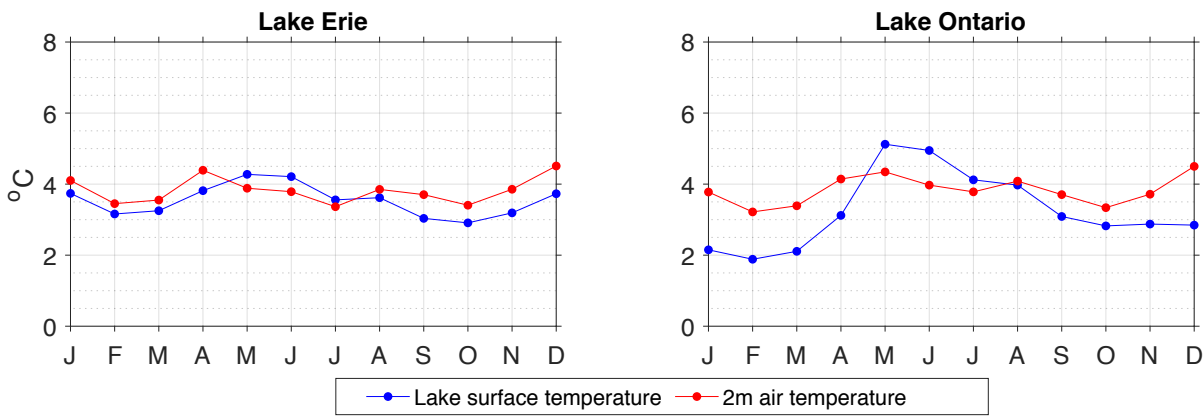

Figure A.30 Monthly changes in lake surface temperature and air temperature over the lakes by 2080-2099 relative to 2000-2019 by downscaling MPI using GLARM with the Great Lakes domain. 